Gean Paulo SCOPEL

\title{
ESTUDO COMPARATIVO DA FIXAÇÃO DOS TRANSPLANTES MUSCULARES NA REANIMAÇÃO FACIAL UNILATERAL COM E SEM O USO DO TENDÃO PALMAR LONGO
}

Tese apresentada à Faculdade de Medicina da

Universidade de São Paulo para obtenção do título de

Doutor em Ciências

Programa de Clínica Cirúrgica

Orientador: Prof. Dr. José Carlos Marques de Faria

São Paulo

2010 


\section{Dados Internacionais de Catalogação na Publicação (CIP)}

Preparada pela Biblioteca da

Faculdade de Medicina da Universidade de São Paulo

Creprodução autorizada pelo autor

Scopel, Gean Paulo

Estudo comparativo da fixação dos transplantes musculares na reanimação facial unilateral com e sem o uso do tendão palmar longo / Gean Paulo Scopel. -- São Paulo, 2010.

Tese(doutorado)--Faculdade de Medicina da Universidade de São Paulo.

Programa de: Clínica Cirúrgica.

Orientador: José Carlos Marques de Faria.

Descritores: 1.Paralisia facial 2.Doenças do sistema nervoso periférico 3.Músculos/transplantes

4.Microcirurgia 5.Retalhos cirúrgicos 


\section{AGRADECIMENTOS}

Ao Prof. Dr. Marcus Castro Ferreira, por permitir e estimular o desenvolvimento e aprimoramento de atividades científicas em Cirurgia Plástica.

Ao Prof. Dr. José Carlos Marques de Faria, por acreditar e incentivar-me desde a graduação no contínuo aperfeiçoamento das atividades ligadas à Cirurgia Plástica, particularmente na área de Microcirurgia, e pela orientação desta tese.

Ao Prof. Dr. Nivaldo Alonso que viabilizou o início e desenvolvimento desta Tese.

Aos Residentes da Disciplina de Cirurgia Plástica da Faculdade de Medicina da Universidade de São Paulo pela colaboração na execução dos procedimentos cirúrgicos e seguimento dos pacientes.

Ao acadêmico Lucas Hortêncio pela colaboração na coleta dos dados e levantamento bibliográfico.

À minha esposa Simone Orpheu, por seu companheirismo e presença constante durante toda minha vida acadêmica.

À minha família pela ética e lealdade sempre reforçadas.

E aos pacientes, pela confiança em mim depositada. 


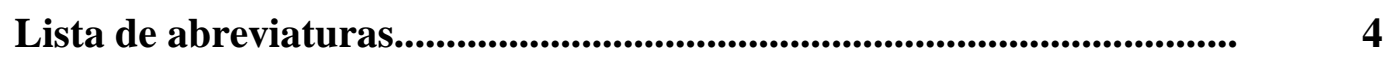

Lista de siglas...............................................................................................................

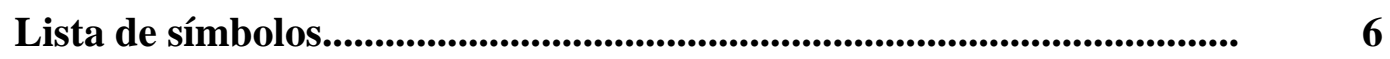

Lista de figuras...........................................................................................................

Lista de tabelas...........................................................................................................

Lista de gráficos....................................................................................................

Resumo.............................................................................................................. 12

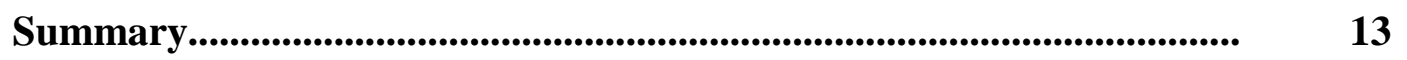

1. INTRODUÇÃO E REVISÃO DE LITERATURA...............................

2. PACIENTES E MÉTODOS............................................................. 30

3. RESULTADOS.........................................................................................

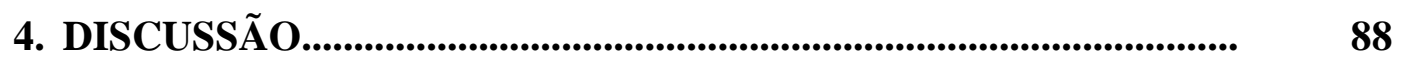

5. CONCLUSÕES............................................................................... 98

6. REFERÊNCIAS BIBLIOGRÁFICAS................................................ 100 


\section{LISTA DE ABREVIATURAS}

\begin{tabular}{|c|c|}
\hline bras. & brasileiro(a) \\
\hline col. & colaborador(es) \\
\hline Dr. & doutor \\
\hline ed. & edição \\
\hline et al. & e outros \\
\hline ex. & exemplo \\
\hline fig. & figura \\
\hline p. & página \\
\hline Prof. & Professor \\
\hline rev. & revista \\
\hline v. & volume \\
\hline$v s$ & versus \\
\hline rep. & repouso \\
\hline din. & dinâmico \\
\hline graf. & gráfico \\
\hline
\end{tabular}




\section{LISTA DE SIGLAS}

ABNT

FM

PF

LP

LNP

IR

USP

SMAS
Associação Brasileira de Normas Técnicas

Faculdade de Medicina

paralisia facial

lado paralisado

lado não paralisado

índice relativo

Universidade de São Paulo

sistema músculo-aponeurótico superficial 


\section{LISTA DE SÍMBOLOS}

\begin{tabular}{ll}
$\mathrm{cm}$ & centímetro \\
$\mathrm{ml}$ & milímetro \\
$\%$ & mililitro \\
+ & porcentagem \\
- & mais \\
\pm & menos \\
$>$ & mais ou menos \\
& \\
$x$ & maior \\
\hline & vezes \\
& menor \\
&
\end{tabular}




\section{LISTA DE FIGURAS}

página

Figura 1. Dissecção segmentar do músculo gracilis. Vasos

circunflexos femorais mediais (seta preta) e nervo obturador (seta amarela).

Figura 2. Dissecção do tendão do músculo palmar longo através de incisões escalonadas.

Figura 3. Pontos de fixação à extremidade bucal do retalho.

Figura 4. Posicionamento do retalho no GRUPO II (sem tendão).

Figura 5. Fixação do retalho muscular no GRUPO II (sem tendão).

Figura 6. Posicionamento do retalho no GRUPO I (com tendão).

Figura 7. Representação esquemática do posicionamento do tendão

palmar longo no lábio superior com uso de agulha de Reverdin (GRUPO I).

Figura 8. Secção transversal da fixação do músculo gracilis com tendão palmar longo (GRUPO II). S: superficial; P: profundo; GM: músculo gracilis; PLT: tendão palmar longo; OOM: músculo orbicular da boca; SC: sutura contínua; ponto "U": ponto em U de Ethibond 3.0 unindo as 3 estruturas.

Figura 9. Aspecto final das fixações muscular e tendinosa, anastomoses vasculares e neurorrafia (GRUPO I).

Figura 10. Graduação do sorriso: ausência de movimento.

Figura 11. Graduação do sorriso: movimentação pobre.

Figura 12. Graduação do sorriso: movimentação regular.

Figura 13. Graduação do sorriso: boa movimentação.

Figura 14. Graduação do sorriso: excelente.

Figura 15. Demonstração do Índice Relativo. Seta preta: lado não 
paralisado (LNP); seta branca: lado paralisado (LP).

Figura 16 (Grupo I - caso 1): Pré e pós-operatório (9 meses).

Graduação do sorriso: excelente.

Figura 17 (Grupo I - caso2): Pré e pós-operatório (9 meses).

Graduação do sorriso: bom.

Figura 18 (Grupo I - caso 3): Pré e pós-operatório (9 meses).

Graduação do sorriso: excelente.

Figura 19 (Grupo I - caso 4): Pré e pós-operatório (9 meses).

Graduação do sorriso: excelente.

Figura 20 (Grupo I - caso 5): Pré e pós-operatório (9 meses).

Graduação do sorriso: excelente.

Figura 21 (Grupo I - caso 6): Pré e pós-operatório (9 meses).

Graduação do sorriso: excelente.

Figura 22 (Grupo I - caso 7): Pré e pós-operatório (9 meses).

Graduação do sorriso: bom.

Figura 23 (Grupo I - caso 8): Pré e pós-operatório (9 meses).

Graduação do sorriso: excelente.

Figura 24 (Grupo I - caso 9): Pré e pós-operatório (9 meses).

Graduação do sorriso: pobre.

Figura 25 (Grupo I - caso 10): Pré e pós-operatório (9 meses).

Graduação do sorriso: excelente.

Figura 26 (Grupo I - caso 11): Pré e pós-operatório (9 meses).

Graduação do sorriso: excelente.

Figura 27 (Grupo I - caso12): Pré e pós-operatório (9 meses).

Graduação do sorriso: bom.

Figura 28 (Grupo I - caso 13): Pré e pós-operatório (9 meses). 
Graduação do sorriso: excelente.

Figura 29 (Grupo I - caso 14): Pré e pós-operatório (9 meses).

Graduação do sorriso: bom.

Figura 30 (Grupo I - caso 15): Pré e pós-operatório (9 meses).

Graduação do sorriso: excelente.

Figura 31 (Grupo I - caso 16): Pré e pós-operatório (9 meses).

Graduação do sorriso: excelente.

Figura 32 (Grupo I - caso17): Pré e pós-operatório (9 meses).

Graduação do sorriso: bom.

Figura 33 (Grupo II - caso 1): Pré e pós-operatório (9 meses).

Graduação do sorriso: bom.

Figura 34 (Grupo II - caso 2): Pré e pós-operatório (9 meses).

Graduação do sorriso: bom.

Figura 35 (Grupo II - caso 3): Pré e pós-operatório (9 meses).

Graduação do sorriso: bom.

Figura 36 (Grupo II - caso 4): Pré e pós-operatório (9 meses).

Graduação do sorriso: excelente.

Figura 37 (Grupo II - caso 5): Pré e pós-operatório (9 meses).

Graduação do sorriso: ausente.

Figura 38 (Grupo II - caso 6): Pré e pós-operatório (9 meses).

Graduação do sorriso: regular. 
Tabela 1. Dados demográficos dos pacientes do GRUPO I (com tendão). (*) Perda do seguimento.

Tabela 2. Dados demográficos dos pacientes do GRUPO II (sem tendão). (*) Perda do retalho.

Tabela 3. Resumo da casuística dos 2 grupos.

Tabela 4: Medidas descritivas da variável repouso pré-operatório

(Rep-pre) e pós-operatório (Rep-pos), em cada grupo.

Tabela 5: Medidas descritivas da variável dinâmico pré-operatório (Din-pre) e pós-operatório (Din-pos), em cada grupo.

Tabela 6: Níveis descritivos obtidos da aplicação do modelo de análise de variância com medidas repetidas.

Tabela 7: Resultados da comparação entre os Grupos I e II com relação à variável dinâmico em cada instante de avaliação.

Tabela 8: Resultados da comparação entre os instantes pré e pósoperatório com relação à variável dinâmico, em cada grupo.

Tabela 9. Análise qualitativa da intensidade e forma do sorriso voluntário após reanimação facial.

Tabela 10. Índice relativo (IR) da distância entre o modíolo e centro do arco de cúpido em repouso.

Tabela 11. Índice relativo (IR) da distância entre o modíolo e centro do arco de cúpido durante sorriso voluntário. 


\section{LISTA DE GRÁFICOS}

página

Gráfico 1: Perfis individuais observados no Grupo I (com tendão) para a variável repouso (Rep).

Gráfico 2: Perfis individuais observados no Grupo II (sem tendão) para a variável repouso (Rep).

Gráfico 3: Perfis individuais observados no Grupo I (com tendão) 56 para a variável dinâmico (Din).

Gráfico 4: Perfis individuais observados no Grupo II (sem tendão) para a variável dinâmico (Din).

Gráfico 5: Perfis médios observados para a variável repouso em 58 ambos os grupos.

Gráfico 6: Perfis médios observados para a variável dinâmico em ambos os grupos. 


\section{RESUMO}

SCOPEL GP. Estudo comparativo da fixação dos transplantes musculares na reanimação facial unilateral com e sem o uso do tendão palmar longo. Tese (Doutorado). São Paulo, 2010. Faculdade de Medicina, Universidade de São Paulo.

Vinte e seis pacientes com paralisia facial unilateral de longa duração foram submetidos à reanimação facial em único estágio com transplante do músculo grácil inervado pelo ramo massetérico do nervo trigêmeo.

Foram divididos em 2 grupos não-randomizados de acordo com a técnica de fixação: Grupo I (19 pacientes), fixação do músculo com uso do tendão palmar longo inserido no músculo orbicular nos lábios superior e inferior do lado não paralisado (além da linha média); Grupo II (7 pacientes), fixação do retalho apenas com pontos separados no músculo orbicular dos lábios superior e inferior no lado paralisado.

A avaliação qualitativa demonstrou melhores resultados no Grupo I (94,1\% vs 66,6\%). Na comparação do posicionamento do arco de cúpido em repouso, no pré e pós-operatório, observamos melhora estatisticamente significante $(\mathrm{p}<0,05)$ em ambos os grupos. Durante o sorriso, entretanto, houve melhora significativamente maior na centralização do arco de cúpido nos pacientes submetidos à fixação com tendão palmar longo (Grupo I)

DESCRITORES: 1.Paralisia facial 2. Doenças do sistema nervoso periférico. 3.Músculos/transplantes. 4. Microcirurgia. 5.Retalhos cirúrgicos. 


\section{SUMMARY}

SCOPEL GP. Comparative study of muscle transplants insertion technique for unilateral facial reanimation with and without the palmaris longus tendon. Thesis (Doctorate). São Paulo. 2010. Faculty of Medicine, University of São Paulo, SP (Brazil).

Twenty-six patients with unilateral long-stading facial palsy underwent 1 -stage reanimation with free gracilis muscle transplant innervated by the masseteric branch of the trigeminal nerve.

They were divided into 2 nonrandomized groups according to insertion technique: group I (19 patients), palmaris longus tendon graft placed between the gracilis free flap and the orbicularis oris of the upper and lower lip on the nonparalyzed side; group II (7 patients), interrupted suture between the free flap and the orbicularis oris of the upper and lower lip on the paralyzed side.

Qualitative evaluation of the smile demonstrated better results in patients from group I $(94,1 \%$ vs $66,6 \%)$. Comparing the position of the Cupid`s bow at rest, pre- and postoperatively in each patient, we observed significant improvement of facial symmetry in both groups. During smile, however, there was significantly higher rate of centralization of the Cupid`s bow in patients submitted to reanimation with the use of the palmaris longus tendon (group I).

DESCRIPTORS: 1.Facial palsy. 2. Peripheral nervous system diseases.

3.Muscle/transplants. 4. Microsurgery. 5. Free flaps. 


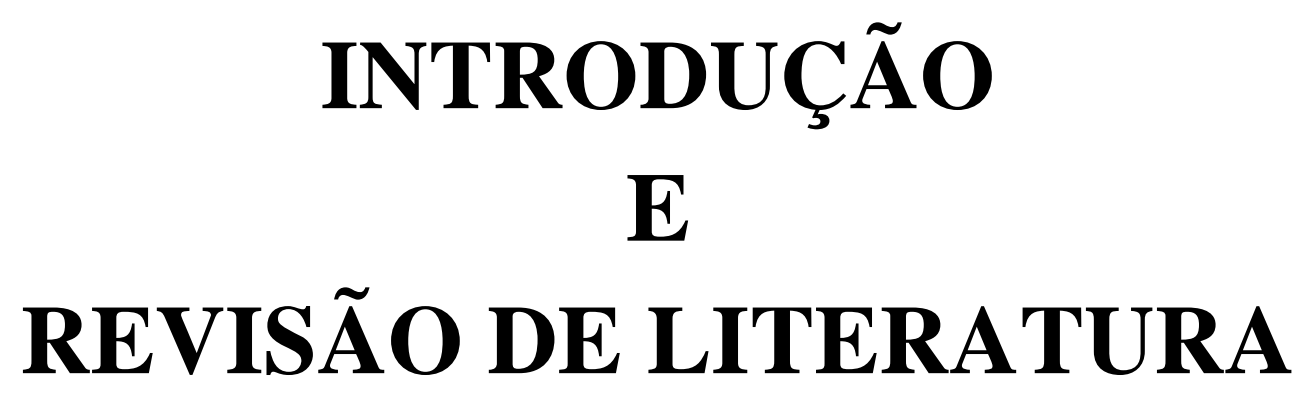




\section{INTRODUÇÃO E REVISÃO DE LITERATURA}

O tônus estático e a animação dinâmica que constituem a expressão facial são fundamentais para as interações humanas. A função dos músculos faciais é essencial para a comunicação afetiva, tanto verbal quanto não-verbal, e o dano ao nervo facial diminui drasticamente a capacidade de relacionamento social. Muitos pacientes têm consciência desta situação e evoluem para o isolamento sócio-afetivo (JACKSON, 2001; FINSTERER, 2008).

A paralisia dos músculos faciais pode resultar também em outros déficits de função, que particularmente comprometem a proteção ocular, a alimentação, a ingestão de líquidos e a respiração nasal (MELVIN, 2008).

Formado por fibras supra e infranucleares que partem do núcleo do facial, o nervo facial contem 10.000 fibras, das quais 7000 são fibras motoras mielinizadas. Emerge do tronco cerebral, cruza o espaço subaracnóideo até o meato acústico interno e entra no canal do facial do osso temporal onde dá origem a três ramos. O nervo petroso maior, que parte ao nível do gânglio geniculado, supre as fibras secretoras da glândula lacrimal e confere sensibilidade gustativa e de pressão ao palato mole. O nervo estapédio inerva 
o músculo do estribo, um dos responsáveis pelo enrijecimento da cadeia ossicular quando exposta a ruídos de alta intensidade. O nervo corda do tímpano fornece as fibras secretoras para as glândulas submaxilar e sublingual, e fibras gustativas para os 2/3 anteriores da língua (BAKER, 1990).

Após o trajeto intratemporal, o nervo facial exterioriza-se pelo forame estilomastóideo e percorre espaço entre o meato acústico externo e o processo da mastóide. Nesse segmento emite o nervo auricular posterior (que supre os músculos extrínsecos da orelha e conduz parte da sensibilidade do pavilhão auricular) e o ramo para o ventre posterior do músculo digástrico e estilohióideo. Penetra na glândula parótida, entre os lobos superficial e profundo, onde dá origem a 2 troncos principais: tronco têmporo-facial de onde partem os ramos temporal, zigomático e bucal; e do cérvico-facial, que dá os ramos marginal da mandíbula e cervical. Há inúmeras anastomoses entre esses ramos, principalmente entre o zigomático e o bucal, formando um verdadeiro plexo nervoso na face. Entretanto, os padrões de distribuição periférica do nervo facial não são constantes conforme verificado em diversos estudos anatômicos (BAKER, 1990).

A paralisia do nervo facial periférica unilateral pode ser primária/idiopática (paralisia de Bell) ou ter uma causa detectável 
(secundária). A paralisa facial secundária pode ser causada por processos neoplásicos, infecciosos e traumáticos em qualquer nível ao longo do trajeto do nervo em suas porções intracrania, intratemporal e extracraniana. As causas secundárias são menos prevalentes que a paralisia de Bell (25\% vs. $75 \%)$. A paralisia de Bell (BELL, 1821) foi inicialmente descrita por Friederich em 1797 e é um diagnóstico de exclusão, após afastadas causas secundárias (FINSTERER, 2008).

O entendimento da classificação das lesões nervosas fornece subsídio para a compreensão do dano ao nervo facial e entender a paralisia resultante. Originalmente, SEDDON (1943) descreveu três estágios de lesão nervosa periférica. Neuropraxia é um bloqueio temporário da condução nervosa devido à desmielinização. Usualmente, há recuperação completa em 12 semanas. Axoniotmese refere-se à secção de fibras individuais. Ela causa degeneração Walleriana distal à lesão. No entanto, o tubo endoneural permanece intacto e os axônios reinervam seus alvos motores e sensitivos. Neurotmese descreve a secção dos fascículos (perineuro) e do epineuro.

SUNDERLAND ampliou o sistema de classificação com cinco graus de lesão nervosa. O primeiro e segundo graus de lesão nervosa estão relacionados com a neuropraxia e axoniotmese, respectivamente. O terceiro grau de lesão nervosa descreve a combinação dos dois primeiros: ocorre degeneração 
Walleriana e os tubos endoneurais não estão intactos, portanto a reinervação dos alvos motores e sensitivos primários pode não ocorrer. O quarto grau de lesão resulta numa grande cicatriz que não permite a passagem para o crescimento nervoso. Intervenções cirúrgicas são necessárias para restaurar a continuidade nervosa. Da mesma forma o quinto grau de lesão, que é a transecção completa do nervo, também requer reparo cirúrgico. Mais recentemente MACKINNON usou o termo "sexto grau de lesão nervosa" para descrever uma lesão nervosa mista envolvendo componentes dos outros graus de lesão indo de fascículos funcionais até fibras nos estágios sem recuperação funcional (MELVIN, 2008).

Embora alguns exames possam ser utilizados na determinação do grau de acometimento do VII par craniano após a lesão, o seu diagnóstico é basicamente clínico, relacionado principalmente às alterações do componente motor do nervo.

A gravidade das repercussões clínicas na paralisia facial está relacionada não apenas com a falta de contrações de um lado, mas também à perda de equilíbrio entre o lado paralisado e não paralisado. As assimetrias faciais em repouso são decorrentes de distúrbios do tônus muscular e, geralmente, são menos perceptíveis nas paralisias de curta duração. Essas alterações acentuam-se durante os movimentos. Nas paralisias de longa 
duração, o desequilíbrio contínuo dos vetores de movimentação resulta no desvio labial, nasal e palpebral, inclusive no repouso (GUELINCKX, 1996).

$\mathrm{Na}$ ausência de função de todos os músculos inervados pelo nervo facial, a paralisia é denominada completa. Na paralisia incompleta, a perda de movimentos é parcial e a sua localização geralmente corresponde ao território dos ramos do nervo facial lesado (frontal, zigomático, bucal, marginal da mandíbula e cervical) (ROSSON, 2008).

A falta de oclusão palpebral pode levar ao aparecimento de lesões secundárias e irreversíveis do globo ocular, complicação clínica mais grave e precoce da paralisia facial. Por este motivo, as medidas de proteção do olho assumem prioridade frente à correção de outras deformidades presentes (BERGERON, 2008; FREY, 2004). Já nas paralisias de longa duração o maior impacto ocorre na região bucal.

De modo geral, a adoção da conduta sobre o nervo facial depende da localização da lesão. Quando o fator etiológico da paralisia compromete o segmento intracraniano, o neurocirurgião conduz o paciente. Lesões intratemporais requerem procedimentos e acompanhamento otorrinolaringológicos. As operações em Cirurgia Plástica estão concentradas sobre o segmento extratemporal do nervo facial. 
Lesão e reparo podem ser divididos em três estágios: (1) imediato (até 3 semanas); (2) retardado (3 semanas a 2 anos); e (3) tardio (mais de 2 anos). $\mathrm{O}$ objetivo desejado por qualquer protocolo de tratamento da paralisia facial é restabelecer a função motora dinâmica que é controlável, simétrica e espontânea. Isso é atingido da melhor forma quando a inervação dos músculos faciais paralisados é restabelecida por reparo direto do nervo facial (BAKER, 1990; BAUER, 1996).

Lacerações e lesões iatrogênicas do nervo facial são melhores reparadas imediatamente. Logo após a lesão, a distensibilidade do nervo permite a coaptação quando há perda de segmentos mínimos. Além disso, a anatomia não é distorcida por cicatrizes e fibrose (FERREIRA, 1994). Dentro das primeiras três semanas após a lesão os elementos neuromusculares têm maior probabilidade de recuperação completa (LIN, 2009; MALIK, 2005).

Após três semanas o corpo celular e o segmento proximal do nervo continuam a apresentar capacidade de regeneração por até dois anos. Durante este período os túbulos endoneurais são preservados, e podem direcionar axônios em regeneração para os músculos. Embora os músculos faciais sofram mudanças histológicas e degeneração, são capazes de se restaurar próximo ao normal se receberem novo aporte nervoso. Neste período, o procedimento 
cirúrgico de escolha deveria ser aquele que permitisse novas aferências neurais para o tecido muscular (HOFFMAN, 2005).

Quando o reparo nervoso direto não é viável, outros métodos de reinervação podem ser utilizados como enxertos interpostos, enxertos transfaciais de nervo (cross-face), e a transposição de outros pares cranianos como o nervo hipoglosso, massetérico ou acessório (SAMII, 1994). A reinervação com sucesso da face paralisada requer a presença de fibras musculares viáveis, placas motoras funcionais, e conduítes nervosos não fibrosados, pelos quais a regeneração axonal possa acontecer.

Os enxertos transfaciais de nervo (cross-face) foram primeiramente descritos por SCARAMELLA em 1971, e mais tarde popularizados por SMITH (1971), ANDERL $(1973,1979)$ e outros. Ainda hoje os enxertos transfaciais permanecem como opção no tratamento da paralisia facial (CHEM, 1990; LEE,2008).

No Hospital das Clínicas da Faculdade de Medicina da Universidade de São Paulo, FERREIRA (1984) introduziu a cirurgia microvascular na América do Sul e o enxerto nervoso tipo cross-face para o tratamento de paralisia facial em 1976.

As transposições nervosas constituem outra alternativa para reinervação da musculatura facial viável. A transferência hipoglosso-facial foi descrita por 
EVANS em 1974, e é a mais comumente usada. Pode ser feita isoladamente, com ou sem interposição de enxerto de nervo (ARAI, 1995; CAMPERO, 2007; MARTINS, 2008; UEDA 2007), ou como parte de procedimento combinado como na técnica de baby-sitting descrita por TERZIS em 1984 (TEZIS, 2008; YOLERI, 2001). No entanto, o uso do nervo hipoglosso não é livre de limitações, notadamente atrofia hemi-lingual e sincinesia facial (YETISER, 2007).

Alguns autores apresentaram técnica alternativa utilizando o ramo massetérico do nervo trigêmeo para neurotização do nervo facial (BERMUDEZ, 2004; COOMBS, 2008; FARIA, 2010). Acreditam que essa técnica tenha potencial para produzir uma poderosa reinervação dos músculos faciais, com mínima morbidade funcional mastigatória compensada por outros músculos (temporal e pterigóides), além do potencial para motricidade espontânea.

Nos casos em que o restabelecimento da inervação não é viável até 2 anos, a transferência de músculos se torna a próxima opção (AVIV, 1992; BOAHENE, 2008). O grau de denervação pode ser avaliado por eletroneuromiografia, que demonstra inexistência de potenciais de ação, ou biópsia para demonstrar ausência de fibras musculares viáveis. Entretanto, na prática a decisão é clínica e após 2 anos está indicada a substituição muscular. 
A atrofia muscular severa requer a transferência de novo grupo muscular para a face, seja regional (BAKER, 1979) ou à distância através de técnicas microcirúrgicas (BOVE, 1998).

A transferência dinâmica de músculos envolve o uso de um músculo estriado esquelético funcional, inervado e vascularizado para reproduzir os movimentos faciais desejados. A transposição de músculos regionais e a transferência de músculos livres funcionais por técnicas microcirúrgicas são os dois métodos de transferência muscular dinâmica.

Os objetivos da reanimação facial com transferências musculares incluem: (1) melhorar aparência em repouso; (2) simetria com a movimentação voluntária; (3) restauração dos esfíncteres oral, nasal e ocular; (4) simetria com a mobilidade involuntária e balanço controlado na expressão de emoções; e (5) evitar perda de outras funções (CHUANG, 2002, 2008; HARII, 1976; HARRISON, 2002, 2005). Não há técnica cirúrgica que cumpra com todos esses objetivos e um único procedimento pode não ser adequado para todos os pacientes. A escolha do procedimento corretivo requer uma análise detalhada da etiologia, duração, extensão da deformidade, bem como do prognóstico global. As reconstruções dinâmicas (reanimação) são sempre preferíveis a métodos estáticos, exceto sob circunstâncias especiais (FERREIRA, 2002). 
LEXER e EDEN realizaram a primeira transposição muscular em 1911 utilizando o músculo masséter. Os autores que se seguiram apresentaram resultados variáveis que dependiam, como se verificou posteriormente, da viabilidade neurovascular do músculo transposto. Quando a indicação era precisa e o músculo ideal, os resultados e a taxa de satisfação do paciente eram elevados (CORREIA, 1973).

Alguns dos maus resultados obtidos com a técnica de LEXER derivaram da transecção do suprimento nervoso do músculo. Isso foi solucionado através de modificações técnicas que incluíram a abordagem intraoral do músculo masséter, minimizando o risco de lesão de sua inervação ao eliminar-se a incisão externa na pele.

Outro músculo empregado nas transposições é o temporal (GILLIES, 1934), que pode ser usado tanto para reanimação do terço médio (sorriso) como para oclusão palpebral (TARIKI, 1989). Várias são as modificações técnicas para permitir maior rotação e reduzir a deformidade resultante do volume excessivo de tecido muscular como, por exemplo, a remoção do arco zigomático (BAKER, 1979). Apesar das variantes, todas as técnicas que empregam o músculo temporal utilizam uma faixa de fáscia e tecido muscular fixada ao lábio superior, inferior e à comissura oral. A maioria dos autores acredita que o músculo temporal não é longo o bastante para atingir a boca e a 
comissura oral sem o uso dessa faixa adicional de fáscia. Outra técnica consiste em separar o processo coronóide da mandíbula, unindo-o a faixas de fáscia e fixando este conjunto à comissura oral para lhe conferir maior mobilidade (McLAUGHLIN, 1952).

Os princípios da transferência de músculos livres para reanimação facial combinam o conhecimento atual da fisiologia muscular e nervosa com a experiência adquirida em microcirurgia. As características ideais do músculo transferido por técnica microneurovascular são: mobilidade igual ao lado normal da face, padrão neurovascular confiável com vasos de diâmetro similar ao da região receptora, pouco déficit funcional resultante da remoção do músculo, e distância suficiente da face para permitir o trabalho conjunto de 2 equipes cirúrgicas simultâneas (HARII, 1988).

A transferência microvascular do músculo gracilis foi descrita por HARII em 1976 para elevação da comissura oral. Empregava inicialmente o nervo motor do músculo temporal em estágio único. Em 1979 passou a realizar a cirurgia em 2 tempos, o primeiro tempo consistia na realização do cross-face, e o segundo, alguns meses depois, na transferência do músculo gracilis. Posteriormente O'BRIEN (1980, 1990), TERZIS (1982), BUNCKE (1982), DELLON (1985) e MACKINNON (1988) também utilizaram o crossface como origem neuronal, buscando melhor simetria dinâmica, voluntária e 
emocional, porém com o incoveniente de 2 tempos cirúrgicos distantes e o longo tempo necessário para reabilitação.

MANKTELOW (1984) contribuiu com a introdução do conceito de inervação segmentar do músculo gracilis e transferência de apenas parte do retalho com menor efeito de volume e melhora do resultado estético.

Tentativas com outros músculos foram realizadas, como o extensor curto dos dedos, o peitoral menor (TERZIS, MANKTELOW, 1982; TERZIS, 1989; HARRISON, 1985) e o serrátil anterior (BUNCKE, 1982), mas atualmente o músculo de escolha para a maioria dos cirurgiões é o gracilis (O’BRIEN, 1990; BAKER,1990; FERREIRA, 2002; FREY, 1983).

Em 1994 KOSHIMA et al foi o primeiro a relatar sua técnica de reconstrução em um estágio utilizando o músculo reto femoral. Outros autores se seguiram em pouco tempo. KUMAR publicou em 1995 transferência microneurovascular em estágio único do músculo grácil (KUMAR, 2002), JIANG et al (1995) transplante livre em um estágio do músculo abdutor do hálux. Em 1998 HARII et al descreveram a transferência microcirúrgica do músculo grande dorsal em um único tempo com anastomose neural ao nervo facial contralateral. Mais tarde o grupo de HARII relatou resultados em 24 pacientes submetidos à reconstrução em um estágio com o músculo latíssimo do dorso, comparáveis àqueles de reconstruções em dois estágios, porém com 
recuperação funcional mais rápida. Posteriormente vários autores descreveram sua experiência na transferência em único estágio com o músculo grande dorsal (WEI, 1999; TAKUSHIMA, 2006, 2009).

ZUKER em 1995 (2000) introduziu o nervo do músculo masseter como origem neuronal, realizado em um estágio e com reinervação muscular mais rápida (3 a 4 meses). Essas inovações foram de grande importância uma vez que permitiram abreviar de forma significativa o tempo necessário para reanimação facial.

Entretanto, alguns autores (FREY, 2002) acreditam que 3 estágios seriam essenciais para otimização dos resultados com transplantes livres funcionais. A realização do cross-face, 8 a 10 meses antes, permitiria maior liberdade no posicionamento do retalho muscular, e a prevenção de cicatrizes adicionais para acesso ao nervo facial contralateral relizadas nos procedimentos em 1 estágio. No segundo estágio seria feito o transplante muscular. E no terceiro estágio seriam realizadas as suspensões estáticas e dinâmicas adicionais, com melhora no resultado global da função motora, simetria estática e dinâmica, e expressão emocional.

Nota-se com todos esses relatos grande preocupação em se encontrar um músculo e nervo motor com características próximas do ideal. Entretanto, a recuperação natural e balanceada da dinâmica labial continua a ser um dos 
maiores desafios na reanimação facial (FARIA, 2002). Os movimentos obtidos são localizados e unidirecionais e, desse modo, não conseguem reproduzir precisamente a função dos 10 músculos que produzem as expressões bucais.

Embora a contração do músculo transplantado tracione o canto da boca e, conseqüentemente, defina o sulco nasolabial (sorriso), a centralização do filtro e a movimentação do lábio inferior não são proporcionalmente e/ou sistematicamente alcançadas (TERZIS, 1997, 2000).

A estabilidade da fixação do retalho muscular na região labial também interfere na qualidade dos resultados observados (EPPLEY, 1992). Movimentos repetidos parecem causar desinserção gradual e progressiva lateralização da projeção do sulco nasolabial no lado reanimado (YLÄKOTOLA), o que geralmente requer nova intervenção (terceiro estágio).

Este estudo apresenta os resultados obtidos na reanimação facial com a modificação da fixação dos transplantes musculares microcirúrgicos. Com o objetivo de tentar restabelecer a função do esfíncter oral, equilíbrio na centralização do filtro e ângulo de movimentação balanceado dos lábios superior e inferior, introduzimos esta modificação técnica com utilização do tendão do músculo palmar longo associado ao transplante convencional do 
músculo gracilis, comparando-se os resultados obtidos à fixação convencional. 


\section{PACIENTES \\ E MÉTODOS}




\section{PACIENTES E MÉTODOS}

No período de julho de 2005 a dezembro de 2008, vinte e seis (26) pacientes com paralisia facial unilateral completa com tempo de duração maior que 2 anos foram submetidos à reanimação facial com transplante do músculo gracilis. Nesta série 9 pacientes eram do sexo masculino e 17 do sexo feminino. A idade média foi de 30 anos (8 a 65 anos).

Em todos os casos o procedimento foi realizado em tempo único utilizando-se o nervo do músculo masseter ipsilateral (ramo do trigêmeo, $\mathrm{V}_{3}$ ) para neurorrafia e os vasos faciais para anastomoses vasculares. Os 2 grupos foram divididos de forma não randômica de acordo com presença ou ausência do tendão do músculo palmar longo. Dezessete pacientes apresentavam o tendão (GRUPO I, com tendão) e 9 pacientes não apresentavam (GRUPO II, sem tendão). $\mathrm{O}$ resumo dos dados desta casuística são apresentados nas Tabelas 1,2 e 3. 
Tabela 1. Dados demográficos dos pacientes do GRUPO I (com tendão). (*)Perda do seguimento.

\begin{tabular}{|c|c|c|c|c|c|}
\hline Número & Identificação & Idade & Sexo & Lado & Etiologia \\
\hline $\mathbf{1}$ & DSF & 12 & M & E & Congênita \\
$\mathbf{2}$ & KTSM & 17 & F & E & Tumor \\
$\mathbf{3}$ & WJS & 22 & M & E & Tumor \\
$\mathbf{4}$ & APS & 28 & M & D & Idiopática \\
$\mathbf{5}$ & DSLD & 35 & F & E & Tumor \\
$\mathbf{6}$ & GFS & 40 & M & E & Trauma \\
$\mathbf{7}$ & WRA & 38 & F & D & Idiopática \\
$\mathbf{8}$ & IVS & 30 & F & D & Idiopática \\
$\mathbf{9}$ & LBS & 14 & M & E & Trauma \\
$\mathbf{1 0}$ & AJS & 48 & M & E & Idiopática \\
$\mathbf{1 1}$ & AMB & 41 & F & E & Tumor \\
$\mathbf{1 2}$ & JNS & 59 & M & E & Tumor \\
$\mathbf{1 3}$ & MAS & 40 & F & D & Tumor \\
$\mathbf{1 4}$ & PTR & 27 & F & E & Idiopática \\
$\mathbf{1 5}$ & AMS & 65 & F & D & Idiopática \\
$\mathbf{1 6}$ & MB & 21 & F & D & Idiopática \\
$\mathbf{1 7}$ & TAS & 11 & F & E & Congênita \\
$\mathbf{1 8 *}$ & ERMM & 46 & F & D & Central \\
$\mathbf{1 9 *}$ & RAC & 31 & M & D & Trauma \\
\hline
\end{tabular}


Tabela 2. Dados demográficos dos pacientes do GRUPO II (sem tendão). (*)Perda do retalho.

\begin{tabular}{|c|c|c|c|c|c|}
\hline Número & Identificação & Idade & Sexo & Lado & Etiologia \\
\hline $\mathbf{1}$ & DI & 22 & F & D & Trauma \\
$\mathbf{2}$ & MMGM & 10 & F & E & Tumor \\
$\mathbf{3}$ & GPO & 8 & F & E & Congênita \\
$\mathbf{4}$ & MOM & 34 & F & E & Trauma \\
$\mathbf{5}$ & ASS & 38 & F & E & Idiopática \\
$\mathbf{6}$ & MPS & 39 & F & E & Idiopática \\
$\mathbf{7}^{*}$ & ACBS & 53 & M & D & Tumor \\
\hline
\end{tabular}

Tabela 3. Resumo da casuística dos 2 grupos.

\begin{tabular}{|c|c|c|}
\hline & GRUPO I & GRUPO II \\
\hline $\mathbf{N}^{\circ}$ casos & 17 & 6 \\
Idade média & 32,2 & 25,1 \\
Duração da paralisia & $2-21$ anos & $2-16$ anos \\
& $($ média 7,4$)$ & (média 6,9) \\
Seguimento & $1-3$ anos & $1-3$ anos \\
& (média 24 meses) & (média 22 meses) \\
\hline
\end{tabular}




\subsection{Procedimento cirúrgico}

Com o paciente em decúbito dorsal sob anestesia geral o procedimento cirúrgico foi realizado por duas equipes de forma simultânea.

O descolamento do retalho cutâneo facial foi realizado no plano abaixo do SMAS através de incisão pré-auricular com extensão para a região submandibular. O descolamento prosseguiu até a visualização do músculo orbicular da boca. Através dessa mesma incisão foi feita a dissecção dos vasos faciais, utilizados como receptores em todos os casos.

O nervo do músculo masseter foi dissecado na borda anterior da parótida, utilizando-se como reparos anatômicos palpáveis o triângulo formado pelo arco zigomático superiormente, o processo coronóide anteriormente, e côndilo da mandíbula posteriormente. Com esses parâmetros padronizados encontramos o nervo profundamente ao músculo masseter em todos os casos.

Simultaneamente, a segunda equipe procedeu à dissecção do retalho do músculo gracilis. Uma incisão longitudinal de $8 \mathrm{~cm}$ foi feita na região medial da coxa, 5 centímetros distal à tuberosidade isquiática e 2 centímetros posterior ao músculo adutor longo, facilmente palpável em sua origem no ísquio. O pedículo neurovascular é identificado no septo entre o adutor longo e o gracilis. A dissecção do pedículo foi feita até sua origem nos vasos 
femorais profundos. $\mathrm{O}$ nervo obturador foi dissecado por uma extensão de 7 a $10 \mathrm{~cm}$.

Um segmento do músculo gracilis que corresponde em extensão à distância do modíolo à borda superior do arco zigomático foi retirado, com o pedículo neurovascular centralizado em seu ponto médio. Esse segmento teve aproximadamente $10 \mathrm{~cm}$ aferido com a coxa em posição de repouso. Foram levados apenas $1 / 2$ a $2 / 3$ anteriores para se evitar volume excessivo na face conforme preconizado por MANKTELOW e ZUKER. O preparo do músculo foi feito antes da secção do pedículo para melhor controle da hemostasia e minimizar o tempo de isquemia (Figura 1).

Figura 1. Dissecção segmentar do músculo gracilis. Vasos circunflexos femorais mediais (seta preta) e nervo obturador (seta amarela).

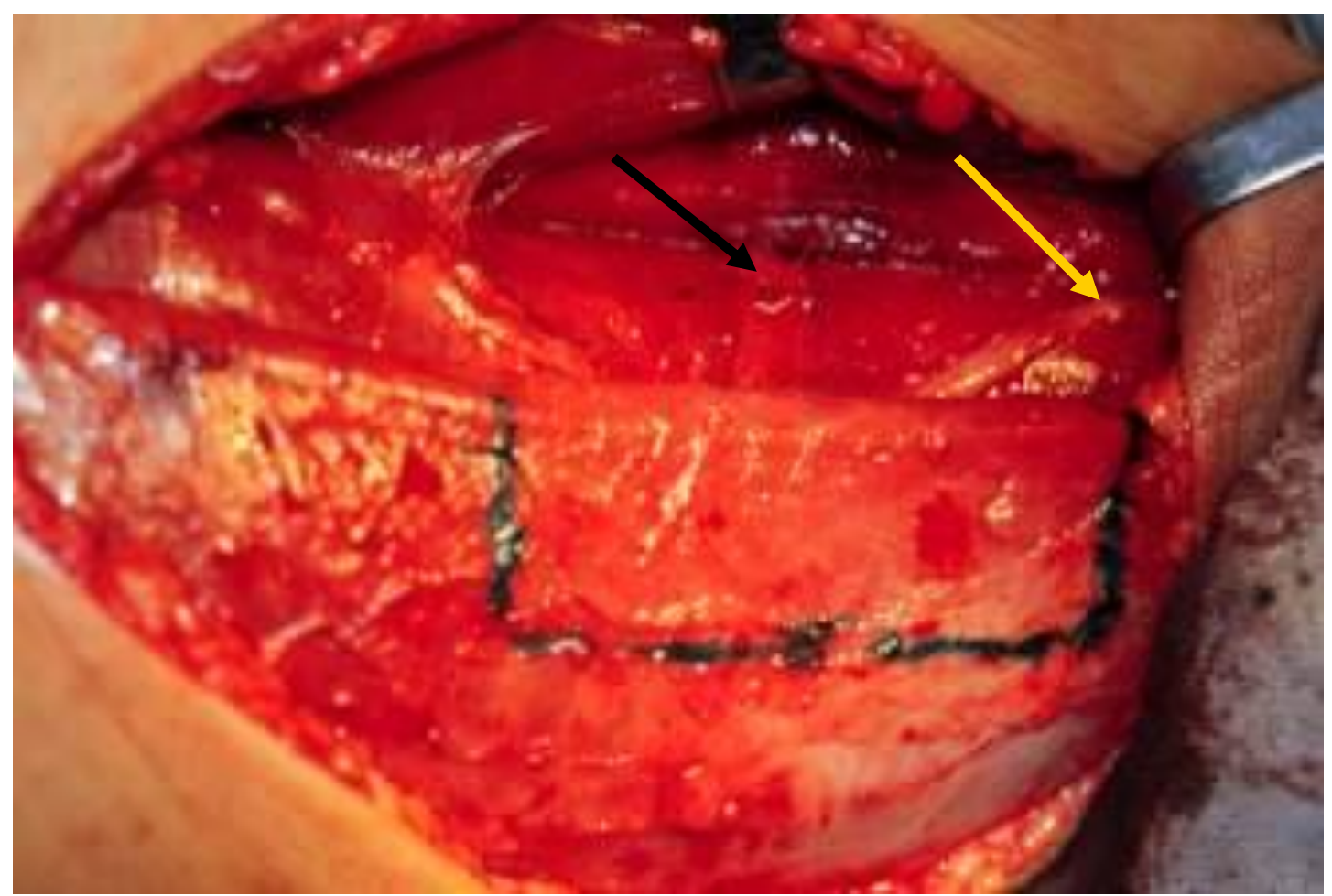


A retirada do tendão do músculo palmar longo foi feita preferencialmente no membro não dominante. A identificação do tendão é realizada através de flexão forçada do punho, paralelo e ulnar em relação ao flexor radial do carpo. Foram feitas 2 a 3 incisões escalonadas, de distal para proximal, o que facilita a identificação do tendão através do tensionamento do mesmo. Para facilitar a retirada do tendão, a extremidade proximal foi seccionada primeiramente. Um segmento médio de $13 \mathrm{~cm}$ foi retirado (Figura 2).

Figura 2. Dissecção do tendão do músculo palmar longo através de incisões escalonadas.

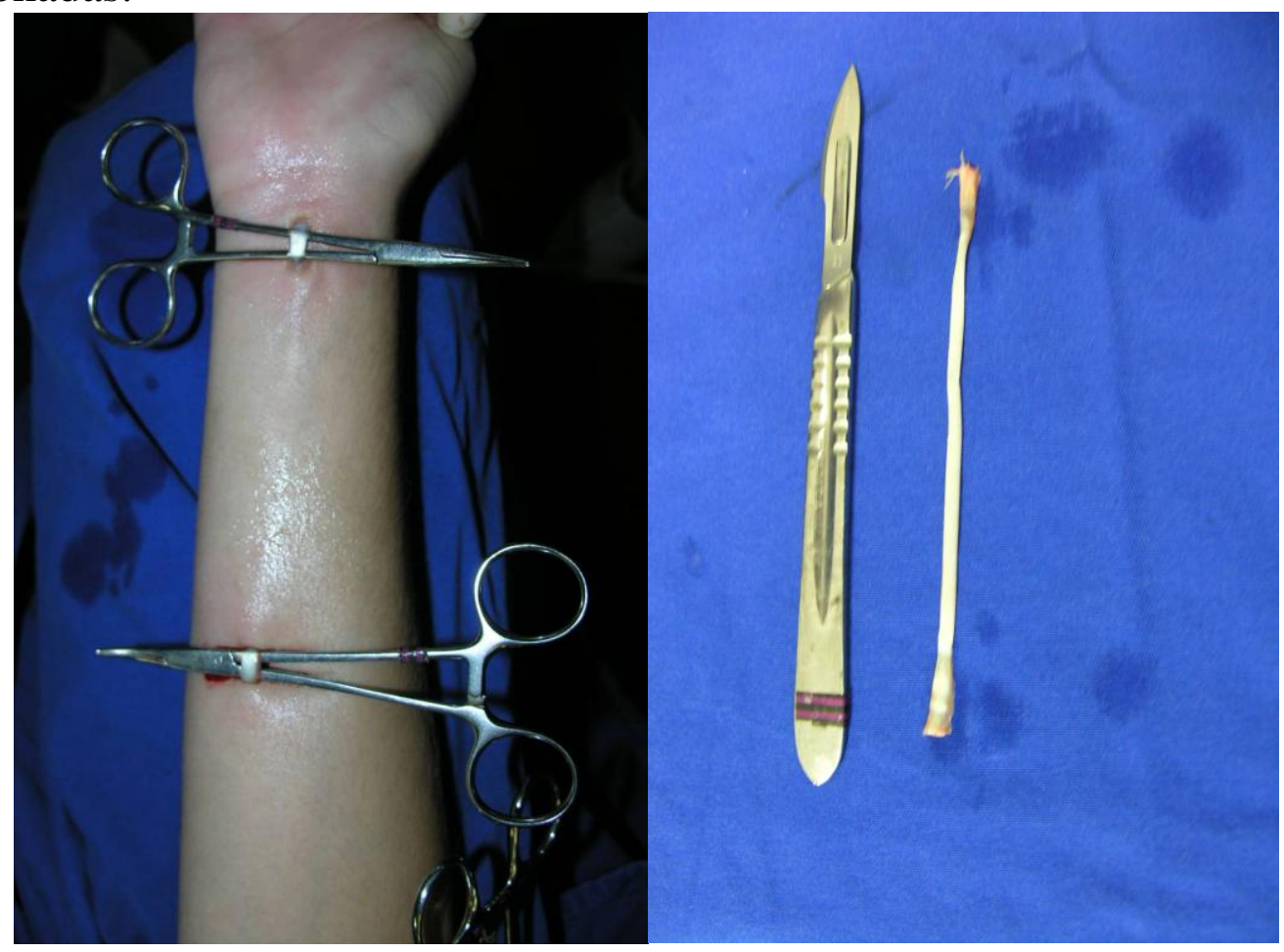


Neste momento o pedículo neurovascular foi seccionado. Com o pedículo orientado inferiormente foi feita uma sutura contínua tipo Parkerker com nylon 4.0 na extremidade de fixação bucal do músculo. Essa sutura tem por objetivo aumentar a resistência e evitar a desinserção do músculo do canto da boca.

Foram passados pontos inabsorvíveis de Ethibond 3.0 (Ethicon, a Johnson \& Johnson Company, Somerville, NJ) no lábio inferior, modíolo e lábio superior para fixação do retalho à comissura oral. No grupo onde foi feita a fixação convencional (GRUPO II) aplicou-se 3 pontos no orbicular do lábio superior, 1 ponto no modíolo e 1 ponto no lábio inferior (Figuras 3, 4, 5).

Figura 3. Pontos de fixação à extremidade bucal do retalho.

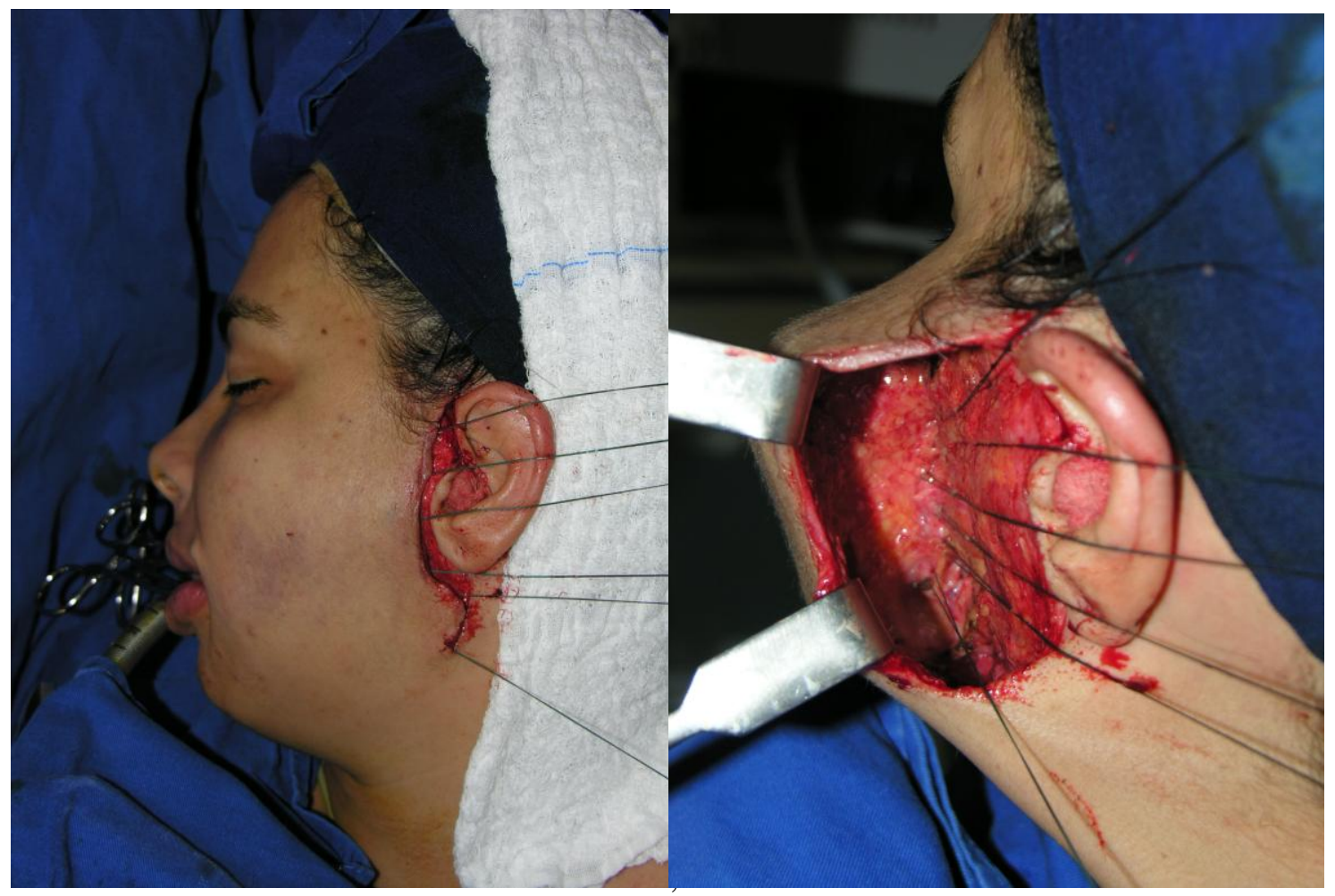


Figura 4. Posicionamento do retalho no GRUPO II (sem tendão).

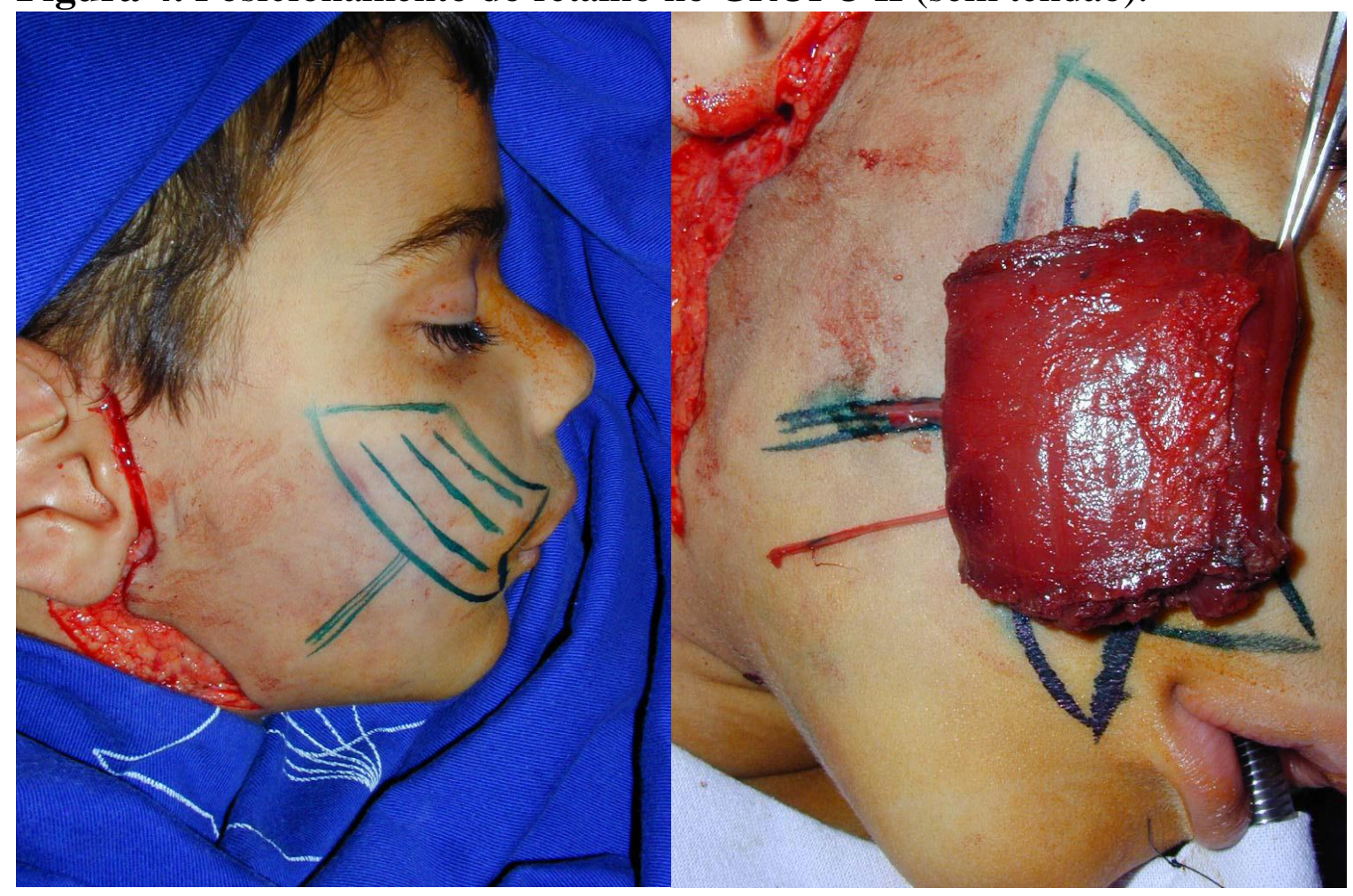

Figura 5. Fixação do retalho muscular no GRUPO II (sem tendão).

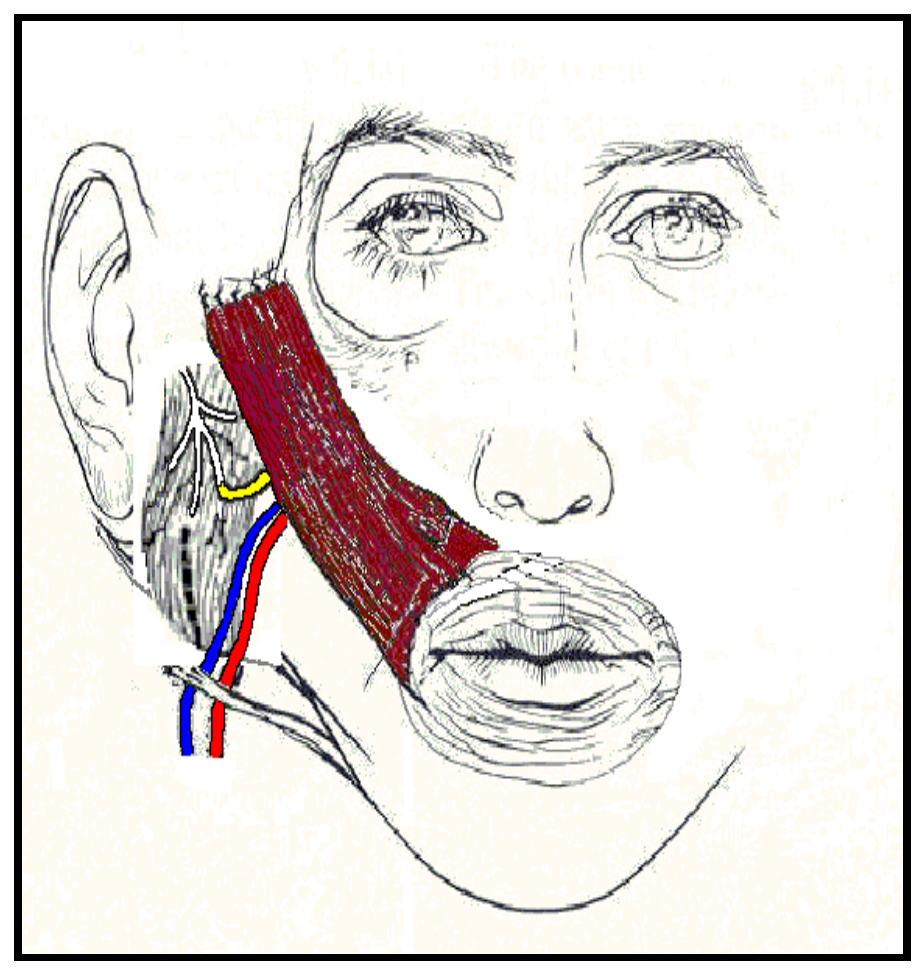


No grupo onde foi utilizada a fixação com associação do palmar longo (GRUPO I) o procedimento ocorreu de forma idêntica até esse momento. Com agulha de Reverdin transfixamos o retalho em toda sua espessura na extremidade de fixação oral para passagem do tendão, de forma que fiquem 2 pontas do tendão de mesma extensão externamente, e o segmento médio no interior do músculo. A seguir foram feitas 2 incisões na parte interna dos lábios superior e inferior, $5 \mathrm{~mm}$ além do ponto médio no lado não paralisado, isolando-se a seguir o orbicular da boca. Através dessa incisão foi feito túnel estreito até o canto da boca para passagem das 2 extremidades do tendão, uma para lábio superior e outra para lábio inferior (Figura 6 e 7).

Figura 6. Posicionamento do retalho no GRUPO I (com tendão).

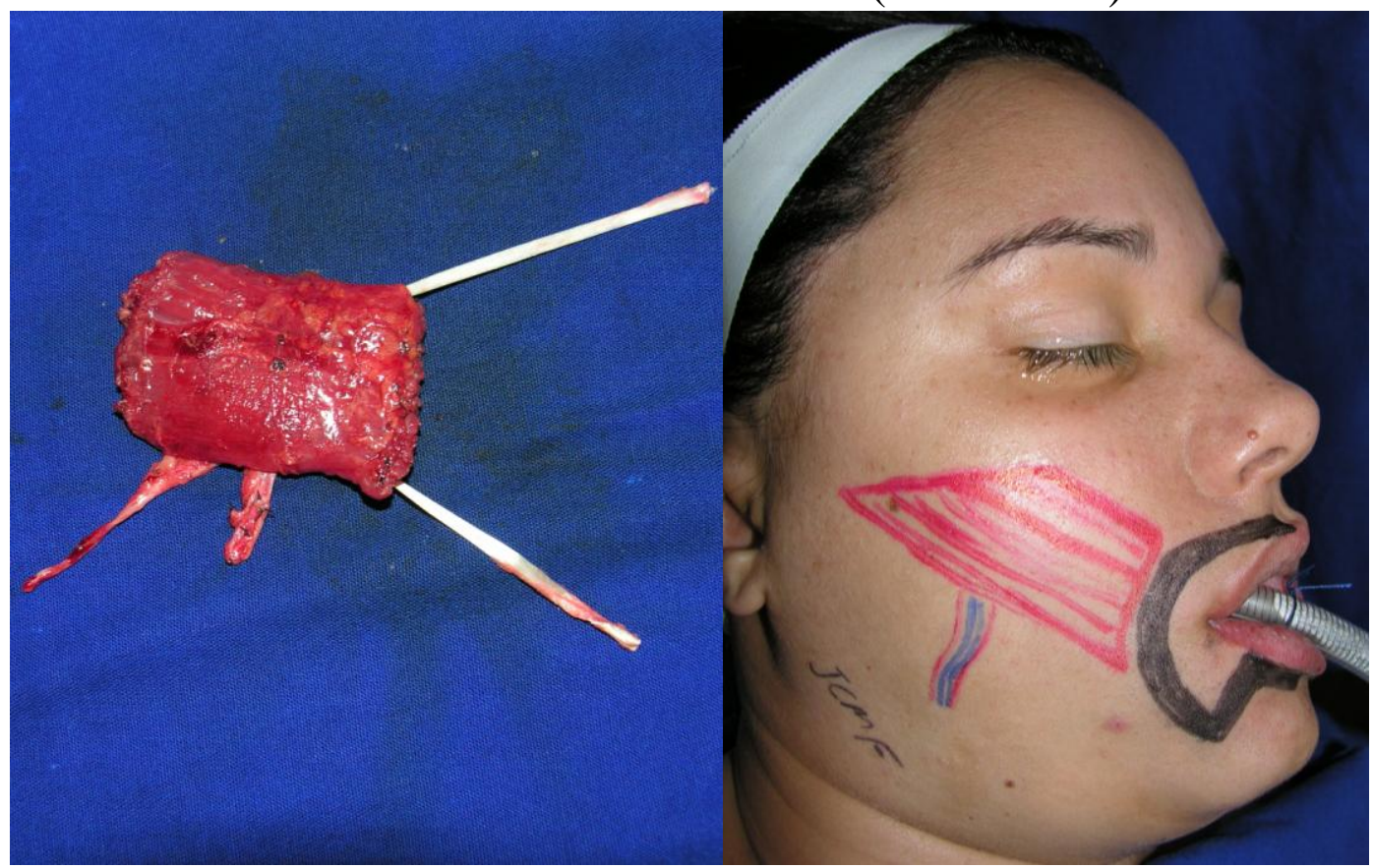


Figura 7. Representação esquemática do posicionamento do tendão palmar longo no lábio superior com uso de agulha de Reverdin (GRUPO I).

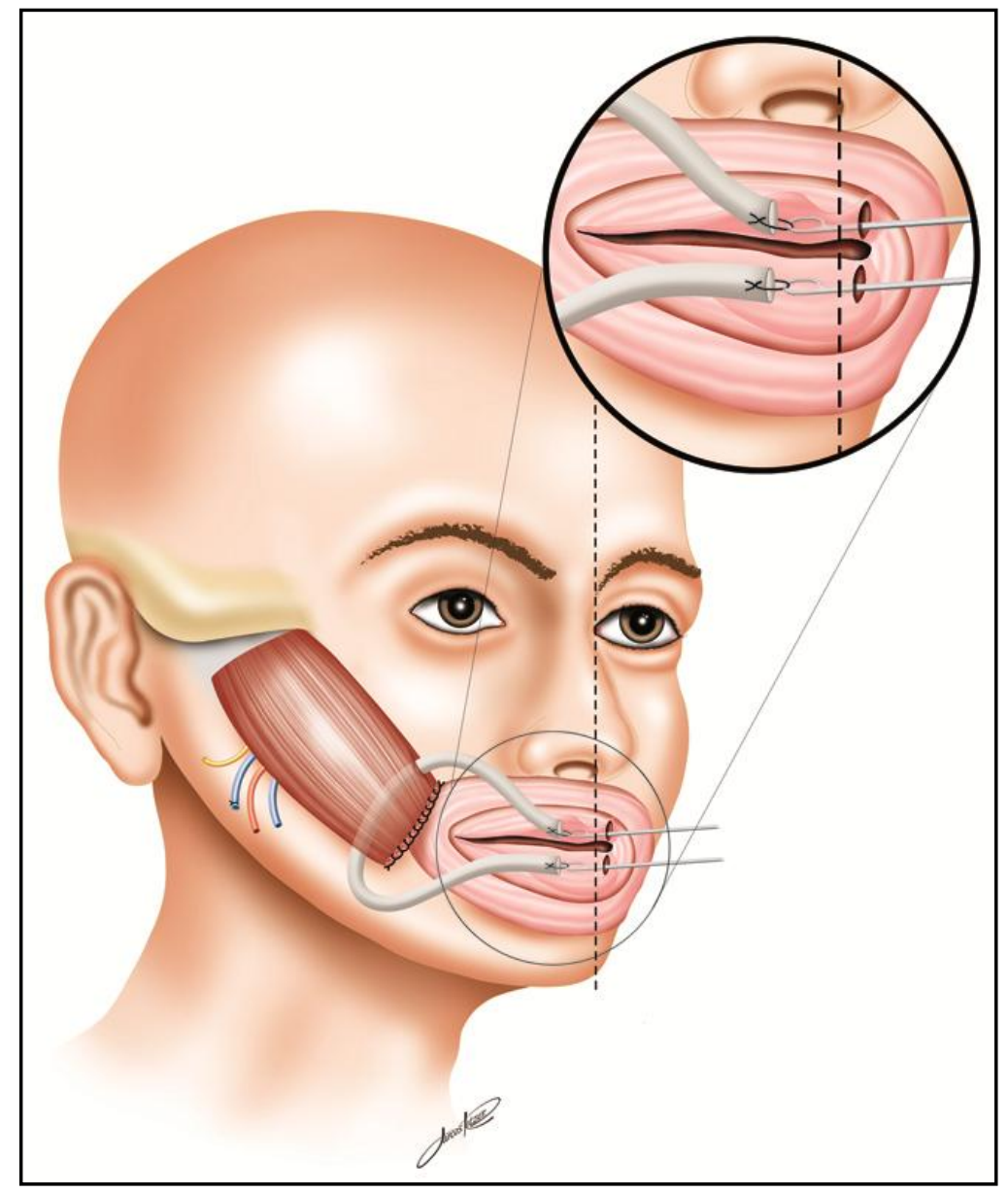

A fixação ao canto da boca foi feita de forma idêntica nos 2 grupos. No grupo em que utilizamos o tendão do palmar longo o mesmo foi transfixado juntamente com o músculo gracilis pelos pontos de ancoragem passados no canto medial da boca (Figura 8). As 2 extremidades livres do tendão foram tunelizadas até ultrapassar a linha média dos lábios e deixadas reparadas. 
Figura 8. Secção transversal da fixação do músculo gracilis com tendão palmar longo (GRUPO II). S: superficial; P: profundo; GM: músculo gracilis; PLT: tendão palmar longo; OOM: músculo orbicular da boca; SC: sutura contínua; Ponto "U": ponto em U de Ethibond 3.0 unindo as 3 estruturas.

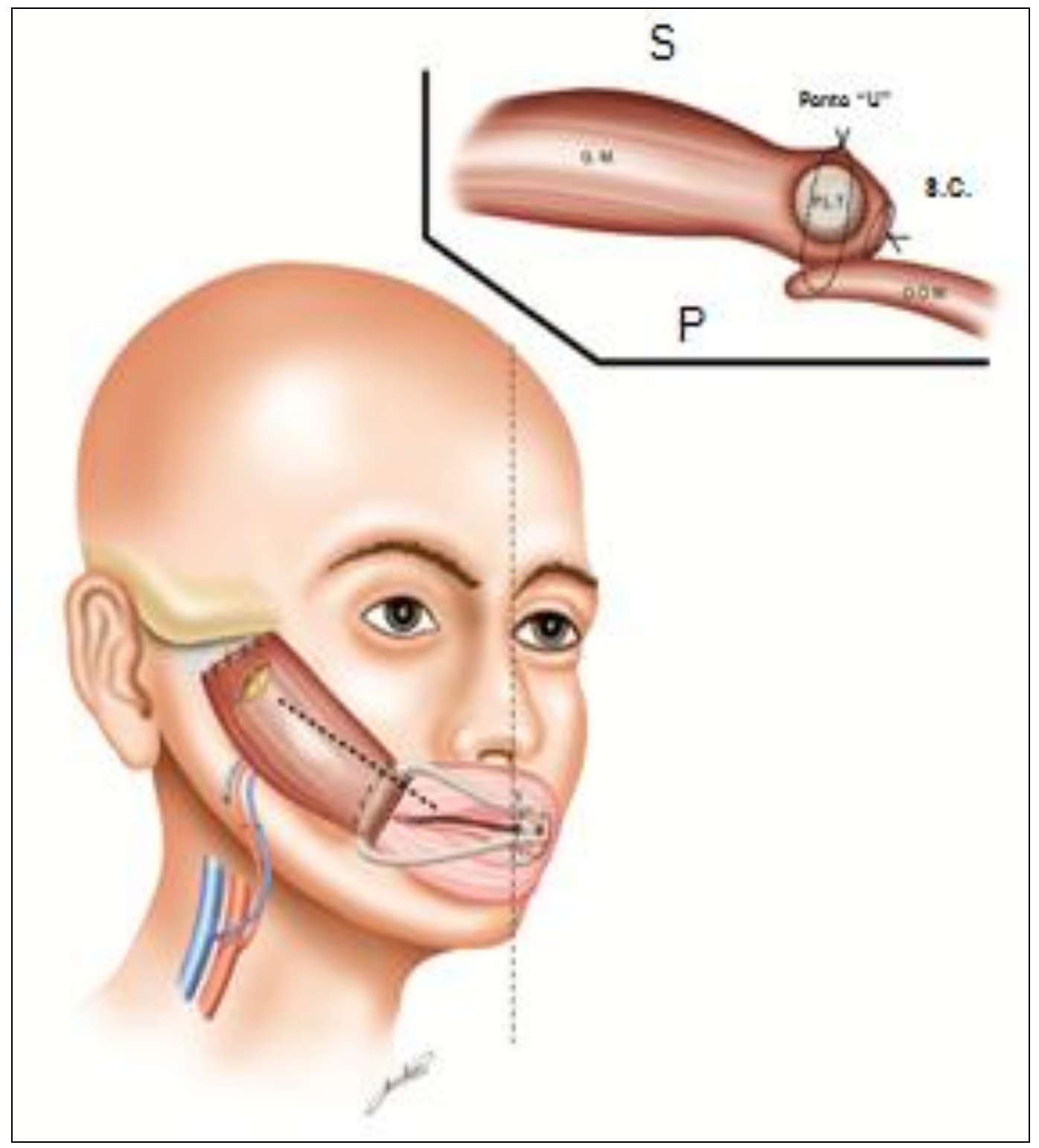


Neste momento foi feita a fixação do retalho no arco zigomático e fáscia parotídea massetérica cm fios inabsorvíveis de Ethibond 3.0. A tensão foi ajustada de forma a se reproduzir um sorriso forçado. A seguir foram realizadas as anastomoses vasculares e neurorrafia com Nylon 10.0 sob magnificação com microscópio. Após seu término checamos a perfusão do retalho e revisamos a hemostasia. Como rotina utilizamos dreno de sucção.

Como última etapa, realizamos a fixação do tendão ao músculo orbicular da boca com pontos em "U" de Ethibond 3.0, ajustando a tensão para equilíbrio da extensão dos lábios superior e inferior entre lado paralisado e não paralisado (Figura 9).

\subsection{Avaliação qualitativa do equilíbrio labial}

Para análise do equilíbrio labial todos os pacientes foram fotografados e filmados, no pré e pós-operatório. Todas as avaliações foram feitas por cirurgião plástico independente que não sabia a qual grupo pertencia cada paciente. As análises foram feitas com 9 meses de pós-operatório e nenhum paciente foi submetido a tratamento complementar prévio com toxina botulínica. 
Figura 9. Aspecto final das fixações muscular e tendinosa, anastomoses vasculares e neurorrafia (GRUPO I).

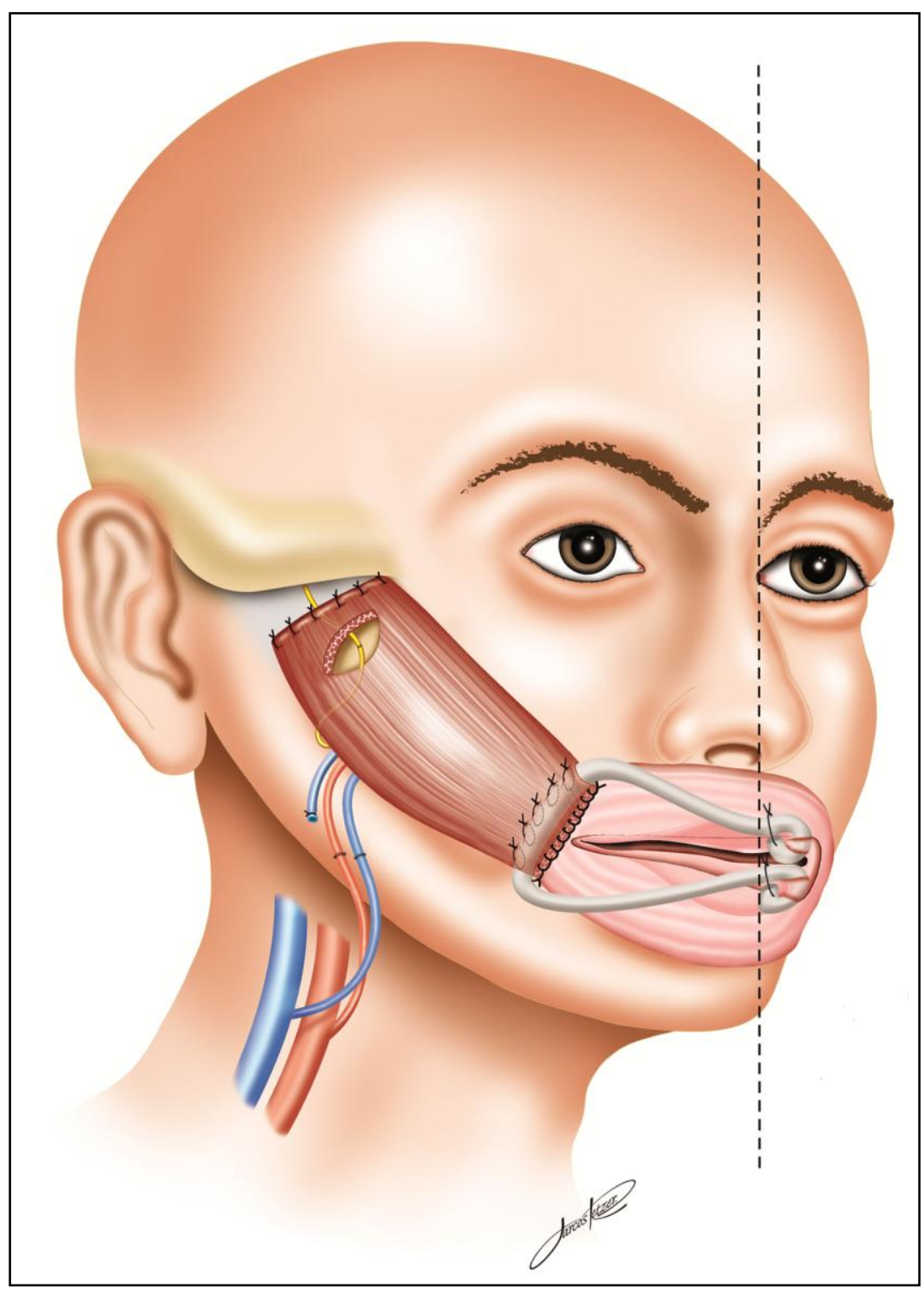

O sorriso alcançado foi graduado baseado na intensidade e forma, sem levar em consideração posição do filtro ou movimentação do lábio inferior:

- Ausência de movimento (Figura 10); 
- Pobre: contração muscular visível sem movimento do modíolo (Figura 11);

- Regular: movimento do modíolo presente, mas não o suficiente para formar o sorriso (Figura 12);

- Bom: presença de sorriso, mas assimétrico em relação ao lado não paralisado (Figura 13);

- Excelente: sorriso simétrico em forma e intensidade (Figura 14).

Figura 10. Graduação do sorriso: ausência de movimento.

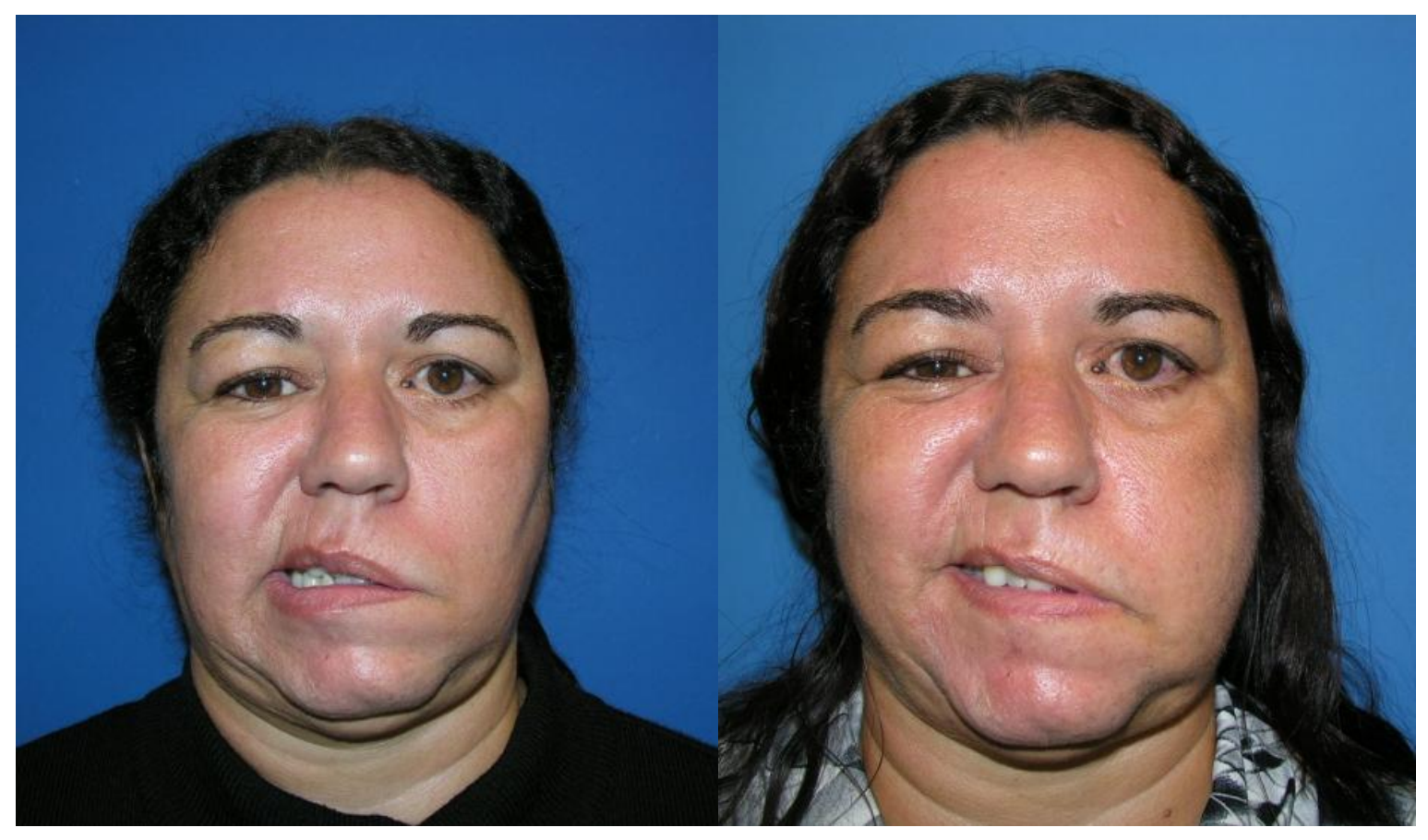


Figura 11. Graduação do sorriso: movimentação pobre.

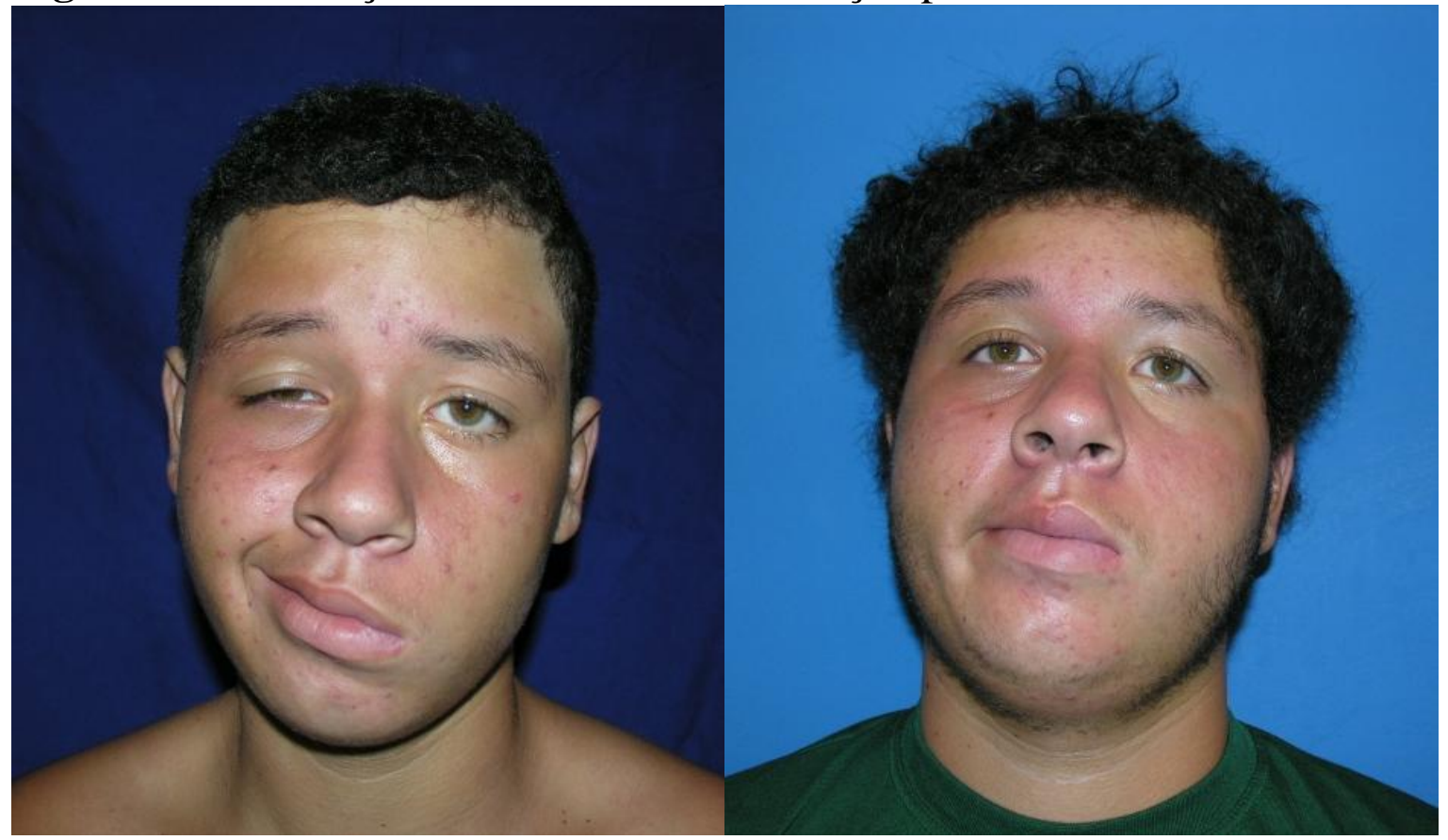

Figura 12. Graduação do sorriso: movimentação regular.

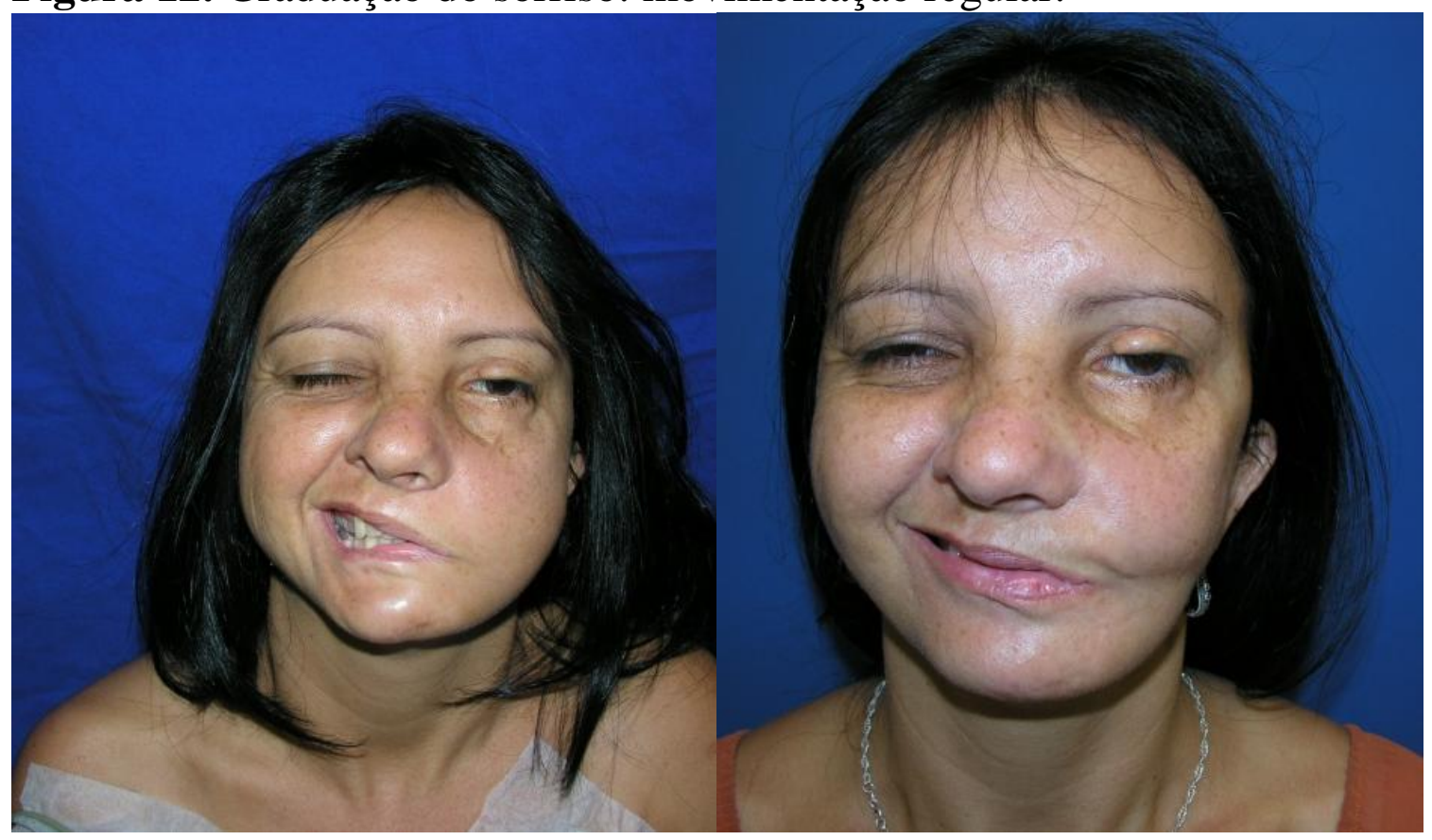


Figura 13. Graduação do sorriso: boa movimentação.

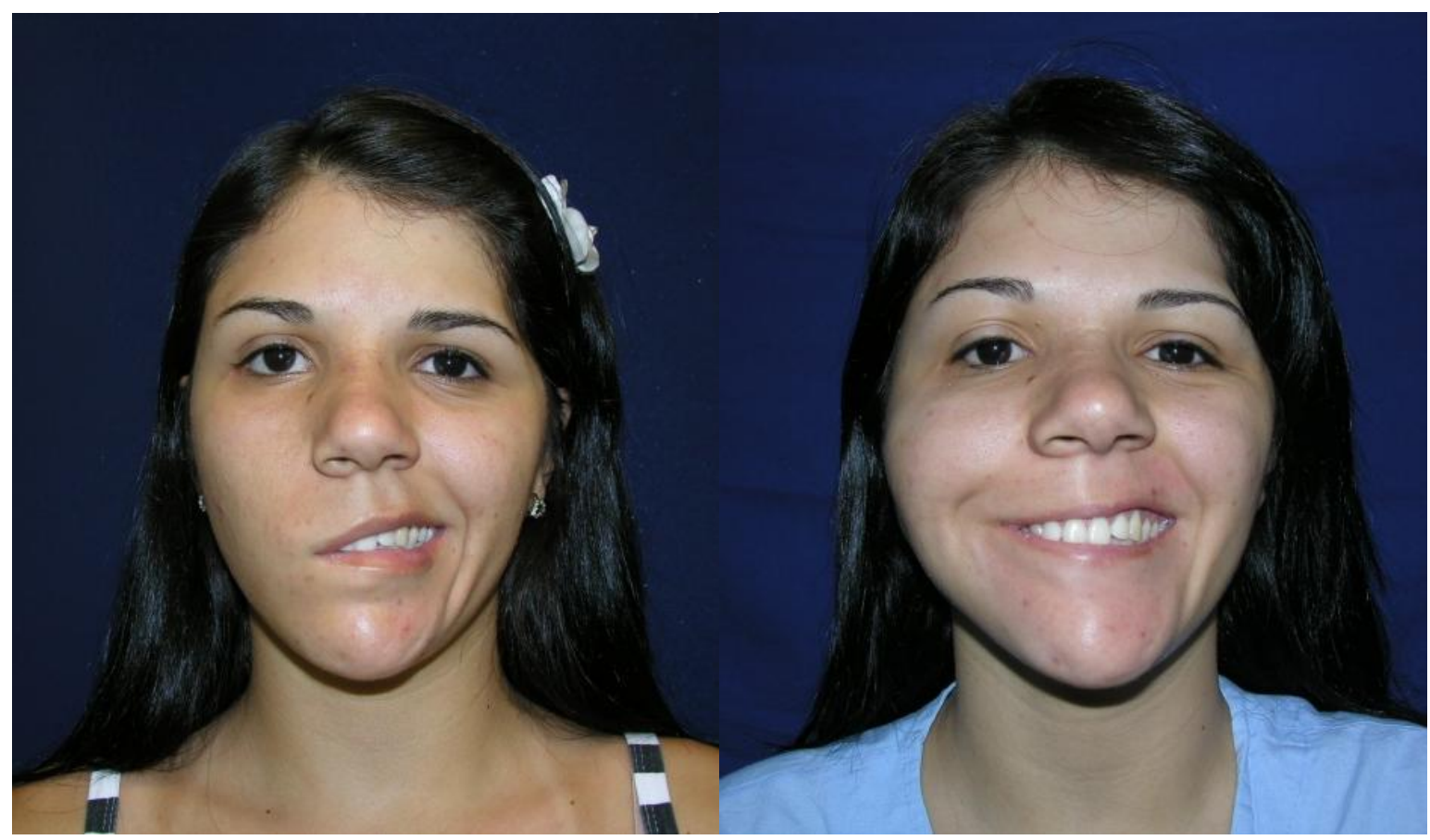

Figura 14. Graduação do sorriso: excelente.

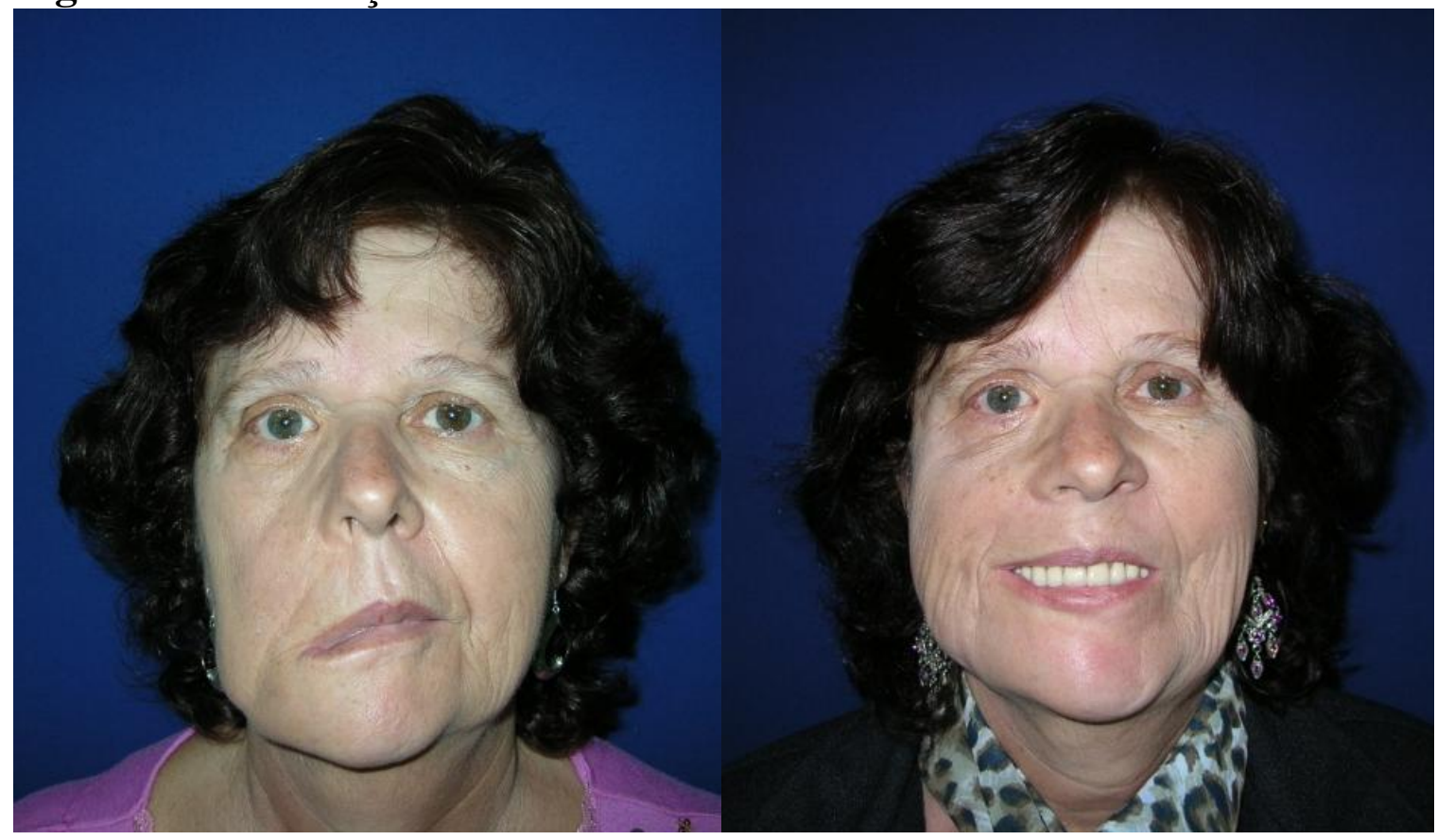




\subsection{Avaliação quantitativa do equilíbrio labial}

Para comparação entre os 2 grupos idealizamos índice relativo (IR) com medidas da distância do ponto médio do arco de cúpido até o modíolo nos lados paralisado (LP) e não paralisado (LNP) (Figura 15). As medidas foram tomadas em repouso e com sorriso forçado, e obtidas a partir de fotografias frontais tiradas no pré e pós-operatório de 9 meses. Nenhum paciente foi submetido a tratamento complementar com toxina botulínica previamente a estas aferições. A medida obtida no lado paralisado (LP) foi dividida pela soma das medidas dos 2 lados:

$$
\text { - } \mathrm{IR}_{\%}=\frac{\mathrm{LP} \times 100}{\mathrm{LP}+\mathrm{LNP}}
$$

Valores de 50\% indicam equilíbrio entre lado paralisado e não paralisado e, portanto, filtro posicionado na linha média. Valores maiores que $50 \%$ indicam desvio do filtro para o lado não paralisado. Valores menores que $50 \%$ indicam desvio para o lado paralisado. 
Figura 15. Demonstração do Índice Relativo. Seta preta: lado não paralisado (LNP); seta branca: lado paralisado (LP).

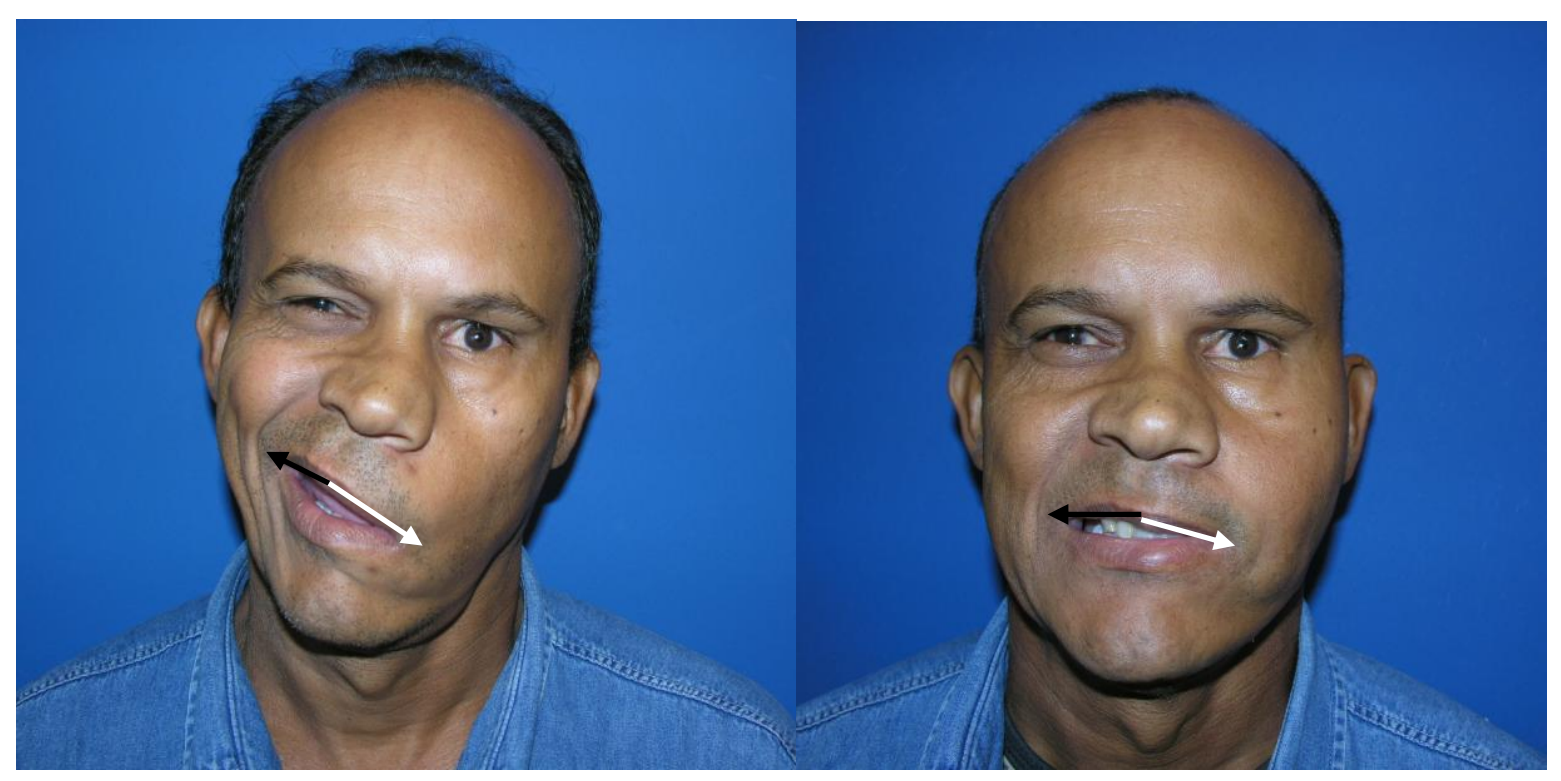




\section{RESULTADOS}




\section{RESULTADOS}

Nesta série houve 1 perda de retalho(3,84\%) no GRUPO II. No GRUPO I dois (2) pacientes abandonaram o seguimento. Não houve queixas significativas nem complicações relacionadas à área doadora do retalho muscular. Nenhum dos pacientes estudados apresentou queixas funcionais ou estéticas com relação à área doadora do tendão do músculo palmar longo.

No grupo I uma paciente apresentou hematoma facial no pós-operatório imediato e foi reoperada $(3,84 \%)$. Apresentava sangramento em um ramo da artéria facial que foi ligado e evoluiu sem novas intercorrências. Durante o seguimento pós-operatório precoce 3 pacientes apresentaram fístula salivar $(11,53 \%)$ caracterizada pelo aumento de volume na região parotídea e confirmadas laboratorialmente (dosagem de amilase). Todos os pacientes foram tratados inicialmente com punções ambulatoriais seriadas e 2 evoluíram com completa resolução do quadro. Um paciente manteve o quadro inalterado após 1 mês e necessitou ser reoperado. Durante a cirurgia observamos viabilidade do retalho e pequena laceração no ducto parotídeo que foi rafiada. As primeiras contrações musculares foram observados num período que variou de 3 a 6 meses (média 3,5 meses). 


\subsection{Análise estatística (avaliação quantitativa)}

Para comparar o comportamento dos grupos ao longo do tempo, considerou-se a relação existente entre medidas tomadas em um mesmo paciente com emprego do modelo de análise de variância com medidas repetidas (WINER, 1971).

\subsubsection{Análise descritiva}

O passo inicial da análise constitui-se em uma descrição geral das informações coletadas. Esse procedimento visa à obtenção de indicações do comportamento dos dados e ao enriquecimento das conclusões que serão tomadas ao final da análise. A seguir, apresentam-se as medidas-resumo e os gráficos pertinentes a esta descrição. 
Tabela 4: Medidas descritivas da variável repouso pré-operatório (Rep-pre) e pós-operatório (Rep-pos), em cada grupo.

\begin{tabular}{clrr}
\hline Grupo & & Rep-pre & Rep-pos \\
\hline I & Média & 56,18 & 52,71 \\
& Desvio- & & \\
& padrão & 3,73 & 2,62 \\
& Mínimo & 50,00 & 48,00 \\
& Máximo & 64,00 & 58,00 \\
& Assimetria & 0,40 & 0,44 \\
& Curtose & $-0,02$ & $-0,01$ \\
\hline II & Média & 58,67 & 55,50 \\
& Desvio- & & \\
& padrão & 6,92 & 4,59 \\
& Mínimo & 50,00 & 50,00 \\
& Máximo & 67,00 & 61,00 \\
& Assimetria & 0,11 & 0,37 \\
& Curtose & $-1,84$ & $-1,69$ \\
\hline Total & Média & 56,83 & 53,43 \\
& Desvio- & & \\
& padrão & 4,72 & 3,37 \\
& Mínimo & 50,00 & 48,00 \\
& Máximo & 67,00 & 61,00 \\
& Assimetria & 0,63 & 0,90 \\
& Curtose & $-0,10$ & 0,54 \\
\hline
\end{tabular}


Tabela 5: Medidas descritivas da variável dinâmico pré-operatório (Din-pre) pós-operatório (Din-pos), em cada grupo.

\begin{tabular}{clrr}
\hline Grupo & & Din-pre & Din-pos \\
\hline I & Média & 58,65 & 50,29 \\
& Desvio- & & \\
& padrão & 4,31 & 2,20 \\
& Mínimo & 52,00 & 47,00 \\
& Máximo & 66,00 & 54,00 \\
& Assimetria & 0,31 & 0,13 \\
& Curtose & $-0,79$ & $-0,71$ \\
\hline II & Média & 62,67 & 61,33 \\
& Desvio- & & \\
& padrão & 3,72 & 7,34 \\
& Mínimo & 56,00 & 54,00 \\
& Máximo & 66,00 & 72,00 \\
& Assimetria & $-1,39$ & 0,83 \\
& Curtose & 1,63 & $-1,42$ \\
\hline Total & Média & 59,70 & 53,17 \\
& Desvio- & & \\
& padrão & 4,47 & 6,35 \\
& Mínimo & 52,00 & 47,00 \\
& Máximo & 66,00 & 72,00 \\
& Assimetria & $-0,04$ & 1,92 \\
& Curtose & $-1,22$ & 3,72 \\
\hline
\end{tabular}


Gráfico 1: Perfis individuais observados no Grupo I (com tendão) para a variável repouso (Rep).
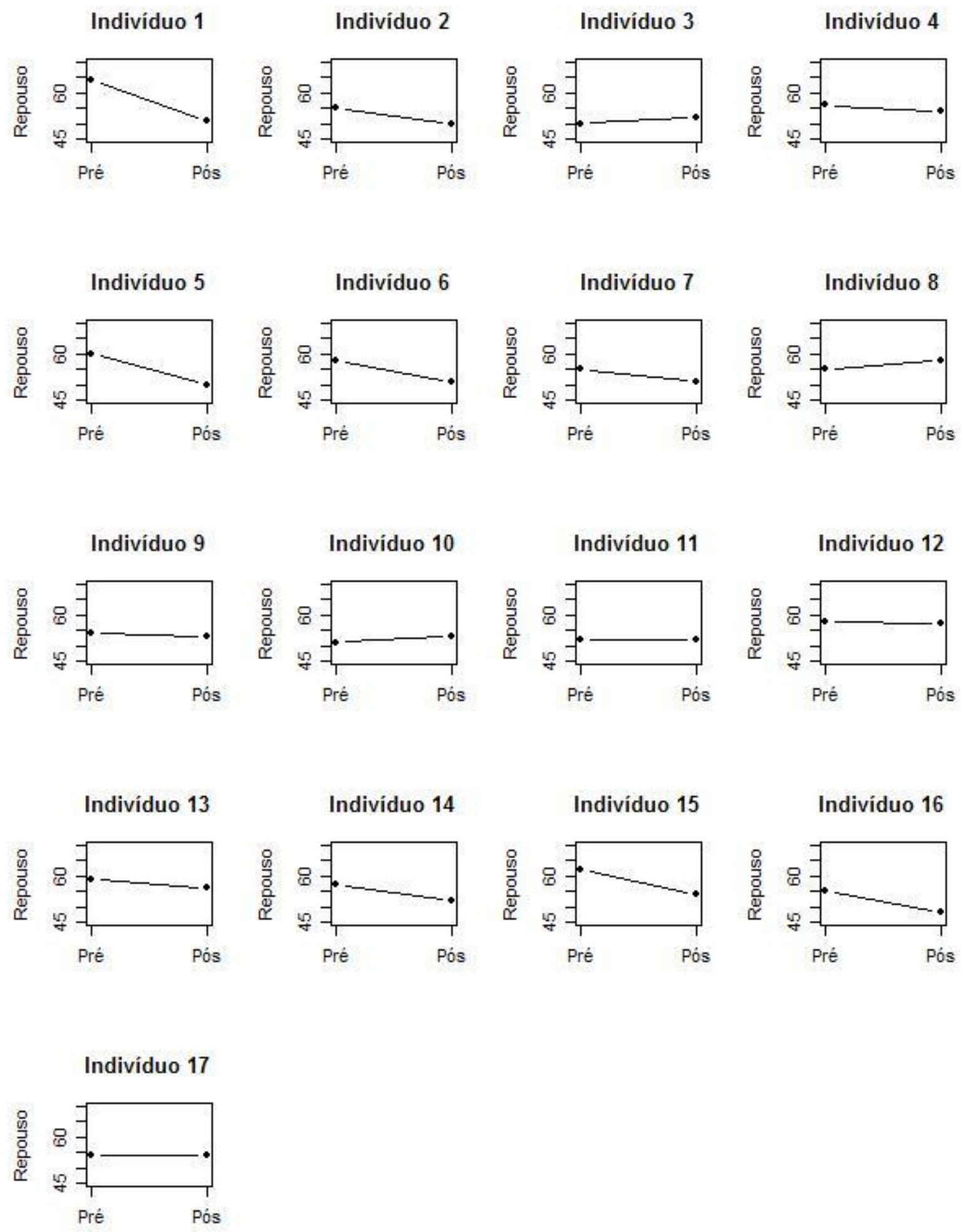
Gráfico 2: Perfis individuais observados no Grupo II (sem tendão) para a variável repouso (Rep).
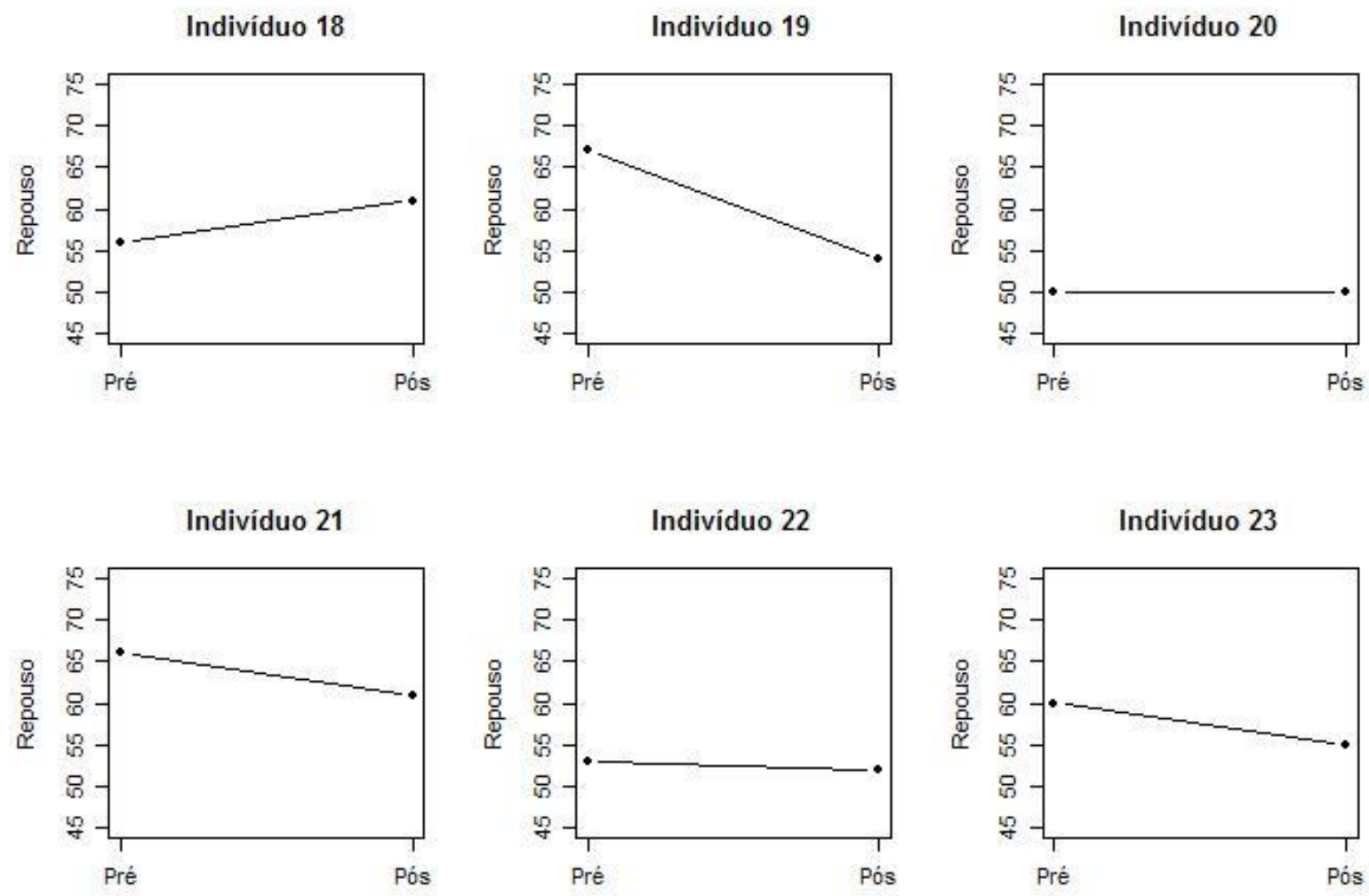
Gráfico 3: Perfis individuais observados no Grupo I (com tendão) para a variável dinâmico (Din).
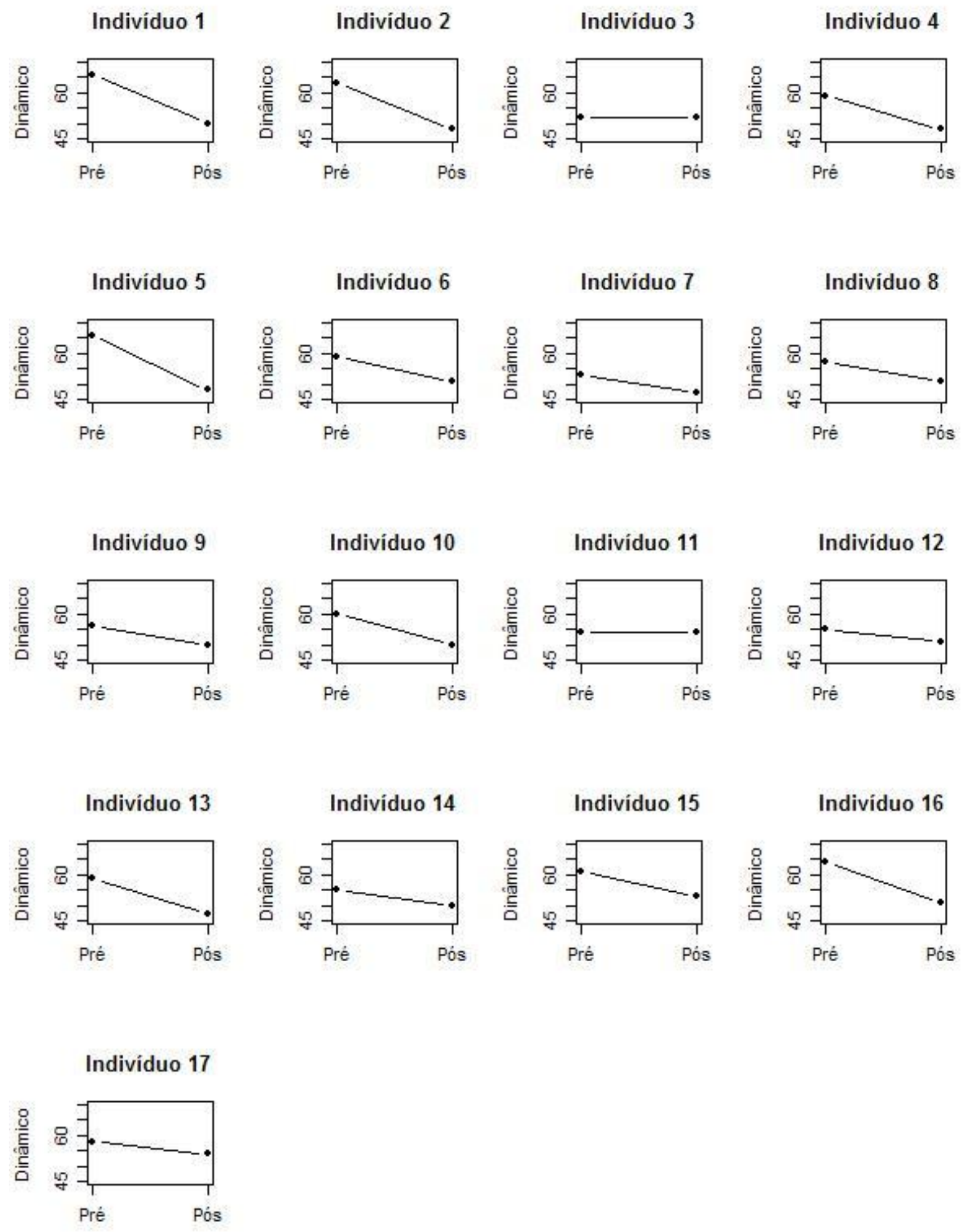
Gráfico 4: Perfis individuais observados no Grupo II (sem tendão) para a variável dinâmico (Din).
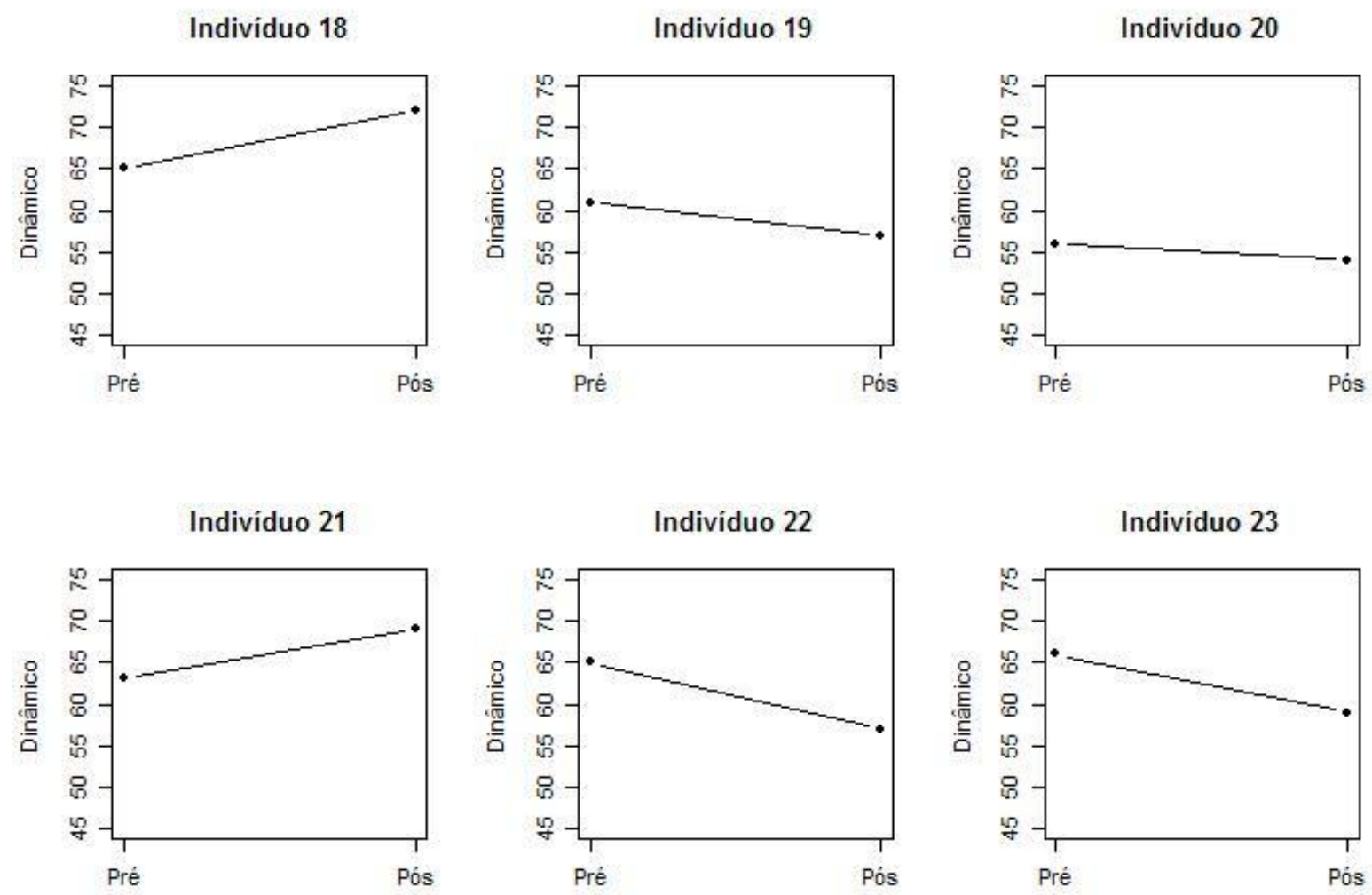
Gráfico 6: Perfis médios observados para a variável repouso em ambos os grupos.

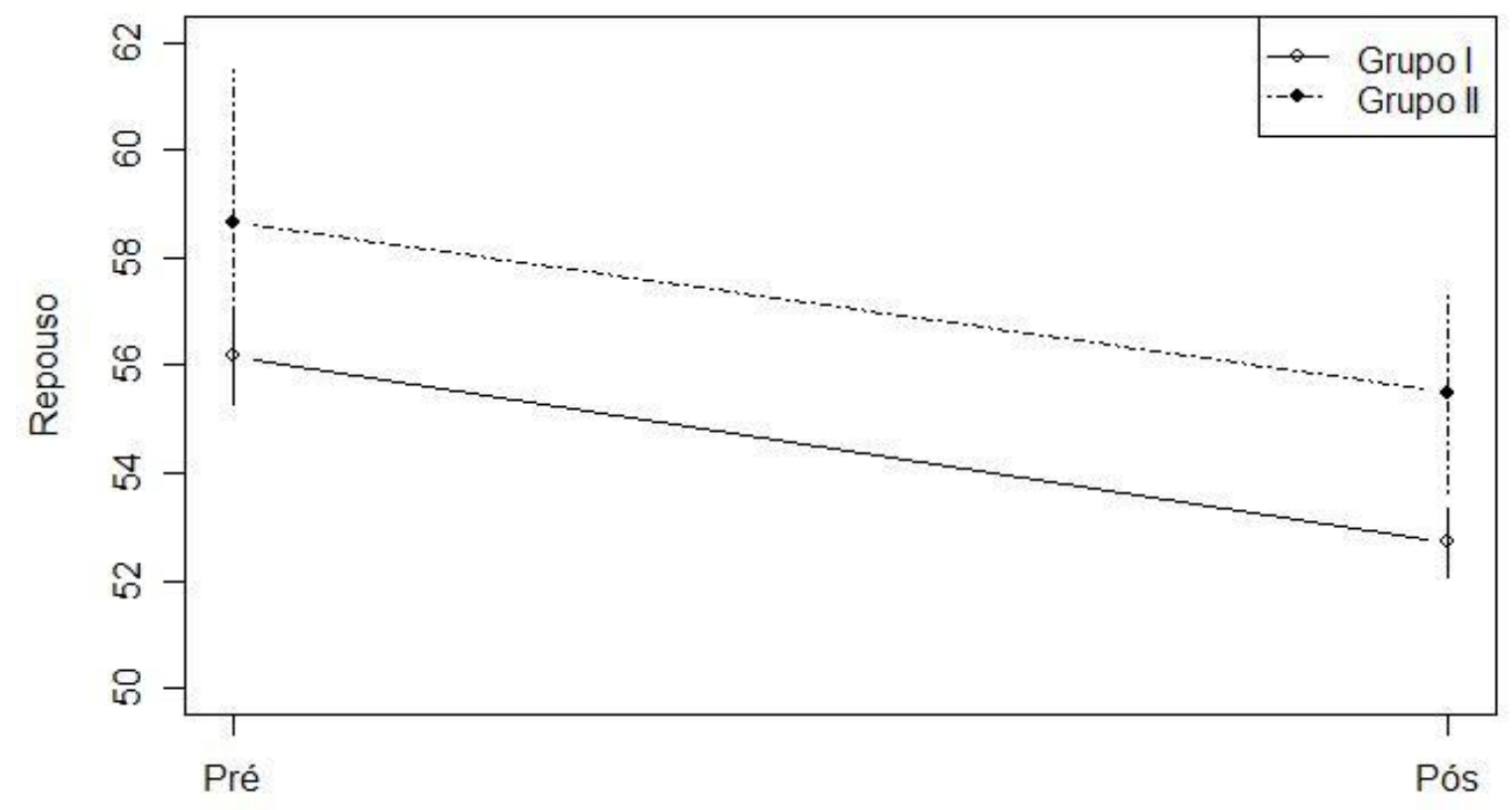

Gráfico 6: Perfis médios observados para a variável dinâmico em ambos os grupos.

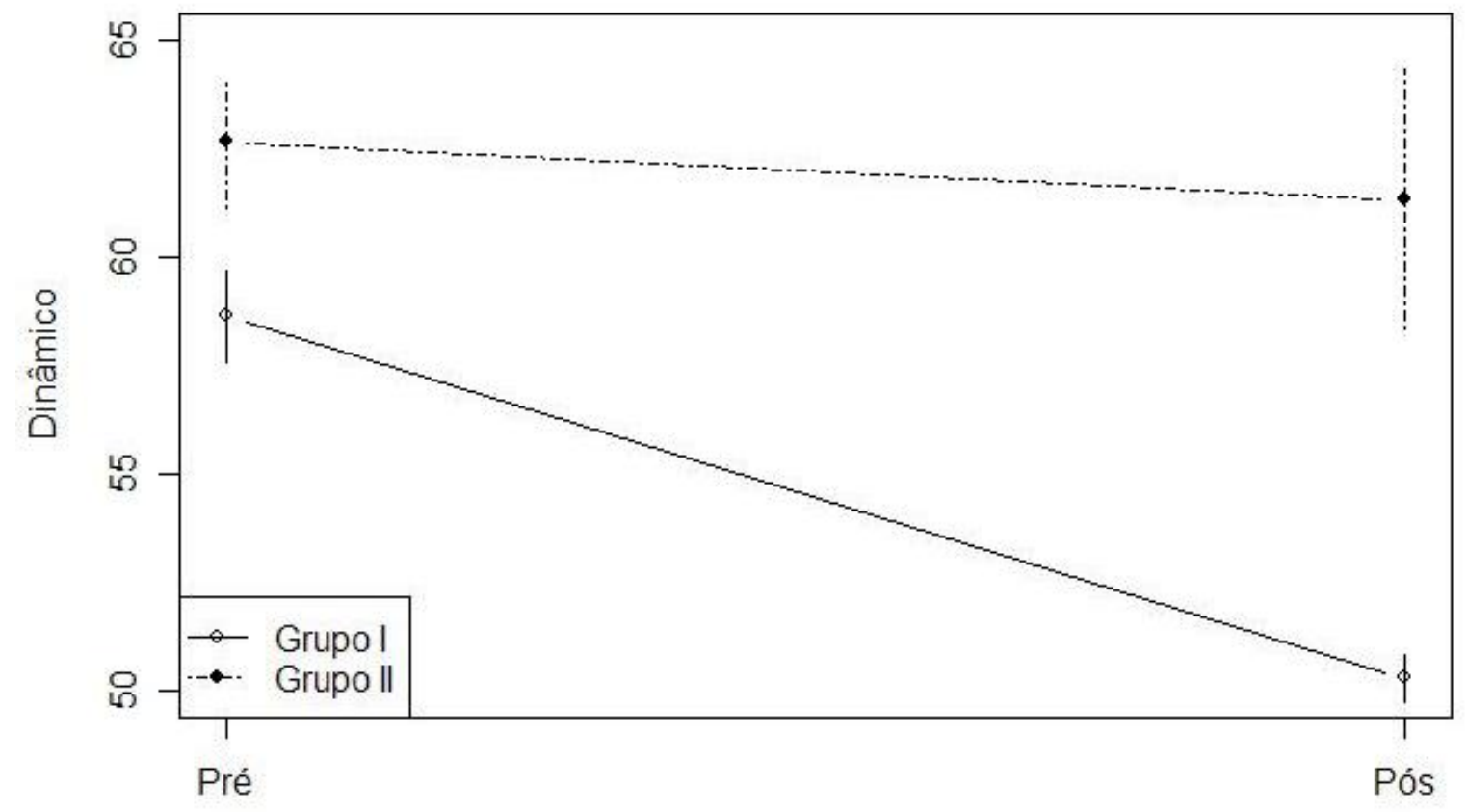




\subsubsection{Análise inferencial}

Para comparar o comportamento dos grupos ao longo do tempo, considerando-se a relação existente entre medidas tomadas em um mesmo indivíduo foi empregado o modelo de análise de variância com medidas repetidas. Valores de $p$ menores que 0,05 foram considerados estatisticamente significantes. Os resultados apresentados nas tabelas a seguir permitem afirmar que:

- Em ambos os grupos (que são iguais), houve diferença entre as medidas Pré e Pós da variável Repouso.

- Em se tratando da variável Dinâmico, houve variação entre as medidas Pré e Pós somente no Grupo I. Os grupos não apresentavam diferença no início do estudo, mas na segunda avaliação, o Grupo I apresentou valores médios menores que o Grupo II. 
Tabela 6: Níveis descritivos obtidos da aplicação do modelo de análise de variância com medidas repetidas.

\section{Repouso Dinâmico}

\begin{tabular}{lcc} 
Grupo I x Grupo II & 0,094 & 0,001 \\
Pré x Pós & 0,010 & 0,001 \\
Interação & 0,898 & 0,015 \\
\hline
\end{tabular}

Tabela 7: Resultados da comparação entre os Grupos I e II com respeito à variável Dinâmico, em cada instante de avaliação.

\begin{tabular}{cc} 
Instante & Nível descritivo \\
\hline Pré & 0,056 \\
& \\
Pós & 0,001 \\
\hline
\end{tabular}


Tabela 8: Resultados da comparação entre os instantes pré e pós-operatório com respeito à variável Dinâmico, em cada grupo.

\begin{tabular}{cc} 
Grupo & Nível descritivo \\
\hline Grupo I & 0,001 \\
& \\
Grupo II & 0,564 \\
\hline
\end{tabular}




\subsection{Avaliação qualitativa}

No GRUPO I, 94,1\% dos pacientes apresentaram bons/excelentes resultados. No GRUPO II 66,6\% apresentaram bons/excelentes resultados (Tabela 9).

Tabela 9. Análise qualitativa da intensidade e forma do sorriso voluntário após reanimação facial.

\begin{tabular}{|c|c|c|c|c|c|c|}
\hline GRUPO & $\mathbf{n}$ & Ausente & Pobre & Regular & Bom & Excelente \\
\hline$\frac{\text { I }}{(\text { TENDÃO) }}$ & 17 & 0 & $\begin{array}{c}1 \\
(5,8 \%)\end{array}$ & 0 & $\begin{array}{c}5 \\
(29,4 \%)\end{array}$ & $\begin{array}{c}11 \\
(64,7 \%)\end{array}$ \\
\hline $\begin{array}{c}\text { II } \\
\text { (SEM } \\
\text { TENDÂO) }\end{array}$ & 6 & $\begin{array}{c}1 \\
(16,6 \%)\end{array}$ & 0 & $\begin{array}{c}1 \\
(16,6 \%)\end{array}$ & $\begin{array}{c}3 \\
(50 \%)\end{array}$ & $\begin{array}{c}1 \\
(16,6 \%)\end{array}$ \\
\hline
\end{tabular}

\subsection{Avaliação quantitativa}

Com relação ao índice relativo de medidas labiais (IR) não observamos diferenças estatisticamente significantes no pré-operatório entre os 2 grupos com relação às medidas em repouso e com sorriso voluntário (dinâmico).

Houve diferença estatisticamente significante $(p<0,05)$ com relação ao IR em repouso, pré e pós-operatório, em ambos os grupos. Entretanto, a 
comparação dos IRs em repouso pós-operatórios não apresentou diferença estatisticamente significante entre os 2 grupos (Tabela 10).

Tabela 10. Índice relativo (IR) da distância entre o modíolo e centro do arco de cúpido em repouso.

\section{REPOUSO}

\section{Pré-operatório Pós-operatório}

$(\%)$

$(\%)$

\begin{tabular}{c|c|c|c}
\hline $\begin{array}{c}\text { Grupo I (n=17) } \\
\text { Média }\end{array}$ & 56,18 & 52,7 & $(p=0,001)$ \\
\hline $\begin{array}{c}\text { Grupo II (n=6) } \\
\text { Média }\end{array}$ & 58,67 & 55,5 & $(p=0,01)$ \\
\hline & $(p=0,094)$ & $(p=0,10)$ & \\
\hline
\end{tabular}

Durante o sorriso voluntário, na comparação entre os IRs pré e pósoperatórios houve diferença estatisticamente significante somente no grupo I $(\mathrm{p}=0,001)$. No grupo II, não foi demonstrada diferença estatisticamente significante entre as medidas dinâmicas pré e pós operatórias $(\mathrm{p}=0,564) \mathrm{Na}$ comparação das medidas dinâmicas pós-operatórias entre os 2 grupos encontramos valores estatisticamente menores no grupo I $(p=0,001)$, 
indicando melhor equilíbrio labial com o uso do tendão do músculo palmar longo (Tabela 11).

Tabela 11. Índice relativo (IR) da distância entre o modíolo e centro do arco de cúpido durante sorriso voluntário.

\section{DINÂMICO}

\section{Pré-operatório Pós-operatório}

$(\%)$

$(\%)$

\begin{tabular}{c|c|c|c}
\hline $\begin{array}{c}\text { Grupo I (n=17) } \\
\text { Média }\end{array}$ & 58,65 & 50,29 & $(p=0,001)$ \\
\hline Grupo II (n=6) & & & \\
Média & 62,67 & 61,33 & $(p=0,564)$ \\
\hline & $(p=0,056)$ & $(p=0,001)$ & \\
\hline
\end{tabular}

Nas figuras 16 a 32 são demonstrados imagens pré e pós-operatórias dos pacientes do GRUPO I (com tendão). As figuras 33 à 38 mostram imagens pré e pós operatórias de pacientes do GRUPO II (sem tendão). 
Figura 16 (Grupo I - caso 1): Pré e pós-operatório (9 meses). Graduação do sorriso: excelente.
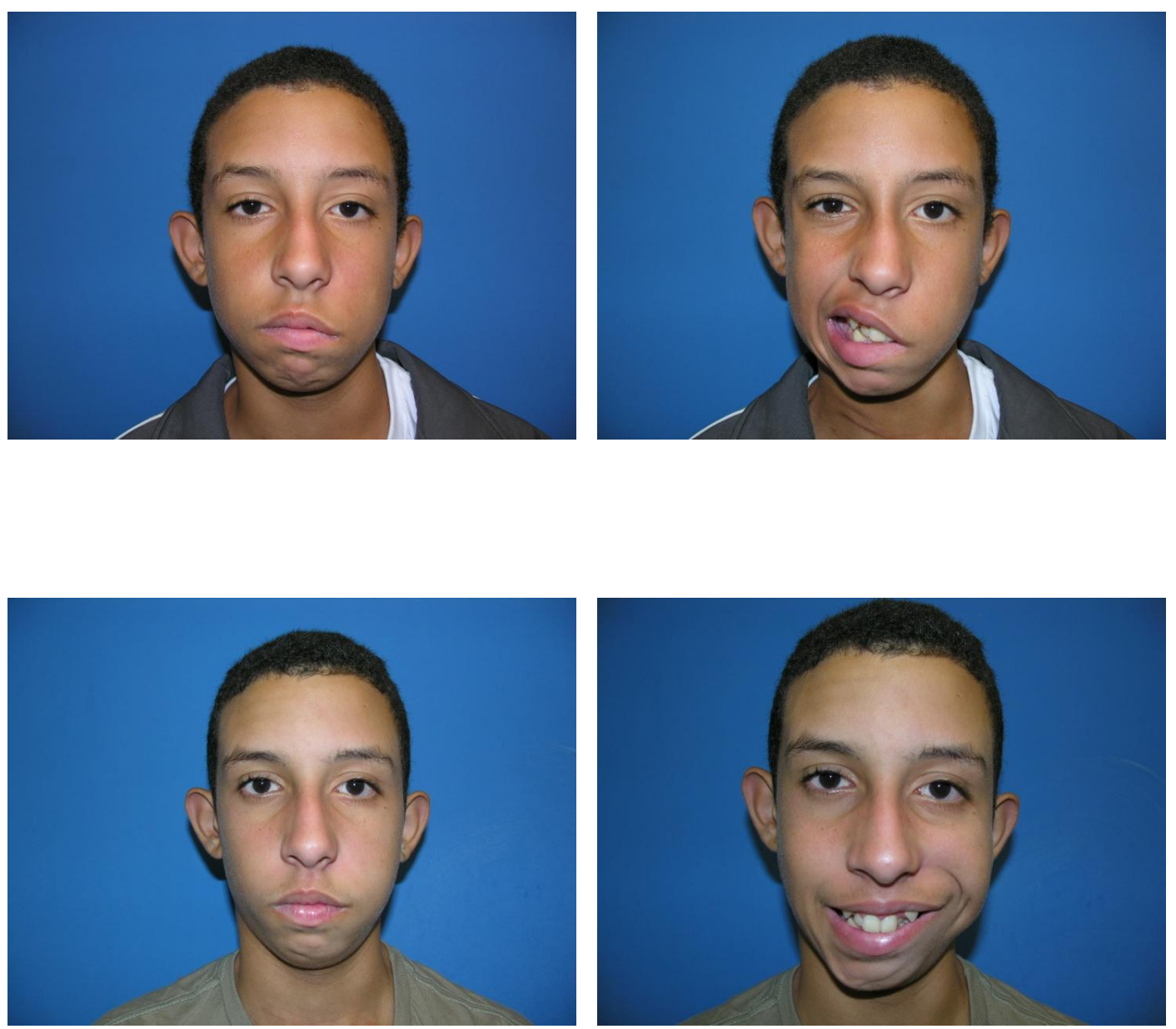
Figura 17(Grupo I - caso2): Pré e pós-operatório (9 meses). Graduação do sorriso: bom.
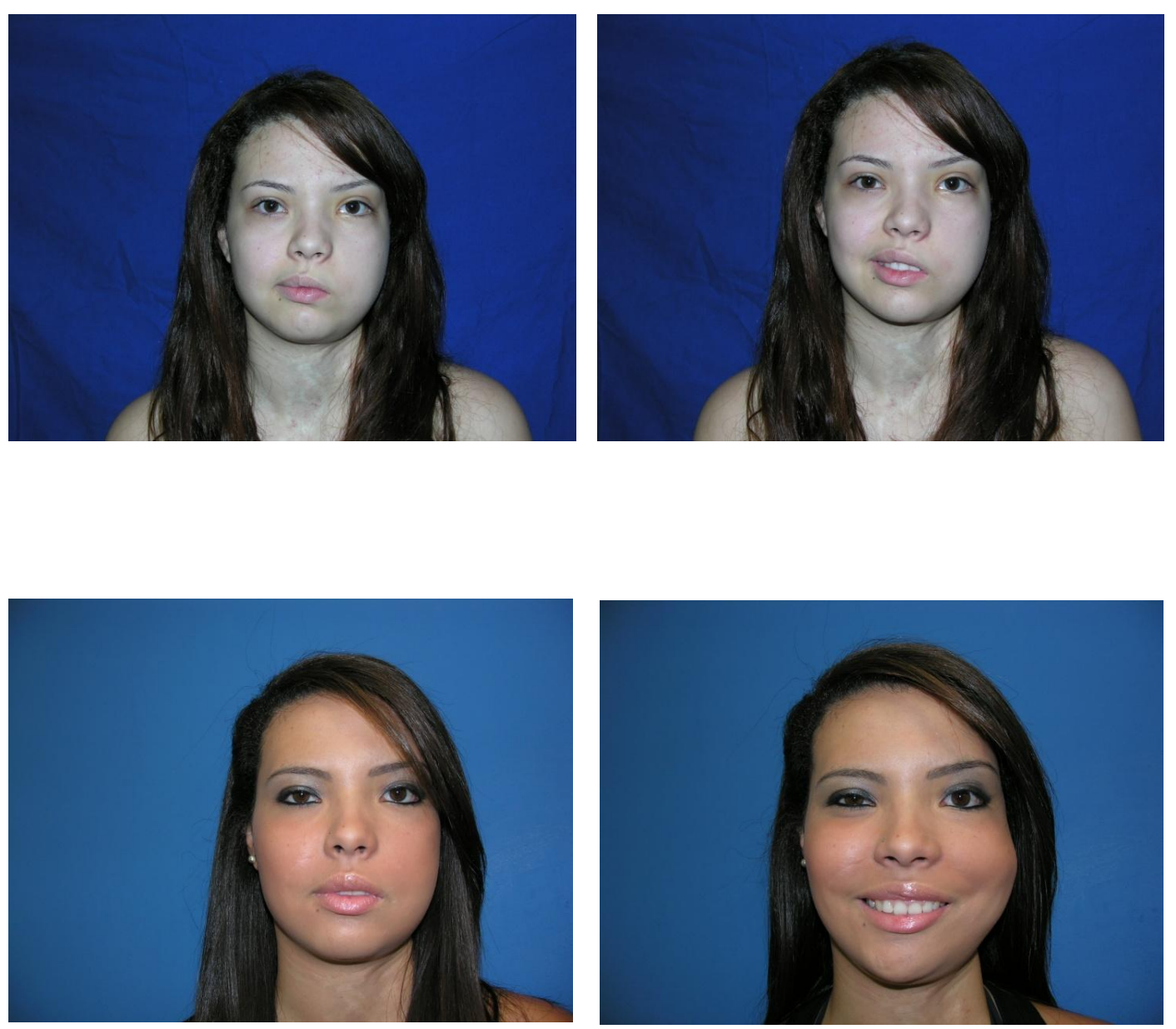
Figura 18 (Grupo I - caso 3): Pré e pós-operatório (9 meses). Graduação do sorriso: excelente.
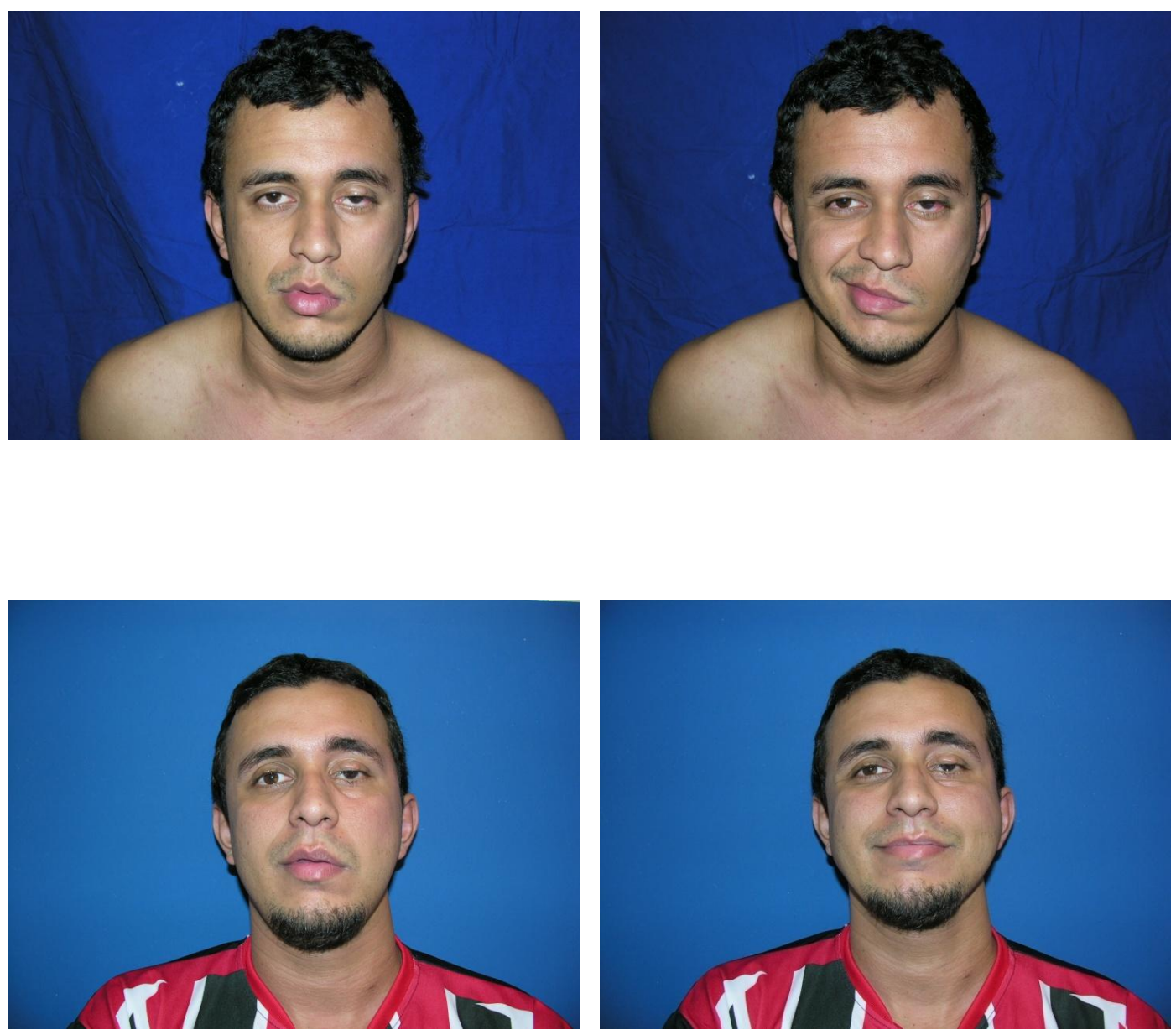
Figura 19 (Grupo I - caso 4): Pré e pós-operatório (9 meses). Graduação do sorriso: excelente.
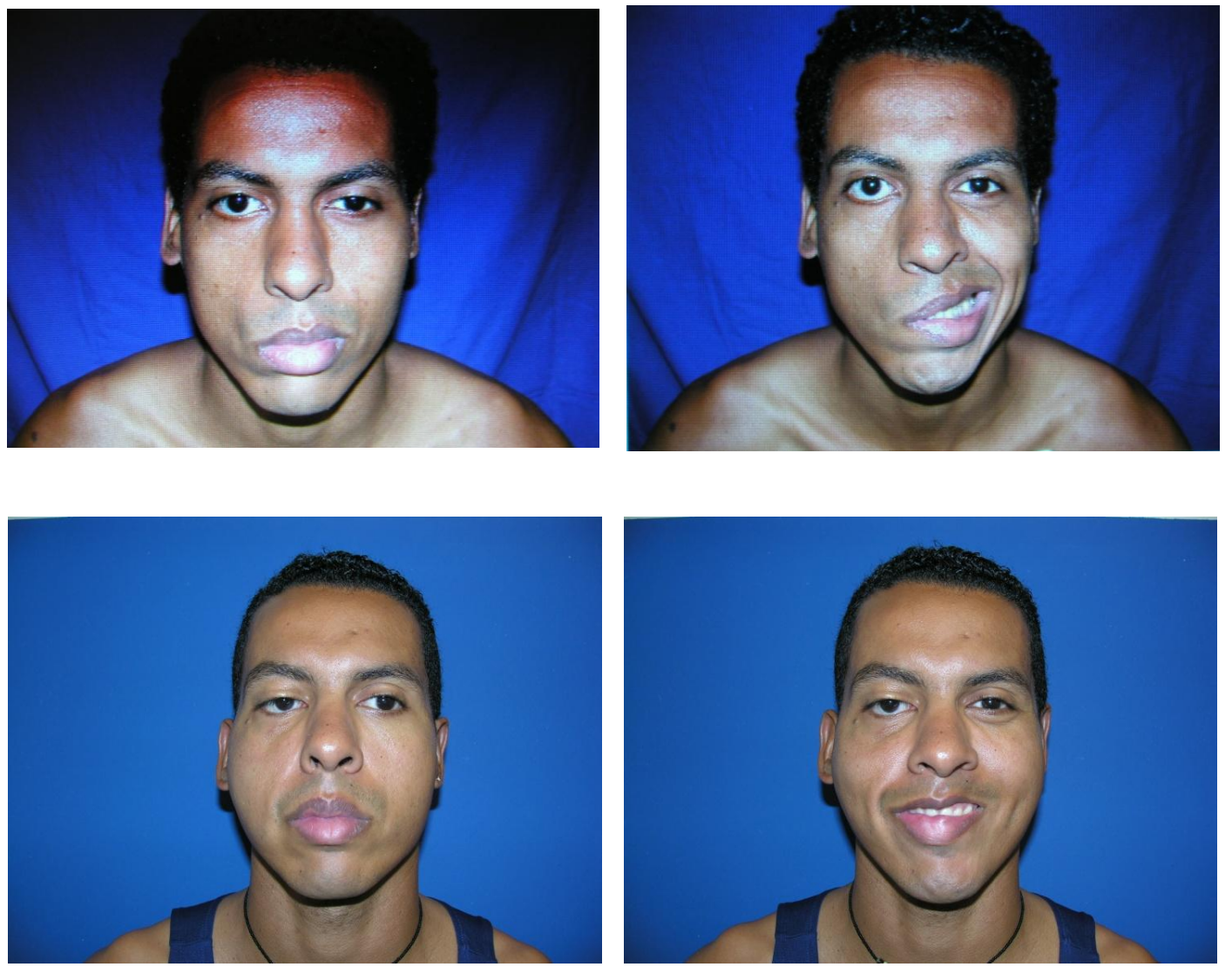
Figura 20 (Grupo I - caso 5): Pré e pós-operatório (9 meses). Graduação do sorriso: excelente.
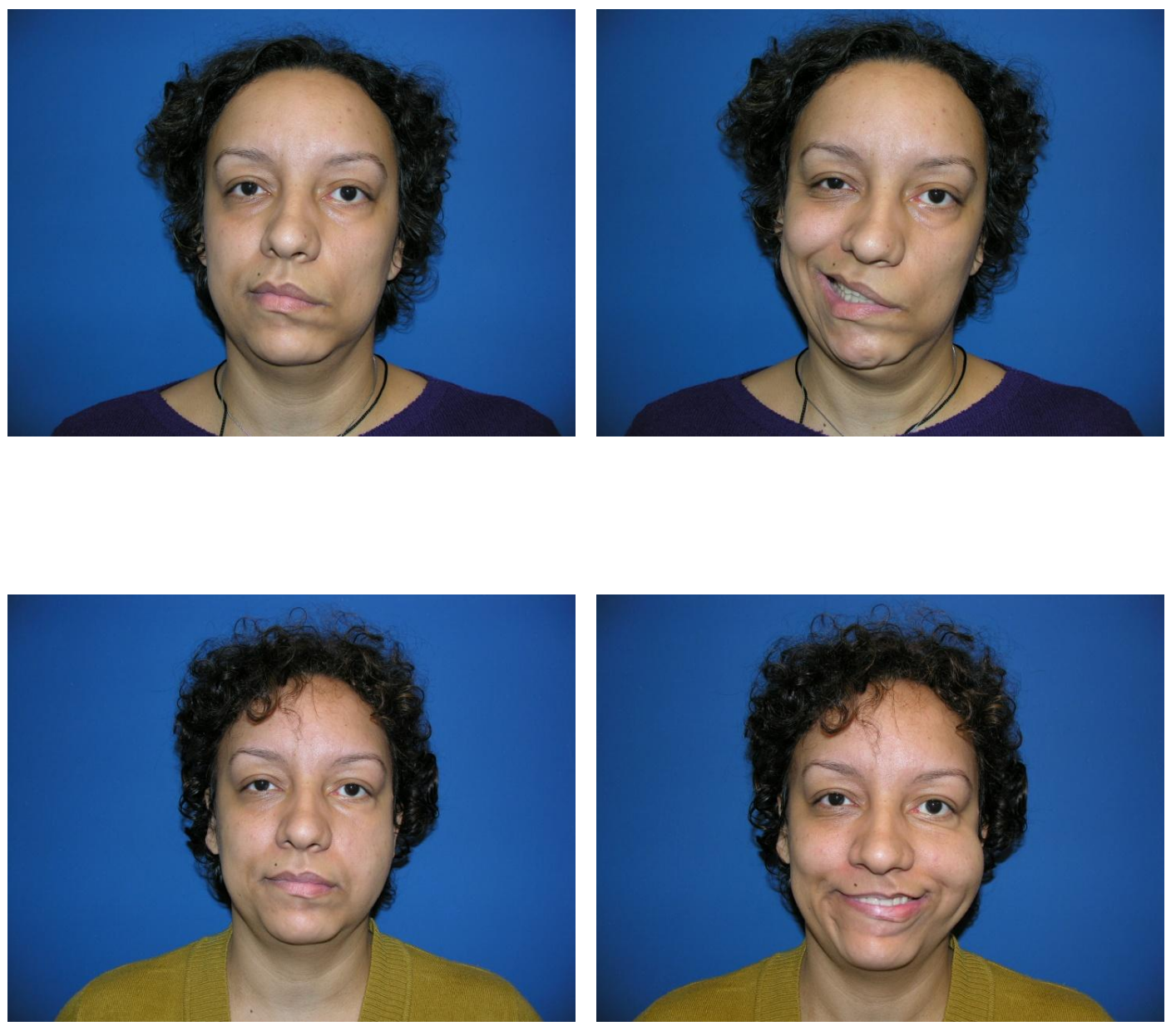
Figura 21 (Grupo I - caso 6): Pré e pós-operatório (9 meses). Graduação do sorriso: excelente.
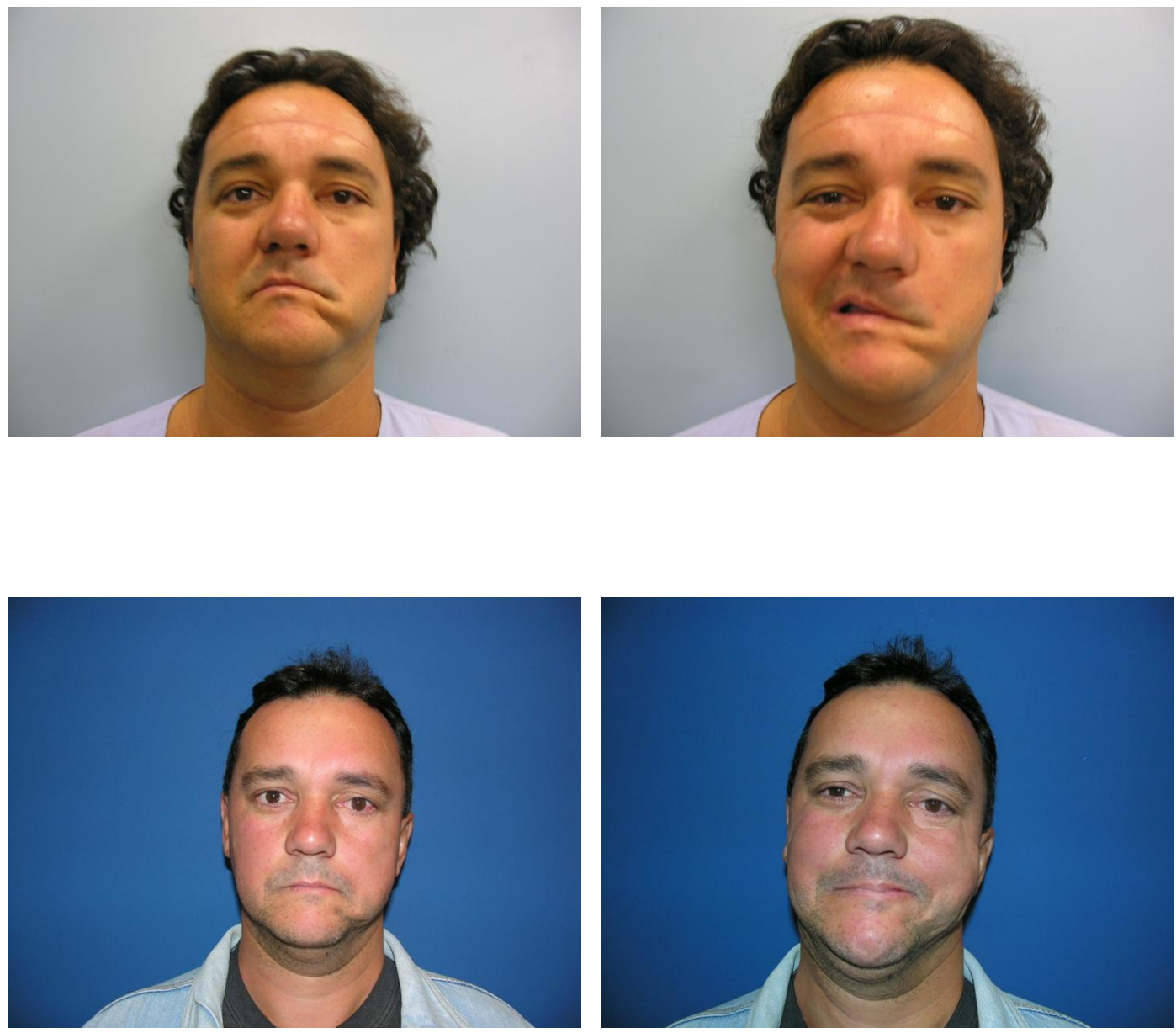
Figura 22 (Grupo I - caso 7): Pré e pós-operatório (9 meses). Graduação do sorriso: bom.
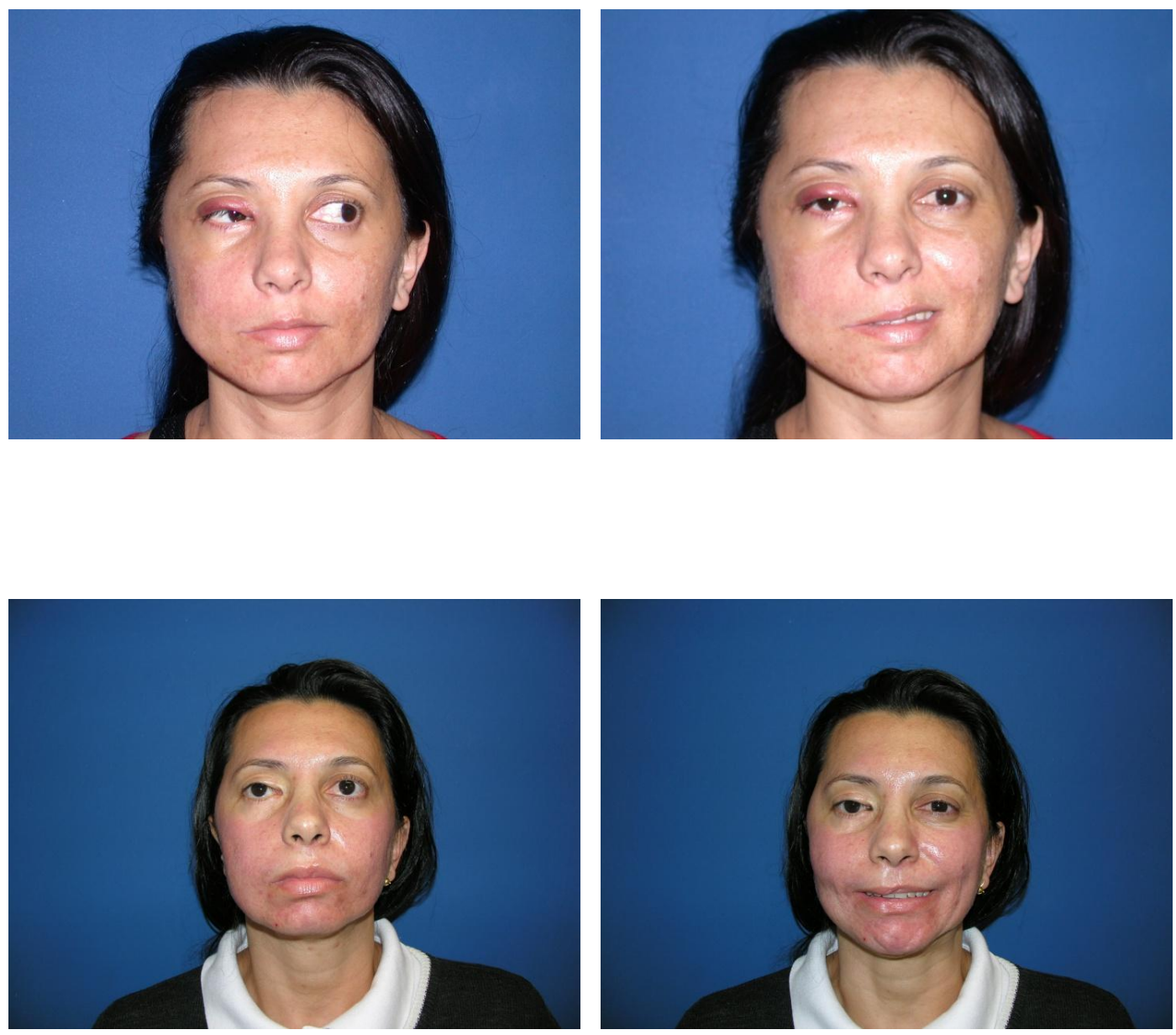
Figura 23 (Grupo I - caso 8): Pré e pós-operatório (9 meses). Graduação do sorriso: excelente.
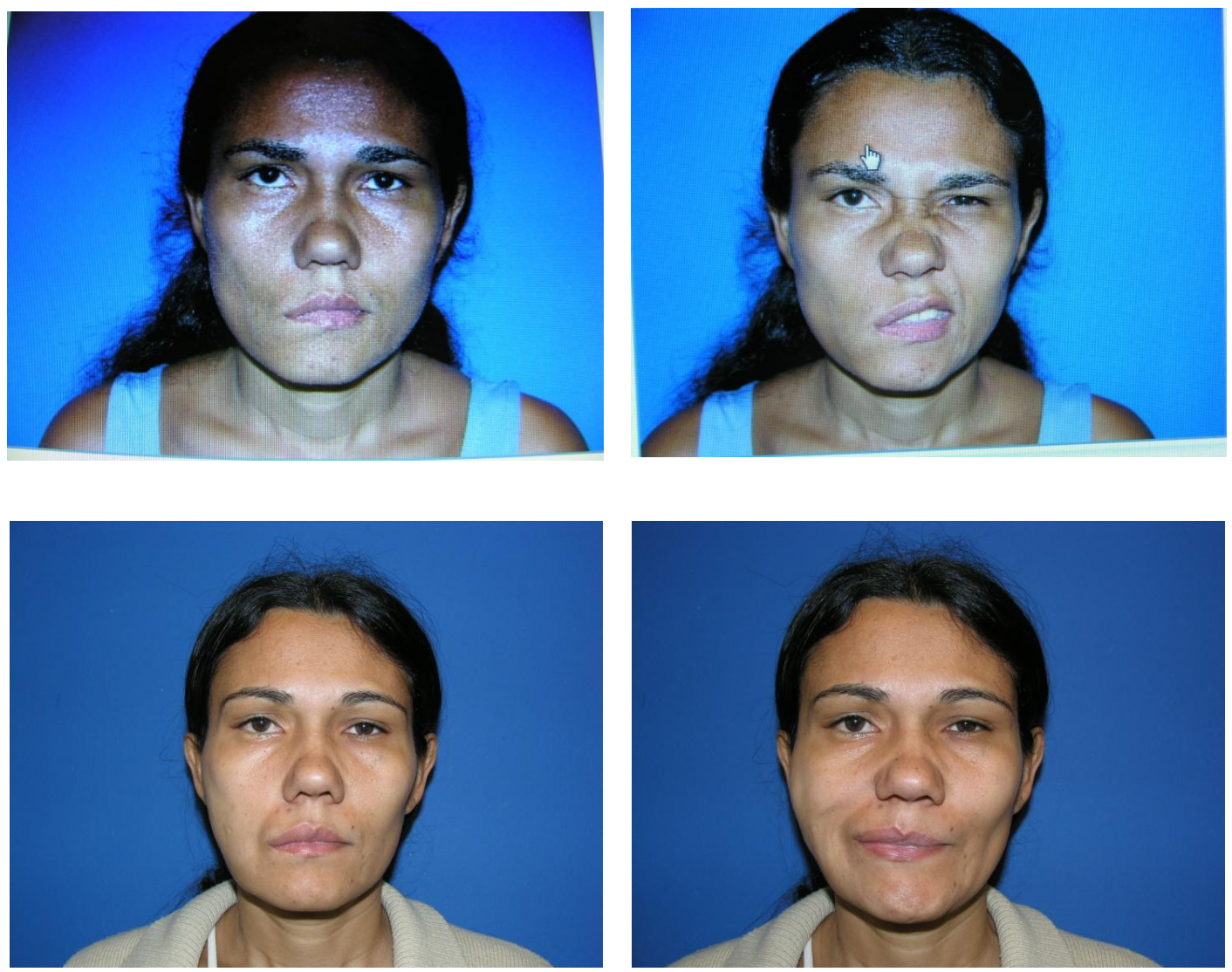
Figura 24 (Grupo I - caso 9): Pré e pós-operatório (9 meses). Graduação do sorriso: pobre.
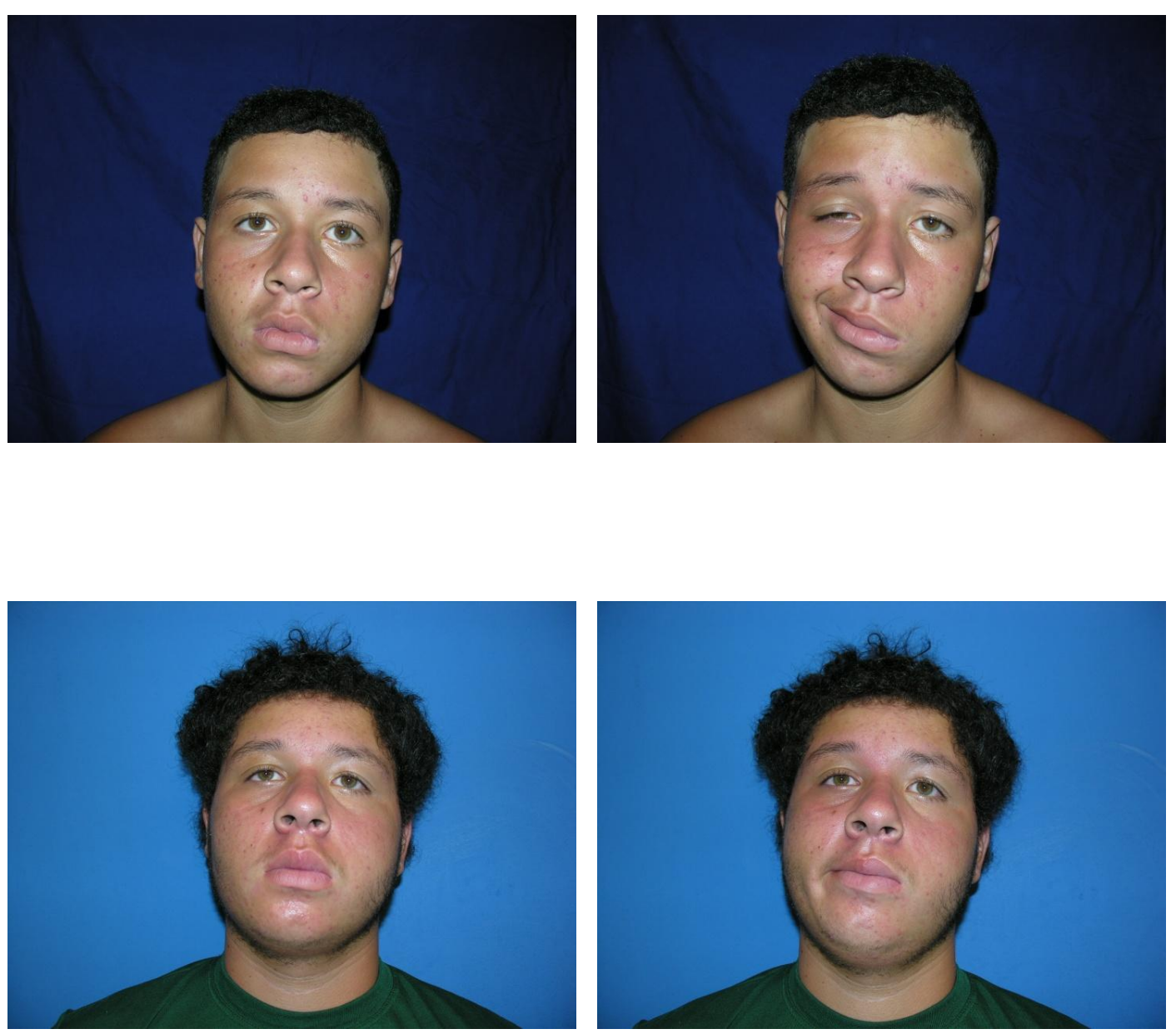
Figura 25(Grupo I - caso 10): Pré e pós-operatório (9 meses). Graduação do sorriso: excelente.
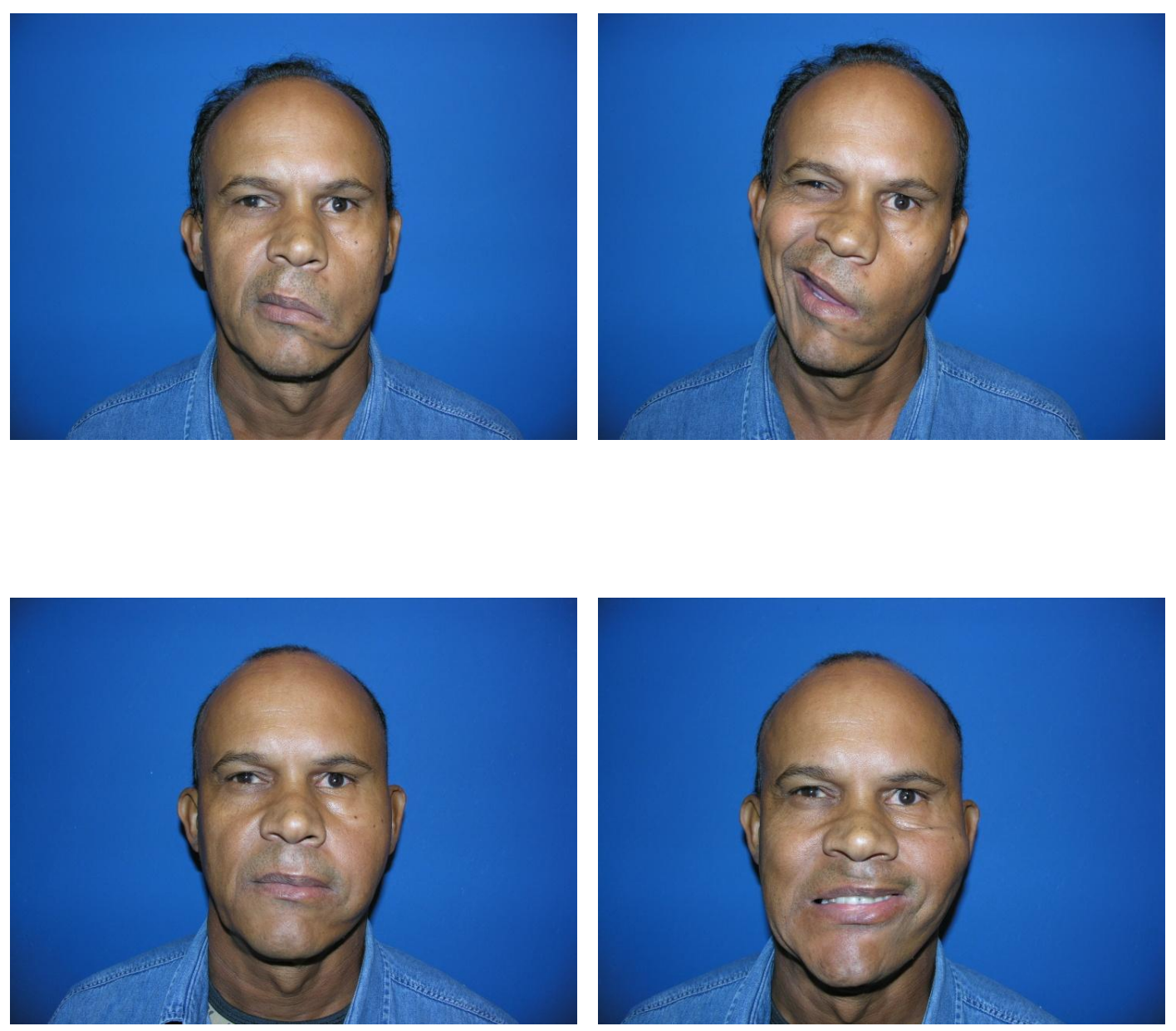
Figura 26 (Grupo I - caso 11): Pré e pós-operatório (9 meses). Graduação do sorriso: excelente.
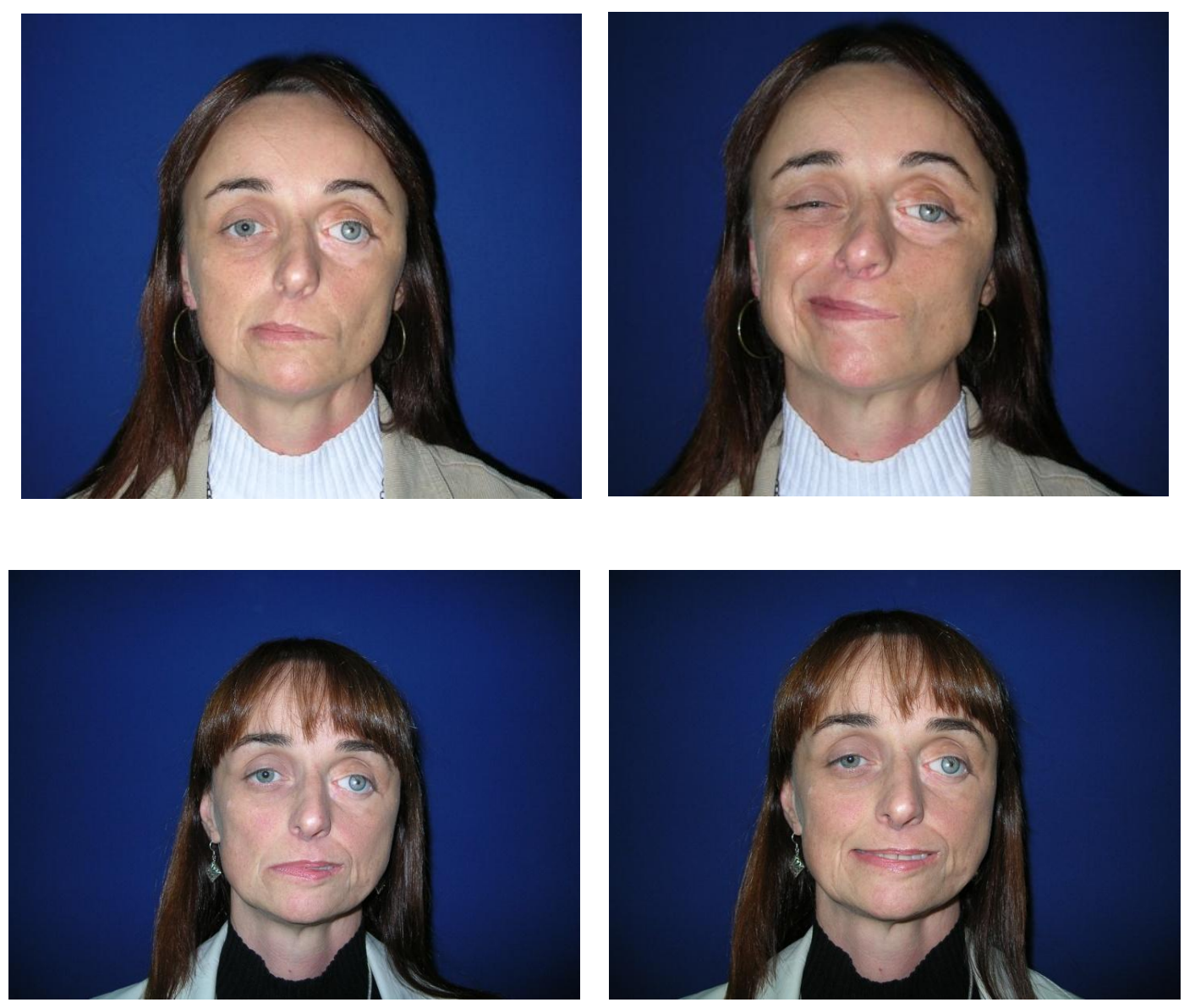
Figura 27 (Grupo I - caso12): Pré e pós-operatório (9 meses). Graduação do sorriso: bom.
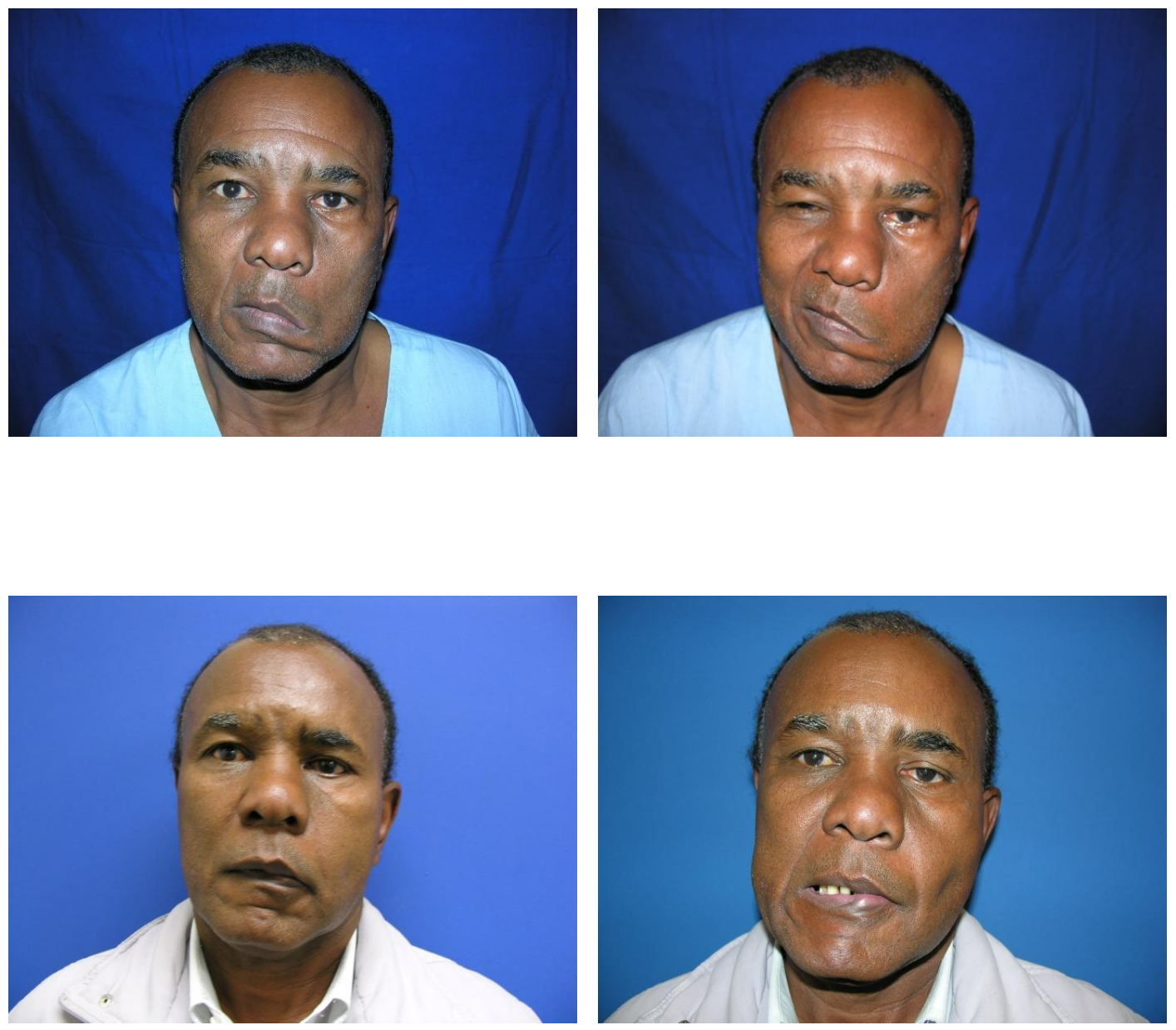
Figura 28 (Grupo I - caso 13): Pré e pós-operatório (9 meses). Graduação do sorriso: excelente.
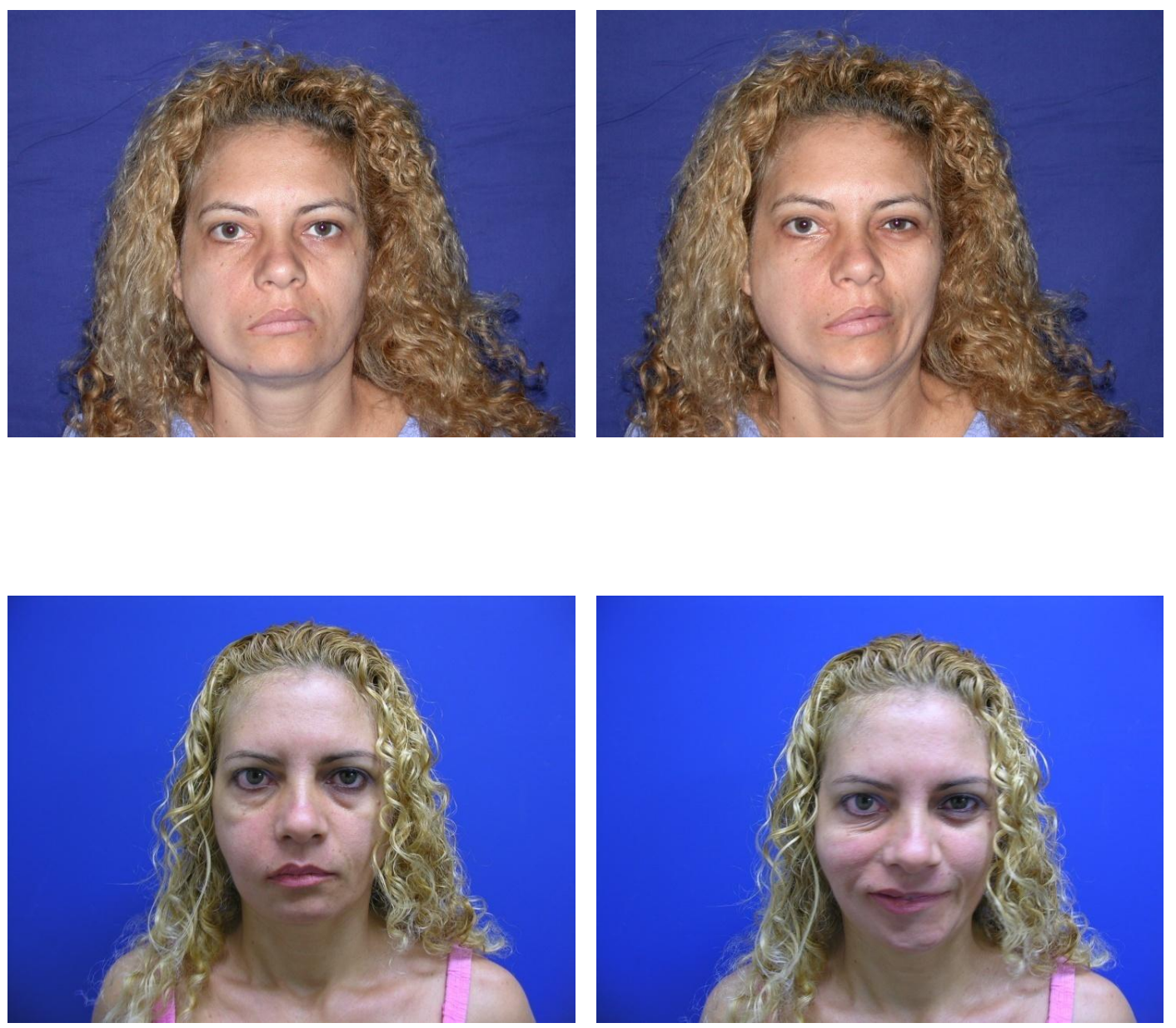
Figura 29 (Grupo I - caso 14): Pré e pós-operatório (9 meses). Graduação do sorriso: bom.
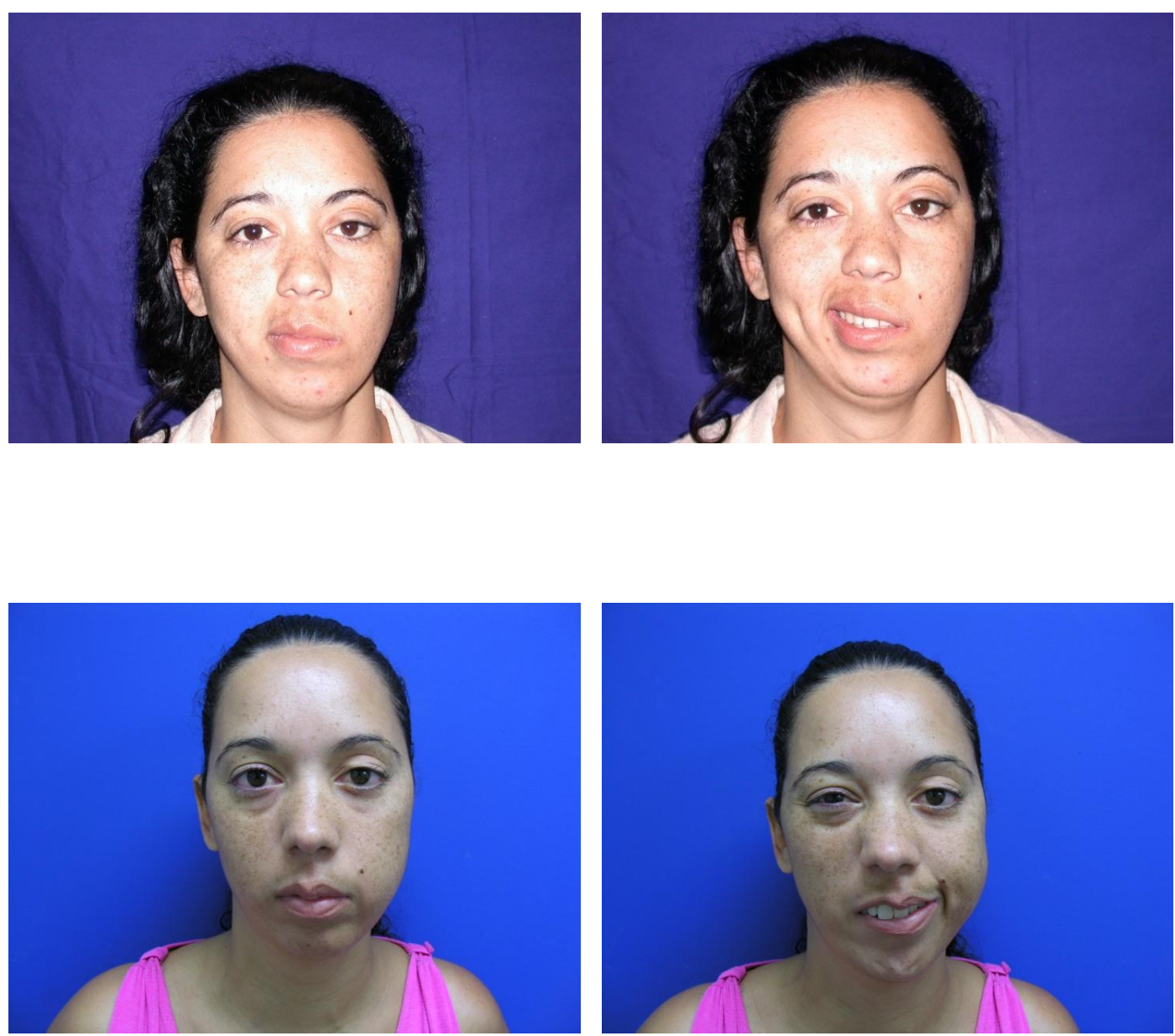
Figura 30 (Grupo I - caso 15): Pré e pós-operatório (9 meses). Graduação do sorriso: excelente.
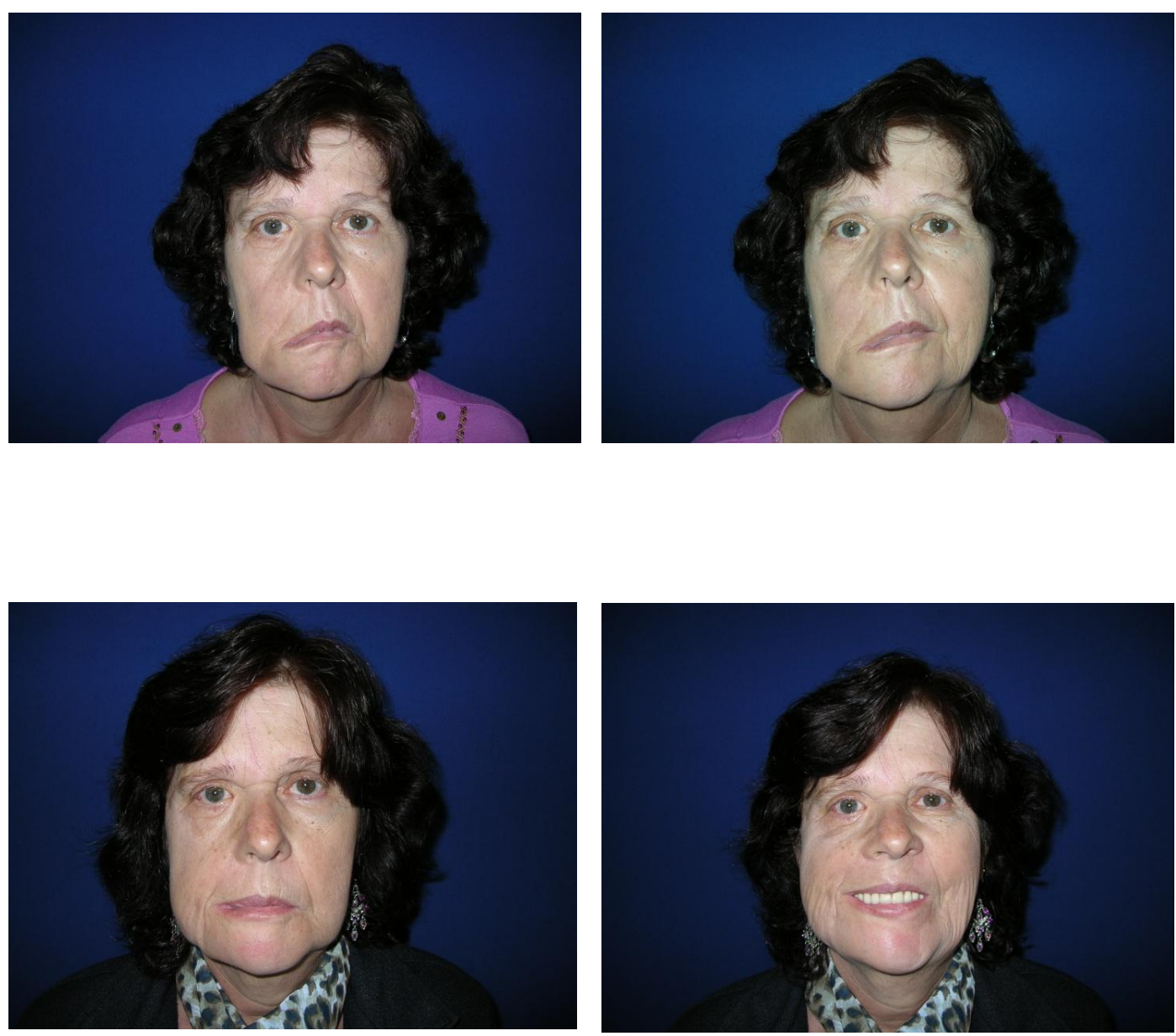
Figura 31 (Grupo I - caso 16): Pré e pós-operatório (9 meses). Graduação do sorriso: excelente.
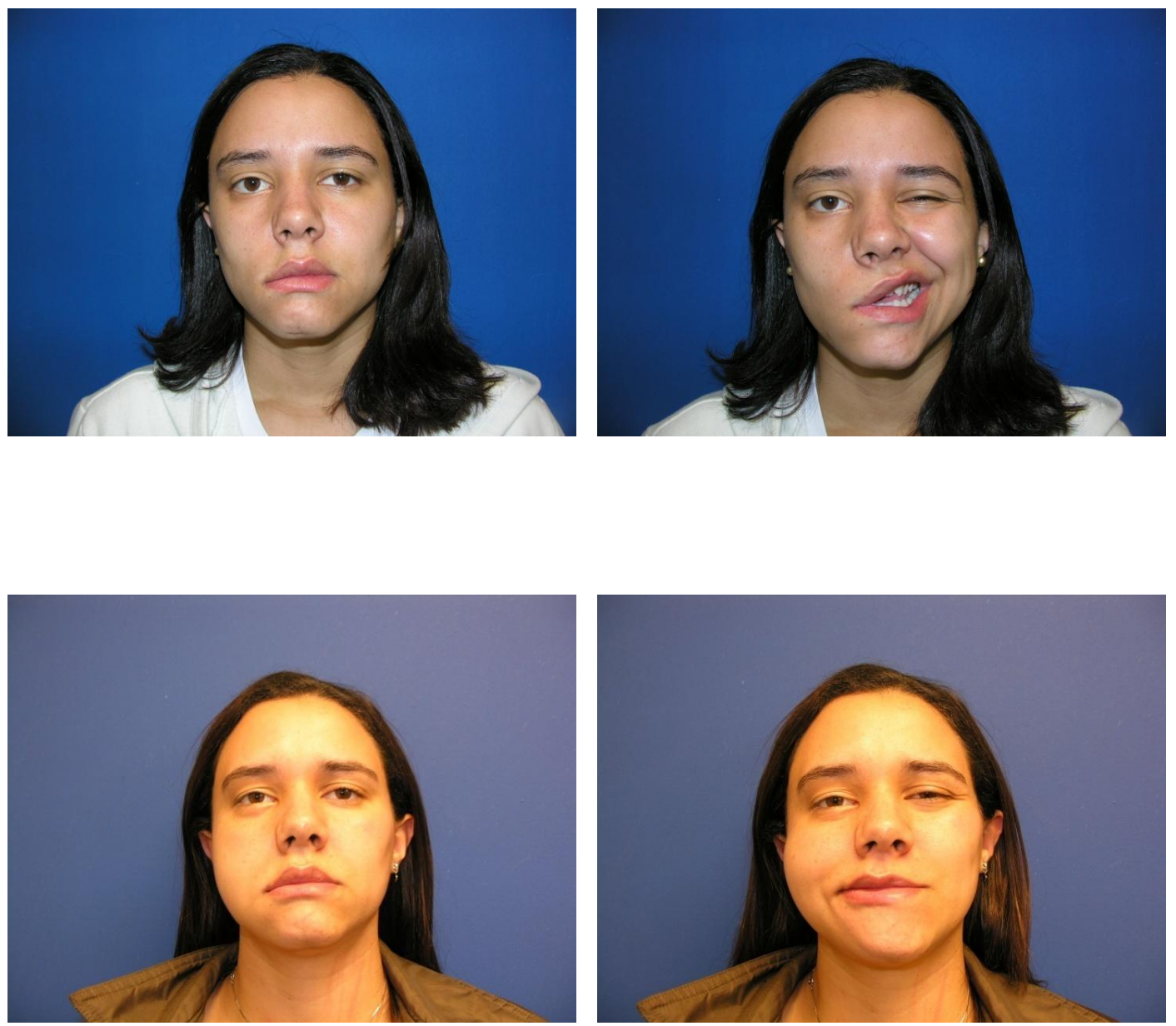
Figura 32 (Grupo I - caso17): Pré e pós-operatório (9 meses). Graduação do sorriso: bom.
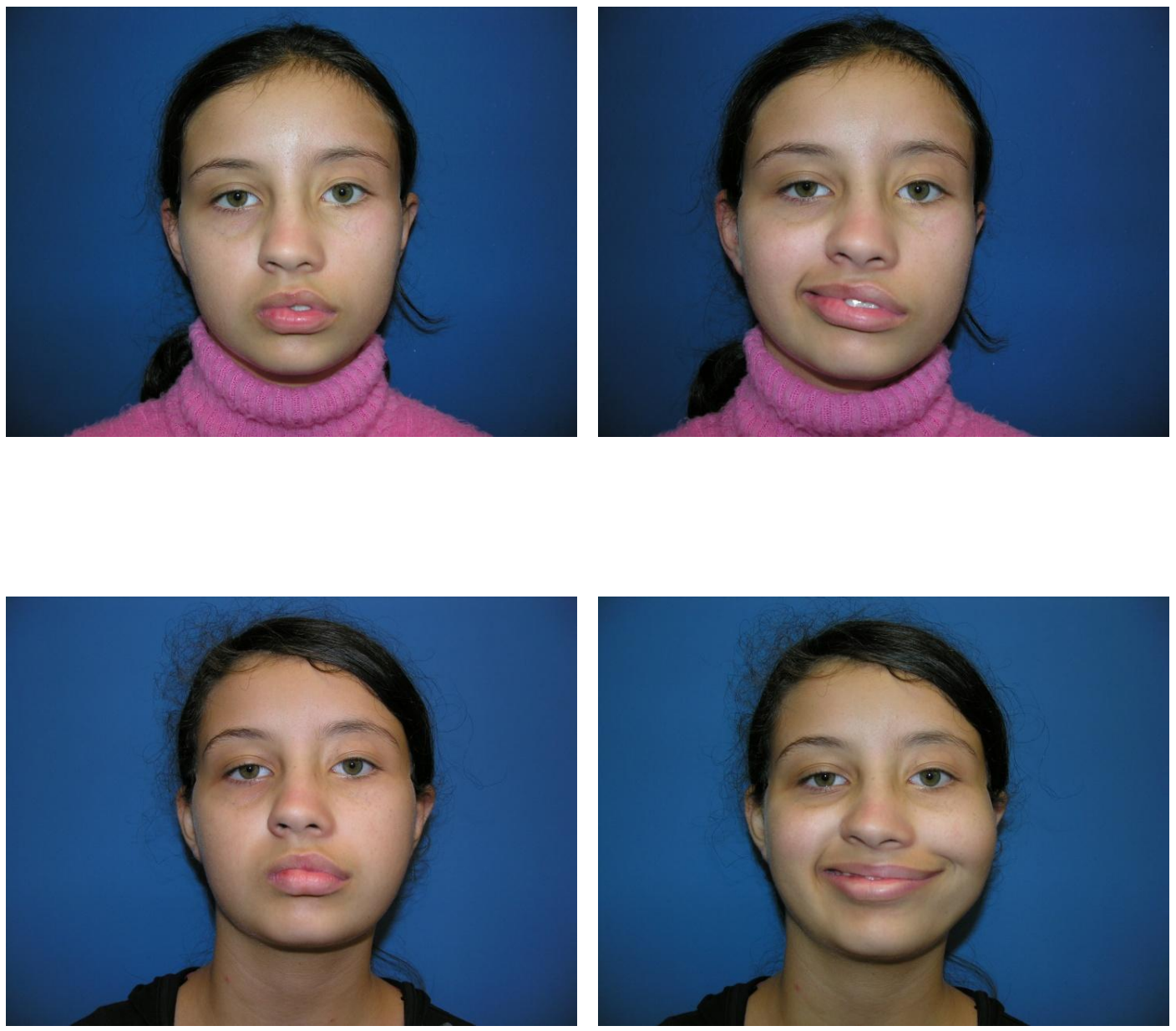
Figura 33 (Grupo II - caso 1): Pré e pós-operatório (9 meses). Graduação do sorriso: bom.
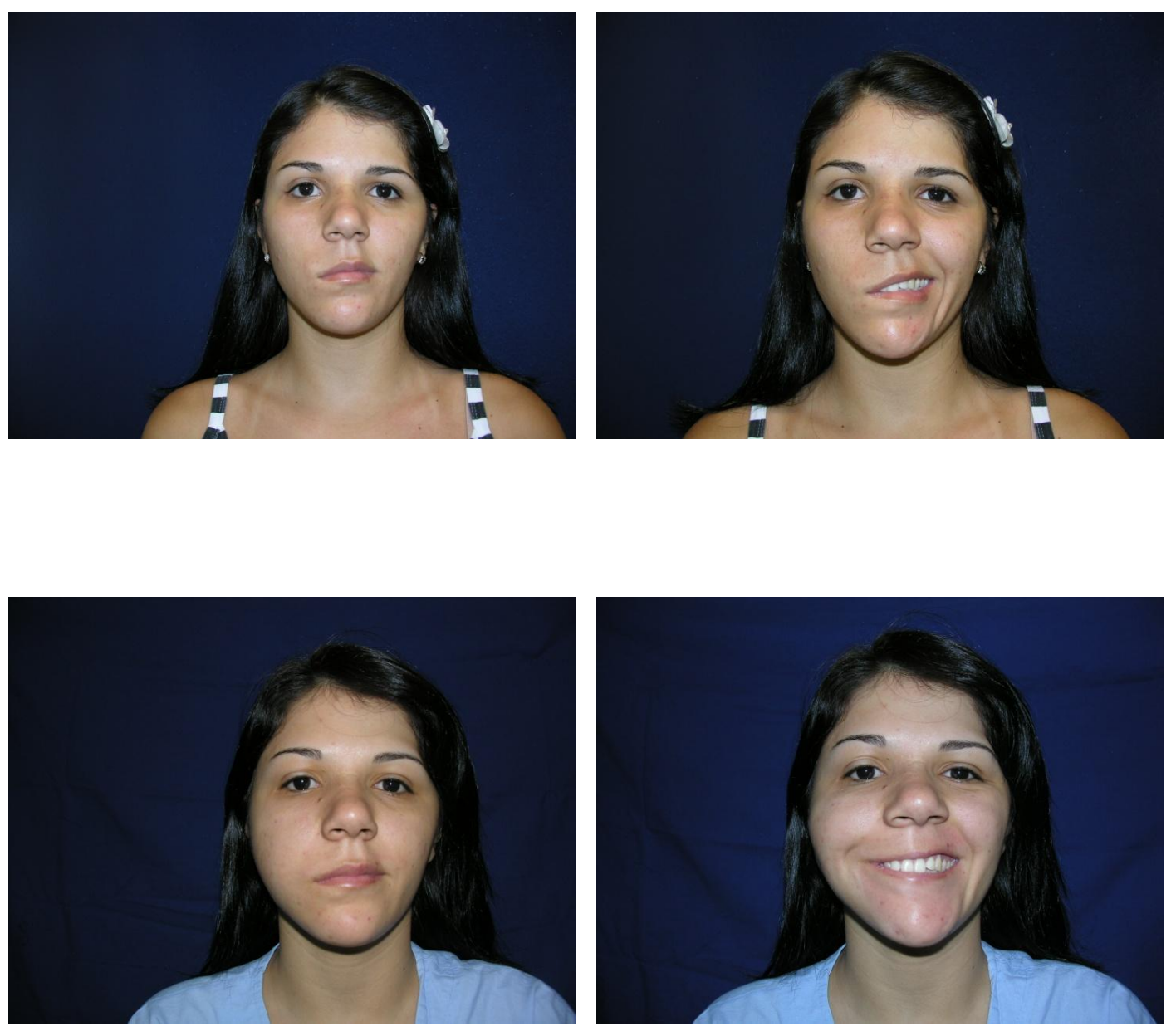
Figura 34 (Grupo II - caso 2): Pré e pós-operatório (9 meses). Graduação do sorriso: bom.
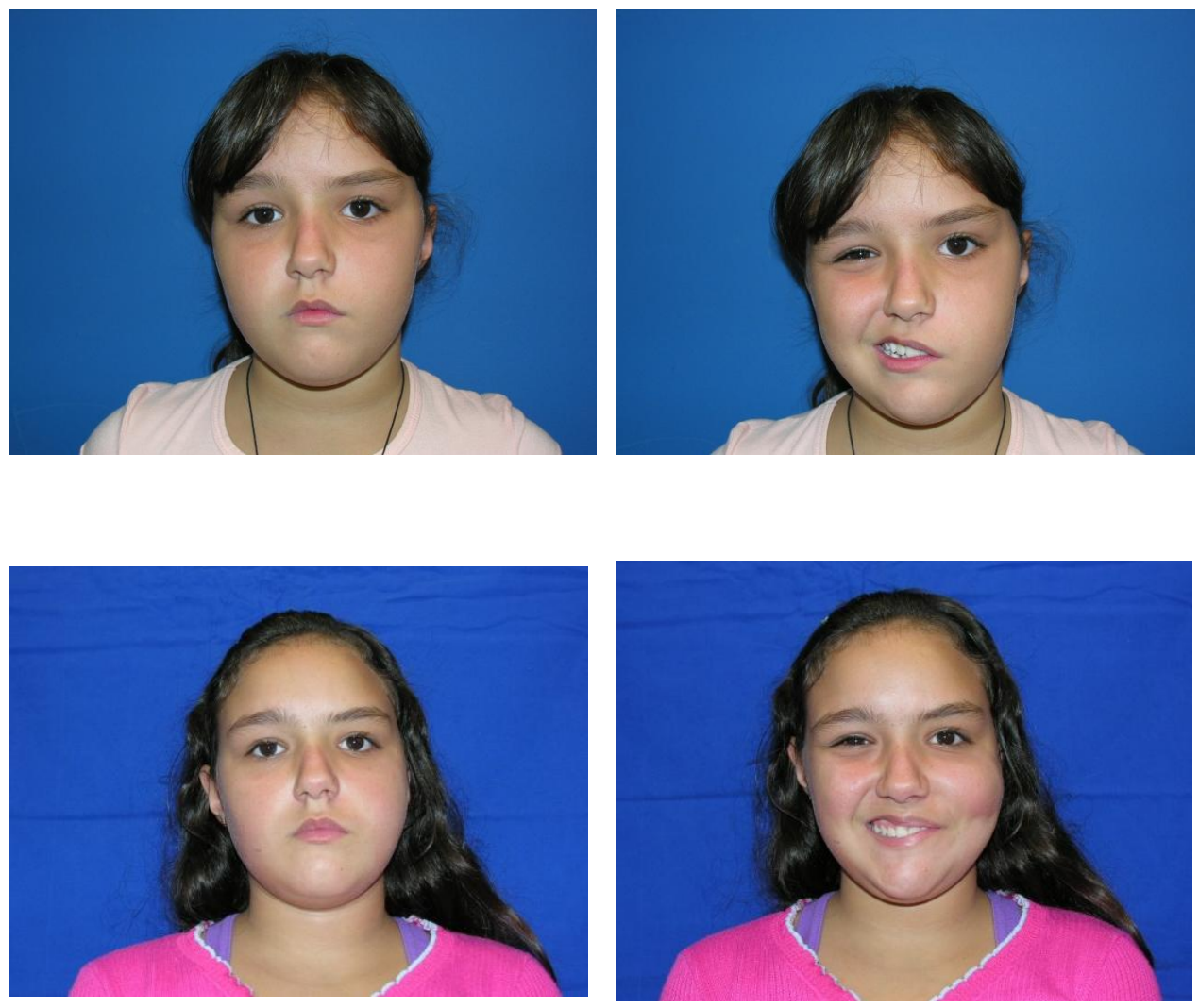
Figura 35 (Grupo II - caso 3): Pré e pós-operatório (9 meses). Graduação do sorriso: bom.
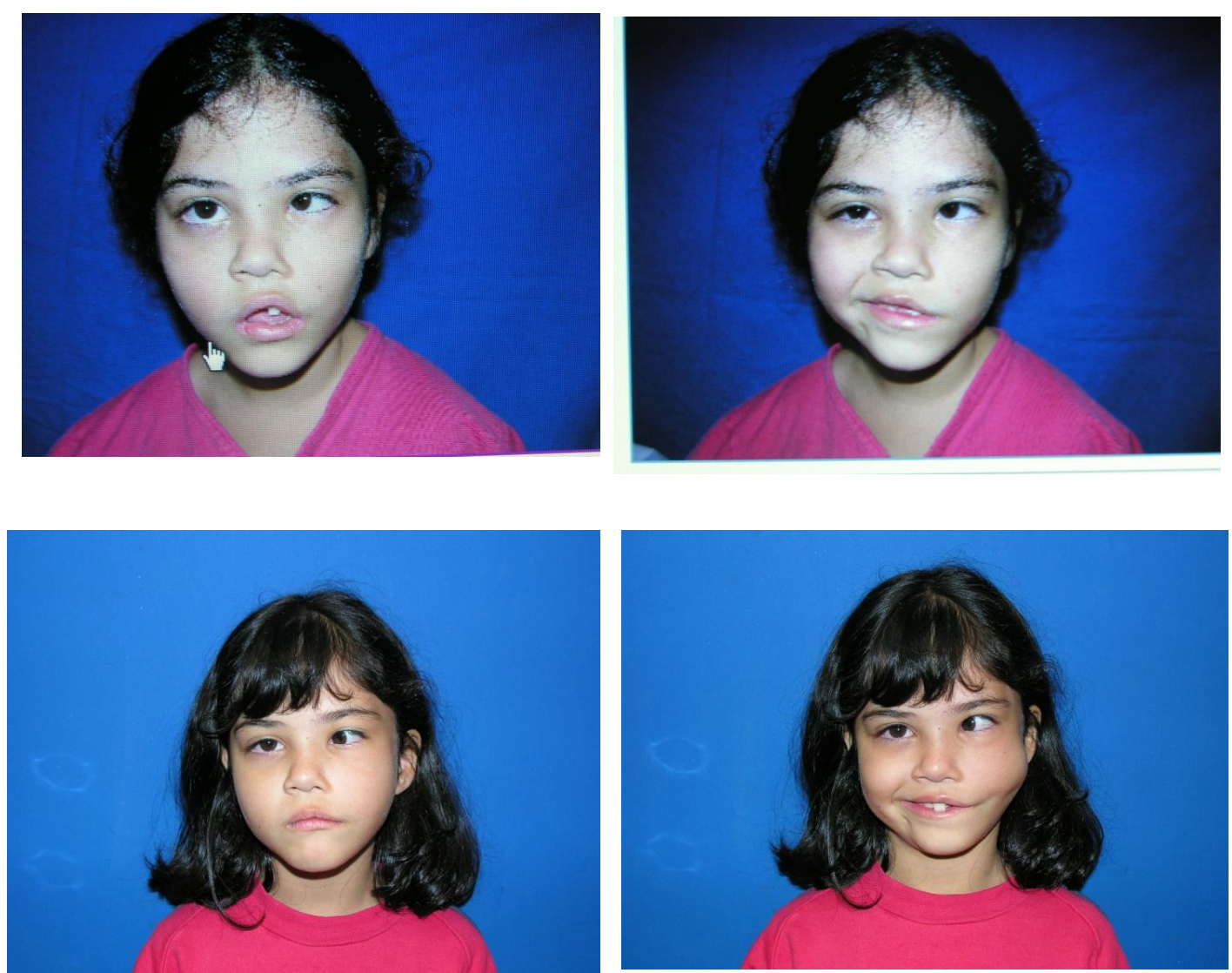
Figura 36 (Grupo II - caso 4): Pré e pós-operatório (9 meses). Graduação do sorriso: excelente.
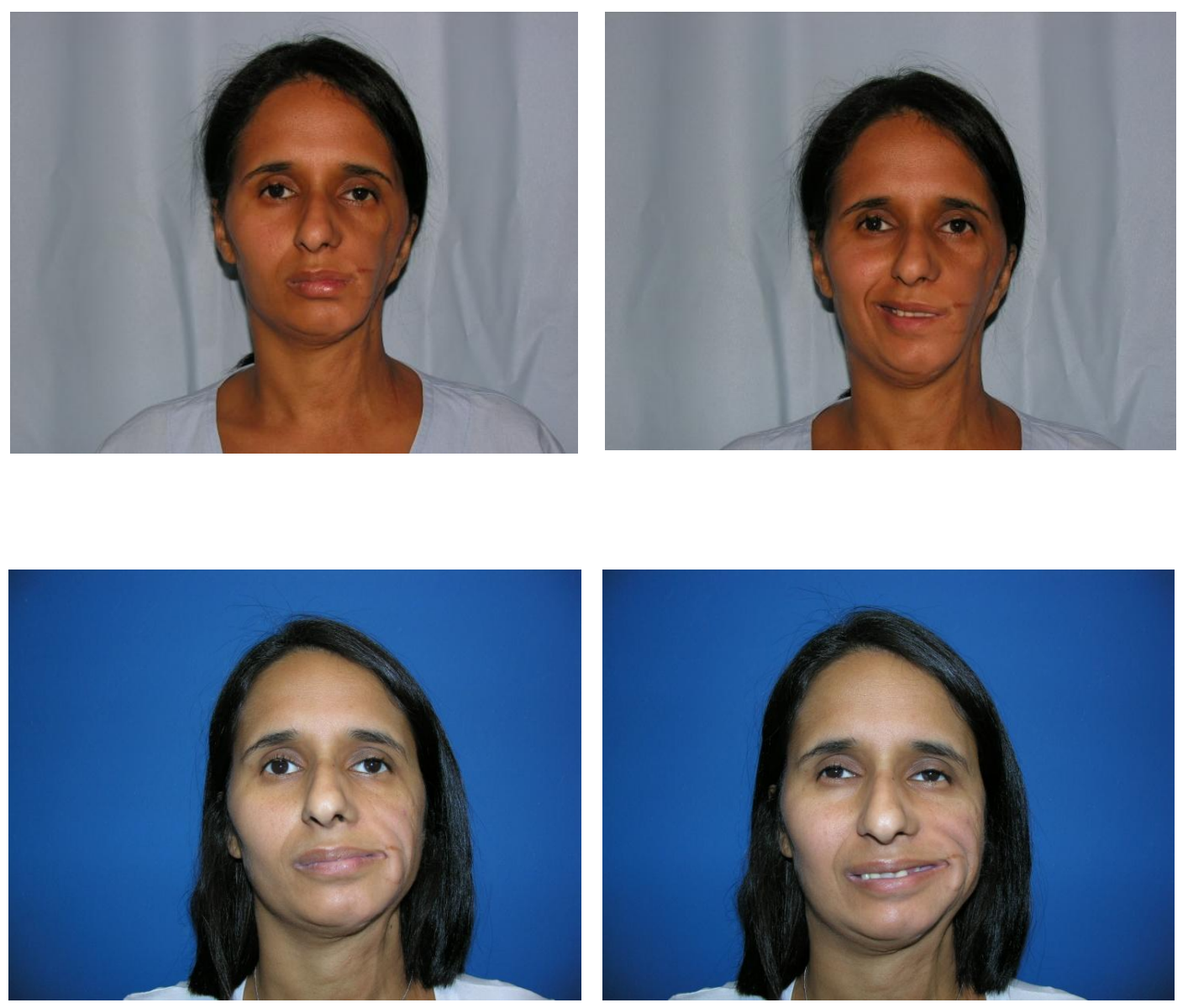
Figura 37 (Grupo II - caso 5): Pré e pós-operatório (9 meses). Graduação do sorriso: ausente.
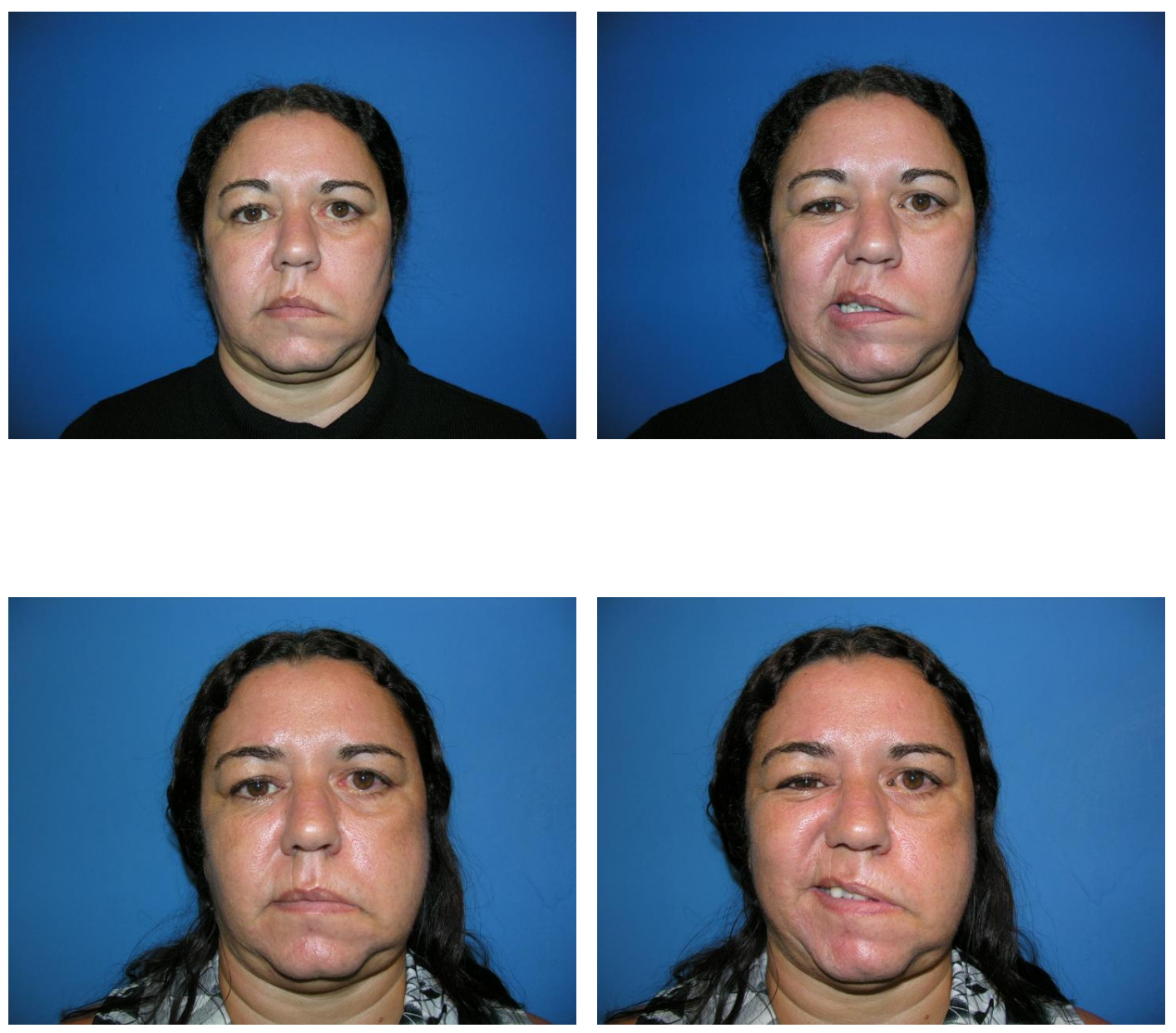
Figura 38 (Grupo II - caso 6): Pré e pós-operatório (9 meses). Graduação do sorriso: regular.
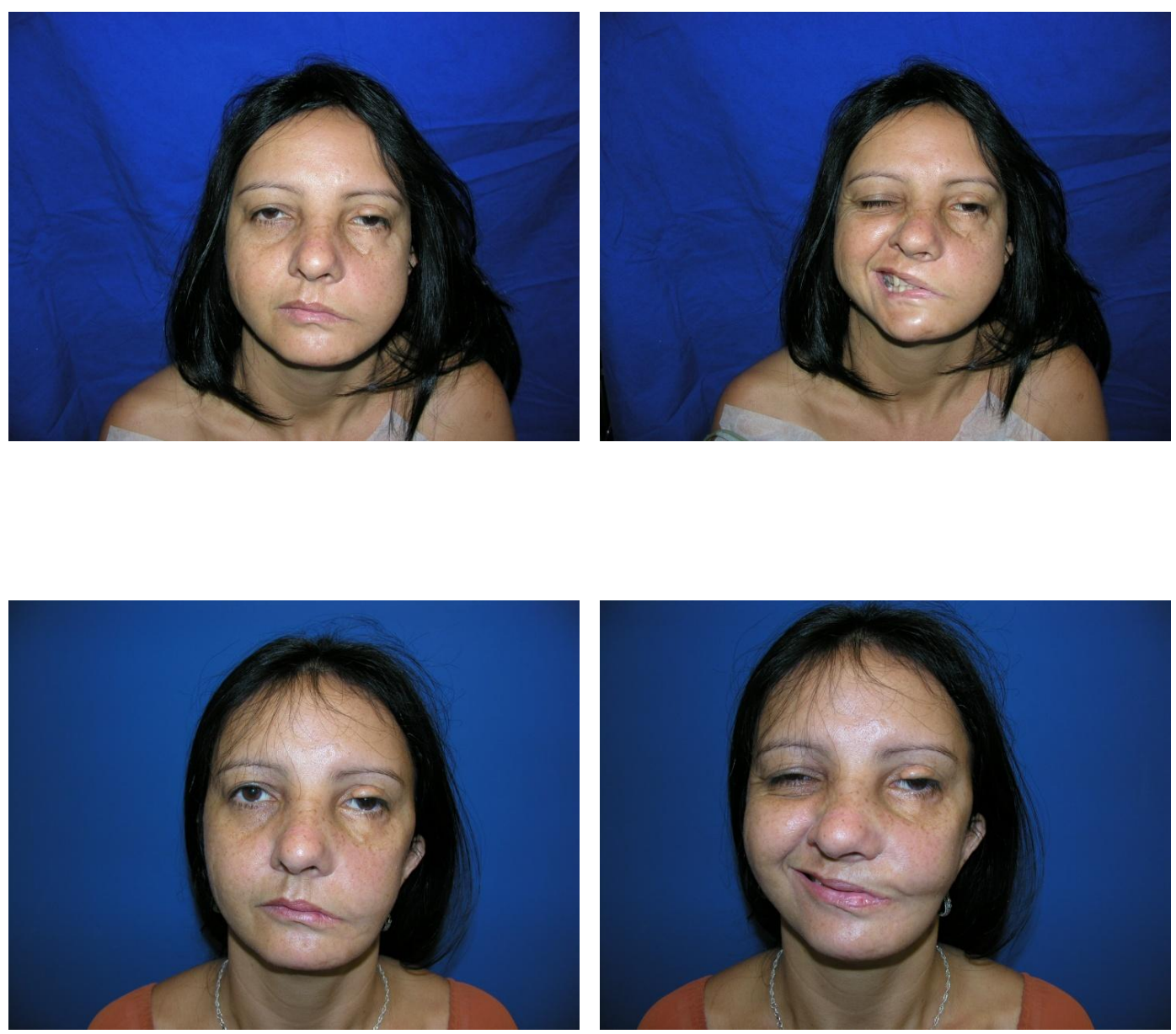
DISCUSSÃO 


\section{DISCUSSÃO}

Os transplantes musculares funcionais são atualmente o método mais eficiente para reanimação do sorriso em pacientes com paralisia facial de longa duração (acima de 2 anos). Um dos fatores críticos desse procedimento é a escolha do nervo motor para inervar o músculo transplantado. Classicamente o nervo facial contralateral tem sido utilizado através de um enxerto nervoso do tipo cross-face para se atingir atividade espontânea e sincronizada (FATEMI, 2008; )

O procedimento cross-face foi introduzido no início dos anos 70 em relatos independentes de SMITH, ANDERL e SCARAMELLA. Nesta técnica o nervo facial contralateral com seus ramos bucais é utilizado como doador motor, e o enxerto de nervo (geralmente nervo sural) cruzado para o lado paralisado. Teoricamente seria o único com potencial para restaurar as expressões da mímica voluntária e involuntária de maneira adequada e simétrica (FOROOTAN, 2008).

Entretanto, FARIA e col. (2007) observaram que apenas $34 \%$ dos pacientes apresentavam sorriso realmente emocional com simetria nos movimentos involuntários, e que a maior parte dos movimentos observados estava sob controle voluntário. Uma possível justificativa para este fenômeno é a de que as fibras relacionadas com a movimentação involuntária teriam 
menor potencial de regeneração do que as fibras que controlam os movimentos voluntários.

Outro potencial nervo motor para a inervação dos transplantes funcionais é o ramo massetérico $\left(\mathrm{V}_{3}\right)$ do nervo trigêmeo. A primeira descrição do uso do nervo massetérico para neurotização do nervo facial foi feita por SPIRA em 1978. Este relato foi apresentado no encontro anual da "American Association of Plastic Surgeons" com rafia do nervo massetérico à divisão inferior do nervo facial em três casos (BRENNER, 1998). Esse relato preliminar foi o único feito sobre esse tópico até que ZUKER, em 1995, descrevesse o uso deste nervo como origem neuronal em transplantes de músculos gracilis para reanimação facial de pacientes com síndrome de Möebius. Esta síndrome é uma anomalia congênita complexa que compromete vários pares cranianos, incluindo os nervos abducente (VI) e facial (VII). As crianças são incapazes ou têm grande dificuldade em expressar suas emoções, o que muitas vezes leva à superestimação errônea de retardo mental. Com está técnica conseguiu melhora não só da expressão facial, bem como fala mais inteligível (GOLDEBERG, 2003).

Posteriormente, o grupo de ZUKER expandiu o uso do nervo massetérico como origem neuronal também para paralisias unilaterais. BAE et al (2006) verificaram que transplantes segmentares do músculo gracilis 
utilizados para reanimação facial, e que têm como origem neuronal o nervo massetérico, apresentam excursões superiores às observados com o cross-face. Este nervo permite excursão da comissura oral comparável a do lado não paralisado.

Esta observação pode ser justificada pelas diferenças no número de fibras axonais. O nervo facial apresenta 7228+950 fibras motoras (ASAOKA, 1999), o ramo bucal do nervo facial tem $834 \pm 285$, e a porção distal de um enxerto nervoso tipo cross-face tem 100 a 200 axônios. O ramo obturador do

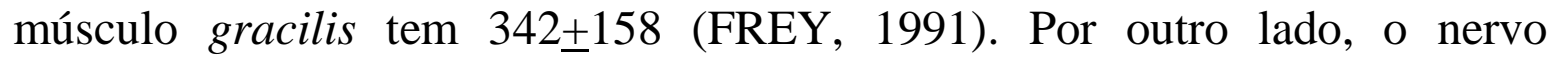
massetérico tem, em média, 1542 $\pm 291,7$ axônios (COOMBS, 2008), ou seja, cerca de 8 vezes mais que o cross-face. Este maior número de fibras proporciona inervação de mais placas motoras e unidades motoras funcionais do músculo transplantado.

Entretanto, a musculatura facial original apresenta unidades motoras muito pequenas, ao passo que o músculo gracilis apresenta unidades bem maiores, e jamais conseguirá com sua excursão univetorial substituir a riqueza de movimentos multivetoriais do lado não paralisado (FREILINGER, 1987).

A origem do nervo massetérico vem do nervo mandibular $\left(\mathrm{V}_{3}\right)$, pouco depois de sua entrada na fossa infratemporal, passa sobre o músculo pterigóideo lateral e sai da fossa infratemporal pela incisura mandibular, 
também chamada incisura sigmóide, acompanhado pela artéria massetérica. ESCAT e VIELA (1925) mediram a distância entre a incisura mandibular e a entrada para o músculo com uma média de $32 \mathrm{~mm}$. Nesse nível o nervo consiste em 1ramo em $25 \%$ dos casos, em 2 ramos $47 \%$, em 3 ramos em $25 \%$ e em quatro ramos em $2.8 \%$ (BRENNER, 1998).

Como mostrado em estudo prévio, a reanimação facial em 1 estágio usando o músculo gracilis inervado pelo nervo massetérico apresenta resultados mais previsíveis e constantes quando comparada ao procedimento em 2 estágios (cross-face seguido do transplante do músculo gracilis) ou 1 estágio usando o músculo grande dorsal inervado pelo facial contra-lateral (FARIA, 2007). O tempo de reinervação também é significativamente menor com média de 3,7 meses, 7,2 meses para grande dorsal em tempo único e 11,1 meses para cross-face, além do tempo demandado no primeiro estágio ( 8 a 10 meses).

Considerando-se todos estes aspectos optamos pelo nervo massetérico como origem neuronal em nosso estudo: (1) a abordagem da incisura mandibular é simples; (2) a reinervação é mais rápida e previsível; (3) a excursão é maior do que a obtida com o cross-face, o que permite melhor avaliação das técnicas de fixação muscular e simetria labial; (4) já que em $75 \%$ dos casos o nervo consiste em dois ou mais ramos, disfunções severas do 
músculo masseter não devem acontecer; (5) e se houver denervação completa do músculo masseter, sua função pode ser compensada pelos músculos temporal e pterigóides.

Entretanto, vale ressaltar que nosso objetivo nesta tese não é defender o nervo massetérico como origem neuronal superior ao cross-face, pois inúmeros outros parâmetros, objetivos e subjetivos, e que fogem aos nossos critérios de avaliação não foram incluídos e seriam objeto de outro estudo mais complexo. Complicações como fístula salivares também devem ser ressaltadas. Embora pareçam a princípio auto-limitadas, observamos que todos os pacientes que apresentaram esta complicação tiveram evolução funcional desfavorável, o que também foi constatado em nossa experiência com a transferência nervo massetérico-facial (FARIA, 2010).

A definição do sulco nasolabial e movimentação adequada do modíolo, conseguidas com o transplante muscular, podem não ser suficientes para restaurar a simetria labial. O posicionamento dos lábios em relação à linha média bem como a movimentação do lábio inferior são elementos adicionais importantes no equilíbrio dinâmico da face.

A flacidez do músculo orbicular da boca no lado paralisado não permite que o tônus ou forças de tração do transplante muscular sejam transferidos 
para a região do filtro labial. Desse modo, desvios estáticos e/ou dinâmicos do filtro podem persistir após o procedimento de reanimação da região perioral.

Existem inúmeras escalas para avaliação dos resultados obtidos na renimação facial (FERREIRA, 1994), como a de HOUSE-BRACKMANN (1985), mas sem padronização e aceitação universal. Estas escalas teriam melhor adequação para os casos de reinervação da própria musculatura facial, seja através de reparo direto do nervo, interposição de enxertos, cross-face ou neurotizações. Quando analisamos transplantes musculares funcionais observamos que via de regra se restringem ao terço médio da face, basicamente o sorriso, e escalas que avaliam toda a face se tornam inadequadas (JOHNSON, 1997).

Assim propusemos método simples de avaliação com análise qualitativa e quantitativa do sorriso, que permite a comparação de resultados obtidos com várias modalidades de transferência muscular para o terço médio da face, sejam locais ou à distância. FREY (2008) propôs método bastante detalhado através da análise de vídeos tridimensionais, mas que é pouco reprodutível e de difícil aplicação nos diferentes centros de tratamento.

Com a análise qualitativa categorizamos o sorriso em 5 níveis, desde a ausência de movimento até a ampla movimentação com simetria do sulco nasolabial e sorriso. Com a análise quantitativa avaliamos os desvios de linha 
média calculando o IR. Este cálculo é simples, e a única padronização fundamental são fotografias em plano frontal centralizadas rigorosamente. A distância da câmera ao paciente, ou seja, a distância focal, não interfere com as medidas, pois o cálculo é uma fração sem unidade métrica, e variações que alterariam os valores agem de forma proporcional em ambos os lados da face.

Este estudo mostra que a distância entre o modíolo e o filtro no lado paralisado tende a aumentar durante o sorriso quando comparada a mesma distância no lado não paralisado (IR: $56,83_{\text {rep }} v s 59,7_{\text {din }}$ ). Vale ressaltar que o IR ideal seria 50, e que valores maiores indicam desvio do filtro para o lado não paralisado, e valores menores desvio do filtro para o lado paralisado.

Fenômeno similar também é observado no lábio inferior. Devido ao posicionamento oblíquo do retalho muscular no lado reanimado a extremidade medial do retalho tende a ficar mais distante do ponto médio do lábio inferior do que do lábio superior, e por isso geralmente é mais fácil a centralização do lábio superior do que inferior.

A inserção do retalho muscular mais próxima à linha média pode aumentar a eficiência da correção do desvio labial. Por outro lado, a inserção mais medial pode comprometer a definição do sulco nasolabial e o contorno bucal com o volume exageradamente desproporcional entre os dois lados.

O tendão do músculo palmar longo é inelástico e permite o 
posicionamento na linha média do filtro e lábio inferior em repouso ( $\operatorname{IR}_{\text {grupo }}$ Irep: $56,18_{\text {pre }}$ vs $52,7_{\text {pos }}$ ). Durante o sorriso, este tendão limita o alongamento do músculo orbicular da boca paralisado e permite que as forças de tração do retalho muscular sejam transmitidas ao filtro e linha média do lábio inferior ( IR $_{\text {grupo Idin }}: 58,65_{\text {pre }} v s$ 50,29 pos $)$.

Embora tenhamos usado apenas o tendão do músculo palmar longo, outros tendões ou estruturas com propriedades mecânicas similares podem ser usados, como, por exemplo, a fáscia lata, que é tradicionalmente reservada para o "refinamento estético" nos estágios finais de reanimação facial. ROSE (2005) usou enxertos autógenos de fáscia lata como opção terapêutica primária no balanceamento facial estático e/ou em conjunto com a transferência dinâmica de músculos para atingir a integridade arquitetônica e restauração funcional da face parcialmente ou totalmente paralisada. Nossa preferência pelo palmar longo reside na simplicidade da retirada e baixa morbidade da área doadora, mas cerca de $15 \%$ da população não tem este tendão sem déficit funcional algum (MOORE, 1992). Em nossa casuística $26,9 \%$ dos pacientes não apresentavam o tendão.

Assim a técnica de inserção do retalho muscular à região bucal associada ao tendão do músculo palmar longo combina princípios de suspensão estática e reanimação dinâmica. 
Teoricamente alguns procedimentos para reanimação dinâmica do lábio inferior já foram propostos. CONLEY (1982) propôs a transposição do ventre anterior do músculo digástrico (TAN, 2002). A ressecção parcial do lábio inferior e transposição do orbicular da boca foi sugerida como procedimento simples para resolver o problema estático e, em certa medida, o problema dinâmico (YAVUZER, 2001). Entretanto, na prática, parecem mais promover a contenção ou limitação do que movimentação efetiva no lado operado.

UEDA (1995) propôs transplante neurovascular duplo de músculos para paralisia facial. Um segmento do músculo latíssimo do dorso foi colocado entre a prega nasolabial e o zigoma para substituir os músculos zigomáticos e levantadores dos lábios, enquanto outro segmento do músculo serrátil anterior foi colocado entre o lábio inferior e a margem mandibular para substituir os músculos depressores dos lábios. O príncipio desta cirurgia é interessante, mas o efeito do volume desses 2 músculos compromete a qualidade do resultado.

Devido ao fato do lábio inferior não ter parâmetro anatômico tão bem definido quanto ao filtro no lábio superior, estas medidas não foram quantificadas nas imagens. Apesar disso, a comparação das imagens demonstra centralização qualitativa similar tanto para lábio superior como inferior nos pacientes em que empregamos o tendão palmar longo para fixação complementar do retalho muscular. 


\section{CONCLUSÕES}




\section{CONCLUSÕES}

A inserção do músculo gracilis com associação do palmar longo otimiza a técnica de reanimação facial, permitindo a correção de desvios labiais da linha média tanto estáticos como dinâmicos, reduz as taxas de fixação inadequada, e melhora a simetria e equilíbrio dos sulcos nasolabiais. 


\section{REFERÊNCIAS}

\section{BIBLIOGRÁFICAS}




\section{REFERÊNCIAS BIBLIOGRÁFICAS}

1. Anderl $\mathrm{H}$. Reconstruction of the face through cross-face nerve transplantation in facial paralyses. Chirurgie Plastica (Berlin), v. 2, p. 17-46, 1973.

2. Anderl H. Cross face nerve transplant. Clin Plast Surg, v. 6, p. 433-48, 1979.

3. Arai H, Sato K, Yanai A. - Hemihypoglossal-facial nerve anastomosis in treating unilateral facial palsy after acoustic neurinoma resection. $\mathbf{J}$ Neurosurg. Jan; 82(1):51-4, 1995.

4. Asaoka K, Sawamura Y, Nagashima M, Fukushima T. Surgical anatomy for direct hypoglossal-facial nerve side-to-end "anastomosis". J Neurosurg. v 91(2):268-75, 1999.

5. Aviv JE, Urken ML: Management of the paralyzed face with microneurovascular free muscle transfer. Arch Otolaryngol Head Neck Surg 118:909-912, 1992.

6. Bae YC, Zuker RM, Manktelow RT, Wade S. - A comparison of commissure excursion following gracilis muscle transplantation for 
facial paralysis using a cross-face nerve graft versus the motor nerve to the masseter nerve. Plast Reconstr Surg. Jun; 117(7):2407-13, 2006.

7. Baker DC, Conley J. Regional muscle transposition for rehabilitation of the paralyzed face. Clin Plast Surg. V 6, p 317-31, 1979.

8. Baker DC: Facial Paralysis. In McCarthy JG (ed): Plastic Surgery. Philadelphia, W.B. Saunders, p 2237-2319, 1990.

9. Bauer CA, Coker NJ: Update on facial Nerve disorders. Otolaryngol Clin North Am 29(3):445-454, 1996.

10. Bell, C. On the nerves, giving an account of some experiments on their structure and function, wich leads to a new arrangement of the system. Trans. R. Soc. Lond., v.3, p.398,1821, apud Hoffman WY. Reanimation of the paralyzed face. Otolaryngol Clin North Am, v. 25, p649-90, 1992.

11. Bergeron CM, Moe KS. - The evaluation and treatment of upper eyelid paralysis. Facial Plast Surg. May; 24(2):220-30. 2008. Review.

12. Bermudez LE, Nieto LE. - Masseteric-facial nerve anastomosis: case report. J Reconstr Microsurg. Jan; 20(1):25-30, 2004.

13. Boahene KD. - Dynamic muscle transfer in facial reanimation. Facial Plast Surg. May; 24(2):204-10, 2008. 
14. Bove A, Chiarini S, D`Andrea V, Matteo FM, Lanzi G, Antoni E: Facial nerve palsy: Wich flap? Microsurgical, anatomical, and functional considerations. Microsurgery 18:286-289, 1998.

15. Brenner E, Schoeller T. - Masseteric nerve: a possible donor for facial nerve anastomosis? Clin Anat. v 11(6):396-400, 1998.

16. Buncke HJ, Buncke GM, Kind GM, Buntic RF, Brooks D, Chin BT. - Cross-facial and functional microvascular muscle transplantation for longstanding facial paralysis. Clin Plast Surg. Oct; 29(4):551-66, 2002.

17. Buncke HJ, Alpert BS, Gordon L. Serratus anterior microvascular transplantation. In: Annual meeting of American Association of Plastic Surgeons, $61^{\text {st }}$, Proceedings. Colorado Springs, 1982, apud Witney TM, Buncke HJ, Alpert BS, Buncke GM, Lineaweaver WC. The serratus anterior free-muscle flap: experience with 100 consecutive cases. Plast Reconstr Surg, v 86, 0 481-90, 1990.

18. Campero A, Socolovsky M. - Facial reanimation by means of the hypoglossal nerve: anatomic comparison of different techniques. Neurosurgery. Sep; 61(3 Suppl):41-9; discussion 49-50, 2007.

19. Chem RC. Avaliação quantitativa e qualitativa dos resultados obtidos no tratamento da paralisia facial pela enxertia transfacial de nervo. São 
Paulo, 1990. Tese (Doutorado) Faculdade de Medicina da Universidade de São Paulo.

20. Chuang DC. - Free tissue transfer for the treatment of facial paralysis. Facial Plast Surg. May; 24(2):194-203, 2008.

21. Chuang DC. - Technique evolution for facial paralysis reconstruction using functioning free muscle transplantation--experience of Chang Gung Memorial Hospital. Clin Plast Surg. Oct; 29(4):449-59, 2002.

22. ConleyJ, Baker DC, Selfe RW. Paralysis of the mandibular branch of the facial nerve. Plast Reconstr Surg. v 70(5):569-77, 1982.

23. Coombs CJ, Ek EW, Wu T, Cleland H, Leung MK. - Massetericfacial nerve coaptation - an alternative technique for facial nerve reinnervation. J Plast Reconstr Aesthet Surg. Oct 6, 2008.

24. Correia PC, Zani R. Masseter muscle rotation in treatment of inferior facial paralysis. Plast Reconstr Surg, v 52, p 370-3, 1973.

25. Dellon AL, Mackinnon SE. Segmentally innervated latissimus dorsi flap. J Reconstr Microsurg, v 2, p 7-12, 1985.

26. Eppley BL, Hennon DK, Sadove AM, et al. Commissure stabilization appliance in facial reanimation surgery. Plast Reconstr Surg. V 89:1152-1154, 1992. 
27. Evans DM. Hypoglossal anastomosis in treatment of facial palsy. Br J Plast Surg, v. 27, p. 251-7, 1974.

28. Faria JCM. Estudo crítico do tratamento da paralisia facial com transplante do músculo grácil. São Paulo, 2002. Tese (Doutorado) Faculdade de Medicina da Universidade de São Paulo.

29. Faria JC, Scopel GP, Busnardo FF, Ferreira MC. - Nerve sources for facial reanimation with muscle transplant in patients with unilateral facial palsy: clinical analysis of 3 techniques. Ann Plast Surg. Jul;59(1):87-91, 2007.

30. Faria JC, Scopel GP, Ferreira MC. Facial reanimation with masseteric nerve: babysitter or permanent procedure? Preliminary results. Ann Plast Surg. v 64(1):31-4, 2010.

31. Fatemi MJ, Forootan SK, Habibi M, Pooli AH, Mansoori MJ. Toward shortening interoperation period in two-stage cross facial nerve graft with muscle transfer. Ann Plast Surg. Jun;60(6):639-43, 2008.

32. Ferreira MC. Cross-facial nerve grafting. Clin Plast Surg, v 11, p 2114, 1984.

33. Ferreira MC, Besteiro JM: Results of reconstruction of the facial nerve. Microsurgery 15:5-8, 1994. 
34. Ferreira MC: Aesthetic considerations in facial reanimation. Clin Plastic Surg 29:523-532, 2002.

35. Ferreira MC, Faria JCM: Result of microvascular gracilis transplantation for facial paralysis-personal series. Clin Plastic Surg 29:515-522, 2002.

36. Finsterer J. - Management of peripheral facial nerve palsy. Eur Arch Otorhinolaryngol. V 265(7):743-52. Epub 2008 Review.

37. Forootan SK, Fatemi MJ, Pooli AH, Habibi M, Javidan S. - Crossfacial nerve graft: a report of chronically paralyzed facial muscle neurotization by a nerve graft. Aesthetic Plast Surg. 2008 Jan;32(1):150-2. 2008.

38. Freilinger G, Gruber H, Happak W; Pechman U. Surgical anatomy of the mimic muscle system and the facial nerve: importance for reconstructive and aesthetic surgery. Plast Reconstr Sur. v 80, p 68690, 1987.

39. Frey M, Grubber H, Freilinger G. The importance of the correct resting tension in muscle transplantation: Experimental and clinical aspects. Plast Reconstr Surg, v 71, p 510-18, 1983. 
40. Frey M, Happak W, Girsch W, Bittner RE, Gruber H: Histomorphometric studies in patiens with facial palsy treated by functional muscle transplantation: New aspects for the surgical concept. Ann Plast Surg 26(4):370-379, 1991.

41. Frey M, Giovanoli P. - The three-stage concept to optimize the results of microsurgical reanimation of the paralyzed face. Clin Plast Surg. Oct;29(4):461-82, 2002.

42. Frey M, Giovanoli P, Tzou CH, Kropf N, Friedl S. - Dynamic reconstruction of eye closure by muscle transposition or functional muscle transplantation in facial palsy. Plast Reconstr Surg. Sep 15;114(4):865-75, 2004.

43. Frey M, Michaelidou M, Tzou CH, Pona I, Mittlböck M, Gerber H, Stüssi E. - Three-dimensional video analysis of the paralyzed face reanimated by cross-face nerve grafting and free gracilis muscle transplantation: quantification of the functional outcome. Plast Reconstr Surg. Dec;122(6):1709-22, 2008.

44. Gillies HD. Experience with fascia lata grafts in the operative treatment of facial paralysis. Proc R Soc Med. v 27, p 1372-8, 1934. 
45. Goldberg C, DeLorie R, Zuker RM, Manktelow RT. - The effects of gracilis muscle transplantation on speech in children with Moebius syndrome. J Craniofac Surg. Sep;14(5):687-90, 2003.

46. Guelinckx PJ, Sinsel NK: Muscle transplantation for reconstruction of a smile after facial paralysis past, present and future. Microsurgery 17:391-401, 1996.

47. Harii K, Ohmori K, Torri S. Free gracilis muscle transplantation with microneurovascular anastomosis for the treatment of facial paralysis. Plast Reconstr Surg. V 57, p 133-43, 1976.

48. Harri K. Microneurovascular free muscle transplantation for reanimation of facial paralysis. Clin Plast Surg. V 6, p 361-75, 1979.

49. Harii K. Redefined microneurovascular free muscle transplantation for reanimation of paralyzed face. Microsurgery, v 9, p 169-76, 1988.

50. Harii K, Asato H, Yoshimura K, Sugarawa Y, Nakatsuka T, Ueda K: One-stage transfer of the latissimus dorsi muscle for reanimation of a paralyzed face: A new alternative. Plast Reconstr Surg 102(4):941-951, 1998.

51. Harrison DH. The pectoralis minor vascularized muscle graft for the treatment of unilateral facial palsy. Plast Reconstr Surg, v 75, p 206-14, 1985. 
52. Harrison DH: The treatment of unilateral and bilateral facial palsy using free muscle transfers. Clin Plastic Surg 29:539-549, 2002.

53. Harrison DH. - Surgical correction of unilateral and bilateral facial palsy. Postgrad Med J. Sep;81(959):562-7, 2005. Review.

54. Hoffman WY. Reanimation of the paralyzed face. Otolaryngol Clin North Am. V 25:649-667, 2005.

55. House JW, Brackmann DE. Facial nerve grading system. Otolaryngol head Neck Surg, v 93, p 146-7, 1985.

56. Jackson CG, Doersten PG: The facial nerve Current trends in diagnosis, treatment an rehabilitation. Med Clin North Am 83(1): 179195, 2001.

57. Jiang H, Kuo ET, Ji ZL, Zhang ML, Lu V. One stage microvascular free abductor hallucis muscle transplantation for reanimation of facial paralysis. Plast Reconstr Surg, 96:78, 1995.

58. Johnson PJ, Bajaj-Lutthra A, Llull R, Johnson PC: Quantitative facial motion analysis after functional free muscle reanimation procedures. Plast Reconstr Surg 100(7): 1710-1722, 1997.

59. Koshima I, Moriguchi $T$, Soeda $S$, Hamanaka $T$, Tanaka H, Ohta S: Free rectus femoris muscle transfer for one-stage reconstruction of established facial paralysis. Plast Reconstr Surg 94(3):421-30, 1994. 
60. Kumar PAV, Hassan KM: Cross-face nerve graft with free-muscle transfer for reanimation of the paralyzed face: a comparative study of the single-stage and two-stage procedures. Plast Reconstr Surg 104(2):451-62, 2002.

61. Lee EI, Hurvitz KA, Evans GR, Wirth GA. - Cross-facial nerve graft: past and present. J Plast Reconstr Aesthet Surg. V 61(3):250-6, 2008.

62. Lexer E, Eden R. Über die chirurgische behandlung der peripheren facialislähmung. Beitr Klin Chir, 73:116-26, 1911 apud Conway H. Muscle plastic operations for facial paralysis. Ann Surg, v. 147, p. 541$52,1958$.

63. Lin V, Jacobson M, Dorion J, Chen J, Nedzelski J. - Global assessment of outcomes after varying reinnervation techniques for patients with facial paralysis subsequent to acoustic neuroma excision. Otol Neurotol. Apr;30(3):408-13, 2009.

64. Mackinnon SE, Dellon AL. Technical considerations of the latissimus dorsi flap. A segmentally innervated muscle for facial reanimation. Microsurgery, v 9, p36-45, 1988.

65. McLauglin CR. Permanent facial paralysis: the role of surgical support [Letter]. Lancet, v. 2, p. 647, 1952. 
66. Manktelow RT, Zuker RM. Muscle transplantation by fascicular territory. Plast Reconstr Surg. v 73:751-757, 1984.

67. Manktelow RT. Free muscle transplantation for facial paralysis. Clin Plast Surg, v 11, p215-20, 1984.

68. Martins RS, Socolovsky M, Siqueira MG, Campero A. Hemihypoglossal-facial neurorrhaphy after mastoid dissection of the facial nerve: results in 24 patients and comparison with the classic technique. Neurosurgery. Aug;63(2):310-6; discussion 317, 2008.

69. Malik TH, Kelly G, Ahmed A, Saeed SR, Ramsden RT. - A comparison of surgical techniques used in dynamic reanimation of the paralyzed face. Otol Neurotol. Mar;26(2):284-91, 2005.

70. Melvin TA, Limb CJ. - Overview of facial paralysis: current concepts. Facial Plast Surg. May;24(2):155-63, 2008, Review.

71. Moore KL. - Clinically Oriented Anatomy. p. 514, Third edition, 1992.

72. O`Brien BC, Franklin JD, Morrison WA. Cross-facial nerve grafts and microneujrovascular free muscle transfer for long established facial palsy. Br J Plast Surg, v 33, p 202-15, 1980. 
73. O`Brien BC, Pederson WC, Khazanchi Rk, Morrison WA, MacLeod AM, Kumar V: Results of management of facial palsy with mivrovascular free-muscle transfer. Plast Reconstr Surg 86(1):12-24, 1990.

74. Rose EH. - Autogenous fascia lata grafts: clinical applications in reanimation of the totally or partially paralyzed face. Plast Reconstr Surg. v 116(1):20-32; discussion 33-5, 2005.

75. Rosson GD, Redett RJ. - Facial palsy: anatomy, etiology, grading, and surgical treatment. J Reconstr Microsurg. Aug; 24(6):379-89, 2008. Review.

76. Samii M, Matthies C: Indication, technique and results of facial nerve reconstruction. Acta Neurochir 130:125-139, 1994.

77. Scaramella LF. L`anastomosi tra I due nervi faciali. Arch Otolaryngol, v. 82, p. 209-15, 1971, apud Scaramella LF. Anastomosis between the two facial nerves. Laryngoscope, v. 85, p. 1359-66, 1975.

78. Seddon HJ. Three types of nerve injury. Brain, v. 66, p. 237-88, 1943.

79. Smith JW. A new technique of facial animation. In: International Congress of Plastic and Reconstructive Surgery, Fifth, Chatswood, 1971. Transactions. London, Butterworths, p. 83, 1971. 
80. Takushima A, Harii K, Asato H, Momosawa A, Okazaki M. - Onestage reconstruction of facial paralysis associated with skin/soft tissue defects using latissimus dorsi compound flap. J Plast Reconstr Aesthet Surg. v 59(5):465-73, 2006.

81. Takushima A, Harii K, Okazaki M, Ohura N, Asato H. - Availability of latissimus dorsi minigraft in smile reconstruction for incomplete facial paralysis: quantitative assessment based on the optical flow method. Plast Reconstr Surg. v 123(4):1198-208, 2009.

82. Tan ST. Anterior belly of digastric muscle transfer: a useful technique in head and neck surgery. Head Neck. V 24:947-954, 2002.

83. Tariki JY. Avaliação clínica dos resultados do tratamento da paralisia facial com emprego do músculo temporal. São Paulo, 1989. Tese (Doutorado) Faculdade de Medicina da Universidade de São Paulo.

84. Terzis JK, Manktelow RT. Pectoralis minor: a new concept in facial reanimation. Plast Surg Forum, v 5, p106-10, 1982.

85. Terzis JK, Pectoralis minor: a unique muscle for correction of facial palsy. Plast Reconstr Surg, v 83, p767-76, 1989.

86. Terzis, JK; Noah, ME - Analysis of 100 cases of free-muscle transplantation for facial paralysis. Plast Reconstr Surg. Jun;99(7):190521, 1997. 
87. Terzis JK, Kalantarian B.l Microsurgical strategies in 74 patients for restoration of dynamic depressor muscle mechanism: a neglected target in facial reanimation. Plast Reconstr Surg, v 105, p1917-31, 2000.

88. Terzis JK, Konofaos P. - Nerve transfers in facial palsy. Facial Plast Surg. May;24(2):177-93. 2008. Review.

89. Ueda K, Akiyoshi K, Suzuki Y, Ohkouchi M, Hirose T, Asai E, Tateshita T. - Combination of hypoglossal-facial nerve jump graft by end-to-side neurorrhaphy and cross-face nerve graft for the treatment of facial paralysis. J Reconstr Microsurg. May;23(4):181-7, 2007.

90. Ueda, K; Harii, K; Yamada, A - Free vascularizes doublé muscle transplantation for the treatment of facial paralysis. Plast Reconstr Surg.Jun;95(7):1288-96; discussion 1297-8,. 1995.

91. Wei W, Zuoliang Q, Xiaoxi L, Jiasheng D, Chuang Y, Hussain K, Hongtai H, Gontur S, Li Z, Hua M, Tisheng C: Free split and segmental latissimus dorsi muscle transfer in one stage for facial reanimation. Plast Reconstr Surg 103(2):473-80,1999.

92. Winer, B.J. Statistical Principles in Experimental Design. $2^{\text {nd }}$ ed. Tokyo: McGraw-Hill (1971). 
93. Yavuzer R, Jackson IT. - Partial lip resection with orbicularis oris transposition for lower lip correction in unilateral facial paralysis. Plast Reconstr Surg. v108(7):1874-9, 2001.

94. Yetiser S, Karapinar U. - Hypoglossal-facial nerve anastomosis: a meta-analytic study. Ann Otol Rhinol Laryngol. V 116(7):542-9, 2007.

95. Ylä-Kotola TM, Kauhanen MS, Asko-Seljavaara SL. - Facial reanimation by transplantation of a microneurovascular muscle: longterm follow-up. Scand J Plast Reconstr Surg Hand Surg. v 38(5):272-6, 2004.

96. Yoleri L, Songür E, Mavioğlu H, Yoleri O. - Cross-facial nerve grafting as an adjunct to hypoglossal-facial nerve crossover in reanimation of early facial paralysis: clinical and electrophysiological evaluation. Ann Plast Surg. v 46(3):301-7, 2001.

97. Zuker RM, Eppley BL: Facial Reanimation. In Achauer BM (ed): Plastic Surgery, Mosby, p 1611-1623, 2000.

98. Zuker RM, Goldberg CS, Manktelow RT. - Facial animation in children with Möbius syndrome after segmental gracilis muscle transplant. Plast Reconstr Surg. v 106(1):1-8; discussion 9, 2000. 